\title{
Thermal and Ignition Type Steam Explosions of Single Drops of Molten Aluminum (U)
}

by

D. K. Allison

Westinghouse Savannah River Company

Savannah River Site

Aiken, South Carolina 29808

M. L Hyder

L S. Nelson

Sandia National Laboratores

P. M. Ducla

Ktoch Corporation

D. A Hyndman

Ktech Corporation

This paper was prepared in connection with work done under the above contract number with the U.S.

Department of Energy. By acceptance of this paper, the publisher and/or recipient acknowledges the U.S. Government's right to retain a nonexclusive, royalty-free license in and to any copyright covering this paper, along with the right to reproduce and to authorize others to reproduce all or part of the copyrighted paper. 


\section{THERMAL AND IGNITION TYPE STEAM EXPLOSIONS OF SINGLE DROPS OF MOLTEN ALUMINUM (U)}

L. S. Nelson, P. M. Duda, D. A. Hyndman, D. K. Allison, and M. L. Hyder

July 1995

Westinghouse Savannah River Company Engineering \& Construction Services Aiken, SC 29808

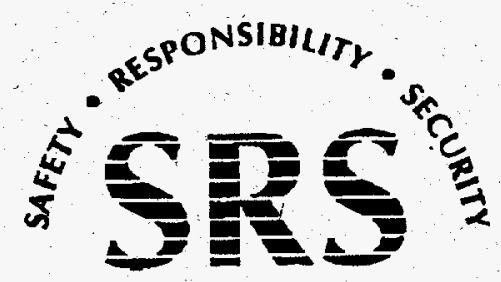

PREPARED FOR THE U.S. DEPARTMENT OF ENERGY UNDER CONTRACT NO. DE-AC09-89SR18035 


\section{DISCLAIMER}

This report was prepared as an account of work sponsored by an agency of the United States Government. Neither the United States Government nor any agency thereof, nor any of their employees, makes any warranty, express or implied, or assumes any legal liability or responsibility for the accuracy, completeness, or usefulness of any information, apparatus, product, or process disclosed, or represents that its use would not infringe privately owned rights. Reference herein to any specific commercial product, process, or service by trade name, trademark, manufacturer, or otherwise does not necessarily constitute or imply its endorsement, recommendation, or favoring by the United States Government or any agency thereof. The views and opinions of authors expressed herein do not necessarily state or reflect those of the United States Government or any agency thereof.

This report has been reproduced lirectly from the best available copy.

Available to DOE and DOE contractors from the Office of Scientific and Technical Information, P.O. Box 62, Oak Ridge, TN 37831; prices available from (615) 576-8401.

Available to the pubiic from the National Technical Information Service, U.S. Department of Commerce, 5285 Port Royal Road, Springfield, VA 22161. 


\section{DISCLAMMER}

Portions of this document may be illegible in electronic image products. Images are produced from the best available original document. 


\section{THERMAL AND IGNITION TYPE STEAM EXPLOSIONS OF SINGLE DROPS OF MOLTEN ALUMINUM (U)}

L. S. Nelson*

P. M. Duda\#

D. A. Hyndman\#

D. K. Allison

M. L. Hyder

July 1995

* Sandia National Laboratories

\#Ktech Corporation

DOES NOT CONTAIN UNCLASSIFIED CONTROLLED NUCLEAR INFORMATION Reviewing

Official:

$$
\text { Authorized Derivative Classifier }
$$

DATE: $\quad 8 / 1 / 95$

Westinghouse Savannah River Company Engineering \& Construction Services Aiken, SC 29808

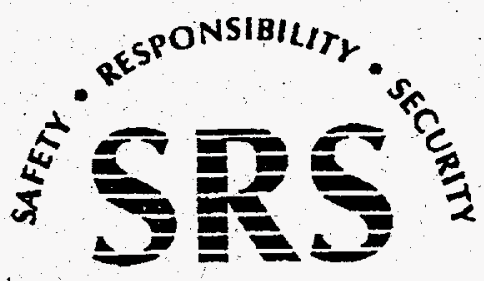


Project: $\quad$ Severe Accident Analysis Program

Document: WSRC-RP-95-718

Title: Thermal and Ignition Type Steam Explosions of Single Drops of Molten Aluminum

Approvals:

Davis ti aelesic

D. K. Allison, Author, DBA/Phenomena Analysis

L. A. Wooten, Manager, DBA/Phenomena Analysis
$9-15-95$

Date:

$9 / 18 / 95$ 


\section{ABSTRACT}

Seventeen steam explosion experiments were performed with 2 to $10 \mathrm{~g}$ drops of molten, high-purity Al. Seven were successfully initiated with underwater exploding bridgewires. At melt release temperatures up to $1400^{\circ} \mathrm{C}$ $(1673 \mathrm{~K})$ only moderate thermal-type explosions occurred that produced bubbles with volumes up to approximately $1 \mathrm{~L}$. Bubble growth intensified in the melt temperature range $1400-1525^{\circ} \mathrm{C}(1673-1798 \mathrm{~K})$ as threshold ignition of Al set in. In this range, one of the explosions emitted a flash of light and generated a bubble that grew very rapidly to approximately $14 \mathrm{~L}$, broke through the water surface, and destroyed the test chamber. We attribute the behavior of this latter bubble, which grew as fast as one produced by the underwater firing of a $0.6 \mathrm{~g}$ explosive detonator, to an ignition-type steam explosion.

Aluminum oxides could not be detected visually in the debris recovered from either typical thermal-type or the ignition-type explosions, and only traces could be detected by X-ray diffraction. In the ignition-type explosion, it is possible however that some oxidic material, probably the smaller particles, was lost during the flooding that occurred as the chamber failed.

Both bubble analyses and the absence of appreciable oxide in the debris suggest that the ignition-type steam explosion was not very efficient, probably involving the combustion of only a small fraction of the original molten aluminum globule. 


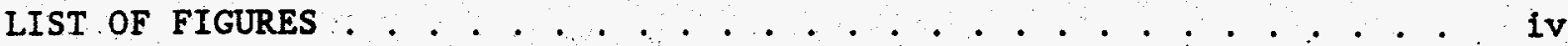

LIST OF TABLES $\quad \ldots \ldots \ldots \ldots$

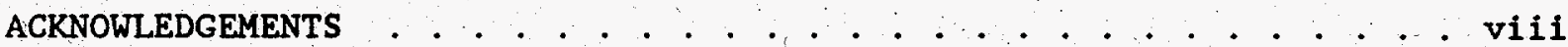

EXECUTIVE SUMMARY $\ldots . . . . . . . . . . . . . . . . . . . .1$

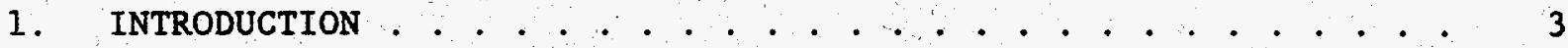

2. EXPERIMENTAL . . . . . . . . . . . . . . . . . 5

2.1 Melt Delivery . . . . . . . . . . . . . . . 5

2.2 Materials . . . . . . . . . . . . . . . . 8

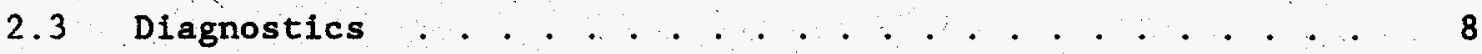

2.4 Water Chamber . . . . . . . . . . . . 8

2.5 Triggering ...................... . . . . 8

2.6 Safety Shlelding . . . . . . . . . . . . . 9.

3. RESULTS . . . . . . . . . . . . . . . . . . 10

3.1 Video and Photographic Images . . . . . . . . . . . . 10

3.2 Bubble Behavior . . . . . . . . . . . . . . . . . 10

3.3 Damage to the Chamber . . . . . . . . . . . . . 35

3.4 Temperature Measurements . . . . . . . . . . . . 35

3.5 Debris . . . . . . . . . . . . . . . . . 35

3.6 Metal/Water Reaction . . . . . . . . . . . 42

4, DISCUSSION . . . . . . . . . . . . . . . . 47

4.1 Comparisons With Earlier Work . . . . . . . . . . . 47

4.2 Comparisons With High Explosives . . . . . . . . . . . . . 48

4.3 Calculations for Future Ignition-Type

Experiments . . . . . . . . . . . . . . 54

4.4 Temperature Thresholds for Ignition-Type Explosions . . . $\quad 55$

5. CONCLUSIONS . . . . . . . . . . . . . . . . . . 59

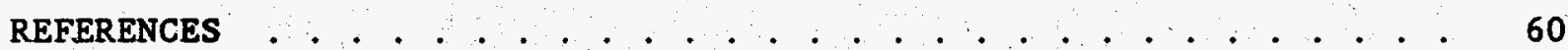

APPENDIX A: Threshold Temperatures for Ignition-Type Explosions of Molten Aluminum . . . . . . . . . . . . 62

APPENDIX B: Authors' Note . . . . . . . . . . . . 66

APPENDIX C: Mass of Aluminum that Participated in a

Laboratory-Scale Steam Explosion of

Molten Aluminum .................. . 68 
FIGURES

Figure

Page

1 Apparatus used to produce drops of

molten aluminum at elevated temperatures . . . . . . 6

2 Another view of the apparatus used to produce drops of molten aluminum at elevated temperatures . . . . . . . 7

3 Selected frames reproduced from the high-speed photographs of experiment $30-78-1 \ldots \ldots 13$

4 Selected frames reproduced from the high-speed photographs of experiment $30-80-1 \ldots . . . . .$. . . . .

Bubble volume and PV product per gram of melt that participated in the triggered steam explosion of a drop of molten aluminum released at $970^{\circ} \mathrm{C}(1243 \mathrm{~K})$ as a function of time $(38-3-1) \ldots \ldots \ldots$

$6 \quad$ Bubble volume and PV product per gram of melt that participated in the triggered steam explosion of a drop of molten aluminum released at $1195^{\circ} \mathrm{C}(1468 \mathrm{~K})$

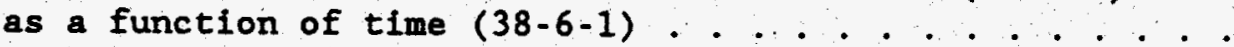

7 Bubble volume and PV product per gram of melt that participated in the triggered steam explosion of a drop of molten aluminum released at $1200^{\circ} \mathrm{C}(1473 \mathrm{~K})$

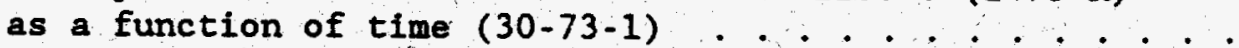

Bubble volume and $P V$ product per gram of melt that participated in the triggered steam explosion of a drop of molten aluminum released at $1400^{\circ} \mathrm{C}$ (1673 $\mathrm{K}$ ) as a function of time $(30-78-1)$

Bubble volume and PV product per gram of melt that participated in the triggered steam explosion of a drop of molten aluminum released at $1410^{\circ} \mathrm{C}(1683 \mathrm{~K})$

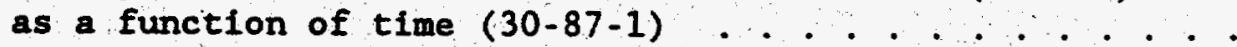

10 Bubble volume and PV product per gram of melt that participated in the triggered steam explosion of a.drop of molten aluminum released at $1400^{\circ} \mathrm{C}$ (1673 K) as a function of time $(30-93-1) \ldots \ldots$

11 Bubble volume and PV product per gram of melt that participated in the triggered steam explosion of a drop of molten aluminum released at $1500^{\circ} \mathrm{C}$ (1773 K) as a function of time $(41-5-1) \ldots \ldots . . . . . .$. 
12. Bubble volume and PV product per gram of melt that participated in the triggered steam explosion of a drop of molten aluminum released at $1525^{\circ} \mathrm{C}$ (1798 $\mathrm{K}$ ) as a function of time $(30-91-1) \quad \ldots . . . \ldots$

13 Bubble volume and PV product per gram of melt that participated in the triggered steam explosion of a drop of molten aluminum released at nominally $1500^{\circ} \mathrm{C}$ $(1773 \mathrm{~K})$ as a function of time $(30-80-1)$. . . . . . .

14 Bubble volume and PV product per gram of melt that participated in the triggered steam explosions of drops of molten aluminum released at nominally $1500^{\circ} \mathrm{C}$ $(1773 \mathrm{~K})$ as a function of time $(30-80-1) \ldots . . . .$.

15 Comparison of the volume and pressure-volume product per gram of melt that participated in the triggered ignitiontype and thermal-type steam explosions of single drops of molten aluminum $(30-93-1$ and $30-80-1) \ldots . . . . . .$.

Lexan water chamber damaged in experiment 30-80-1... .

17 Enlarged view of the upper right corner of the damaged Lexan chamber shown in Figure 16 . . . . . . . . . .

Sieve analyses of debris recovered from steam explosions of drops of molten high-purity aluminum released at $1200^{\circ} \mathrm{C}(1473 \mathrm{~K})(38-6-1)$ and nominally $1500^{\circ} \mathrm{C}(1773 \mathrm{~K})$ $(30-80-1)$

19. A bubble (arrow), presumed to contain hydrogen, observed about $100 \mathrm{~ms}$ after the steam explosion of a $6.54-\mathrm{g}$ globule of molten pure Al released at a temperature of $970^{\circ} \mathrm{C}(1243 \mathrm{~K})$ into water at about $25^{\circ} \mathrm{C}$

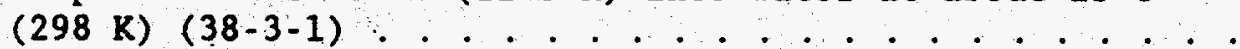

20 A bubble (arrow), presumed to contain hydrogen, observed about $160 \mathrm{~ms}$ after the steam explosion of a $4.50-\mathrm{g}$ globule of molten pure A1 released at a temperature of $1195^{\circ} \mathrm{C}(1468 \mathrm{~K})$ into water at about $25^{\circ} \mathrm{C}$ $(298$ K) $(38-6-1) \ldots . . . \ldots \ldots$

21 Manufacturer's drawing of exploding bridgewire detonator Type RP-1 
FIGURES (concluded)

Figure

Page

22. Manufacturer's drawing of exploding bridgewire detonator Type RP-2 . . . . . . . . . . . . . . . . . . 50

23 Comparison of bubble volumes (left ordinate) and pressurevolume products ( $r i g h t$ ordinate) versus time for an ignition-type steam explosion of molten pure aluminum $(30-80-1)$ and exploding bridgewire detonators Types RP-1 and $R P-2$

24 Comparison of pressure-volume product per gram of aluminum or explosive versus time for an ignition-type steam explosion of molten pure aluminum (30-80-1) and exploding bridgewire detonators Types RP-1 and RP-2 ...

25 Extended bubble volume as a function of time for the Type RP-1 high-explosive detonator fired underwater

Plot of melt temperatures for onset of ignition-type steam explosions of molten aluminum plotted as a function of mass of molten metal . . . . . . . . . . . 
1 Steam Explosion Experiments With Pure Aluminum at Elevated Temperatures . . . . . . . . . . . . . 11

2 Bubble Volume Analyses of Steam Explosions of Drops of Pure Aluminum Arranged in Order of Increasing Melt Release Temperature . . . . . . . . . . . . . . .

3a Particle Size-Weight Data Obtained by Sieving Debris Recovered from Ignition-Type Molten Aluminum-Water Interaction

3b Particle Size-Weight Data Obtained by Sieving Debris Recovered from Thermal-Type Molten Aluminum-Water

4 Metal-Water Reaction for Steam Explosions of Pure Aluminum Drops Determined From Hycam Bubble Images . . .

Comparison of Estimated Maximum Bubble Volumes and Diameters for Ignition-Type Steam Explosions of Molten Aluminum and for Underwater Explosions of the Type RP-1 High Explosive Detonator . . . . . . . . . . . . 
We thank M. O. Eatough for skillfully performing the X-ray diffraction analyses. We also thank M. L. Hyder of the Westinghouse Savannah River Company for valuable support and guidance during the performance of this work.

This work was supported by the Westinghouse Savannah River Company. 


\section{EXECUTIVE SUNAYARY}

The objective of this research was to understand the mechanism of steam explosions with metallic aluminum-based melts. Such explosions are possible in several hypothetical meltdown scenarlos in nonpower production reactors. In the laboratory we demonstrated that rapid exothermic metal-water reactions (ignition) can accompany steam explosions of drops of pure aluminum resulting in rapid chemical reaction and enhanced energy release. The melt temperature threshold for ignition was about $1500^{\circ} \mathrm{C}$ $(1773 \mathrm{~K})$ for our experimental conditions.

Aluminum drops were prepared by melting $10 \mathrm{~g}$ of high púrity $(99.999$ percent) metal under argon in a bottom-drain alumina crucible heated by a radio-frequency furnace. After release into the water, single drops of aluminum normally would fall through the water and freeze benignly at the bottom surface of the chamber, unless a pressure disturbance (trigger) was applied to the water during the fall of the drop. A pressure disturbance was produced by the discharge of a capacitor through an underwater exploding bridgewire that was activated as the drop. fell past a photodetector. Typical discharges were produced at $3 \mathrm{kV}$ and $63 \mu \mathrm{F}$ at a horizontal distance of $57 \mathrm{~mm}$ from the fall path of the drop. Peak pressures of approximately $3 \mathrm{MPa}$ were produced at this location by the bridgewire explosions; impulses were approximately $4 \mathrm{~Pa} \cdot \mathrm{s}$.

The steam explosions of the melts initiated with the pressure disturbances were recorded both by real time VHS video recording and by high-speed, $16-\mathrm{mm}$ photography. Debris was analyzed by sieving and by optical microscopy and $\mathrm{X}$-ray diffraction. The photographic images of the bubbles produced during the interactions were analyzed as a function of time with an automatic video digitizing system.

The parameter varied in these experiments was melt release temperature, which was increased in several 100 degree steps from $1000^{\circ} \mathrm{C}(1273 \mathrm{~K})$. to nominally $1500^{\circ} \mathrm{C}(1773 \mathrm{~K})$. Water temperature was nominally $25^{\circ} \mathrm{C}(298 \mathrm{~K})$. The masses of melt released were 2 to $10 \mathrm{~g}$.

At melt release temperatures up to $1400^{\circ} \mathrm{C}(1673 \mathrm{~K})$, only moderate explosions occurred. Each interaction produced a small (approximately $0.2 \mathrm{~L}$ ) first bubble that collapsed within 5 to $8 \mathrm{~ms}$. After collapse, each of these bubbles was followed by a second that produced a combined volume that did not exceed approximately $1 \mathrm{~L}$. We interpreted these interactions to have been thermal-type steam explosions.

In the melt temperature range $1400-1525^{\circ} \mathrm{C}$ (1673-1798 $\left.\mathrm{K}\right)$, however, bubble growth became more vigorous, due to threshold aluminum-water ignition phenomena. In three experiments in this threshold temperature range, the interaction initially produced a larger $(0.3$ to $0.5 \mathrm{~L})$ first bubble which collapsed at approximately $8 \mathrm{~ms}$. In one experiment, the collapse was followed by a second somewhat larger (approximately $1 \mathrm{~L}$ ) bubble. In a second experiment in this the temperature range, the melt globule was observed to glow dull red as it fell through the water and to liberate a small hydrogen bubble prior to the trigger. The interaction also produced a larger (approximately $0.5 \mathrm{~L}$ ) first bubble; its collapse was followed by the formation of a much smaller (approximately $0.1 \mathrm{~L}$ ) second bubble. 
In a third experiment performed in this elevated temperature range [at nominally $1500^{\circ} \mathrm{C}(1773 \mathrm{~K})$ ], the larger (approximately $0.3 \mathrm{~L}$ ) first bubble formed and collapsed at approximately $8 \mathrm{~ms}$. Just as the second bubble began to form, however, the interaction emitted a flash of light and generated a bubble that grew very rapidly to approximately $14 \mathrm{~L}$ in approximately $4 \mathrm{~ms}$. At this point, the growing bubble broke through the water surface and destroyed the test chamber. We attribute the behavior of this very energetic bubble to an ignition-type steam explosion.

Aluminum oxides could not be detected visually in the debris recovered from typical thermal-type or ignition-type explosions, and only traces could be detected in either type by X-ray diffraction. However, in the ignition-type explosion it is possible that some oxidic material, probably the small particles, was lost during the flooding that occurred as the test chamber failed.

We compared the bubble growth in the ignition-type aluminum-water explosion up to chamber failure with comparable bubbles produced by the underwater explosions of two high-explosive (HE) detonators that contained 0.6 and $0.06 \mathrm{~g}$ of PETN/RDX. The explosions of the nominaliy $10 \mathrm{~g}$ of molten aluminum and $0.6 \mathrm{~g}$ of $\mathrm{HE}$ produced similar bubble growth rates. The nature of the debris and reported rates of the combustion, however, strongly suggest that the amount of aluminum that actually had participated in the ignition was small and that the energy released per gram of metal actually may have been considerably greater.

We believe this to be the first clear observation of an ignition-type steam explosion of a drop of molten aluminum in the laboratory. Moreover, the threshold temperature for our ignition-type interaction falls along a smooth curve through previously reported threshold ignition temperatures plotted against the mass of molten $A 1$ released into liquid water. These temperatures appear to gradually decrease from near the boiling temperature of aluminum $\left(2700^{\circ} \mathrm{C}, 2973 \mathrm{~K}\right)$ to the melting temperature of aluminum $\left(660^{\circ} \mathrm{C}, 933 \mathrm{~K}\right)$ as melt mass increases from $10^{-7}$ to $10^{+5} \mathrm{~g}-12$ orders of magnitude!

With proper theoretical interpretation, this and similar experiments at modest scales should help us understand the very energetic and damaging steam explosions accompanied by flashes of light that are observed when many $\mathrm{kg}$ of molten aluminum comes in contact with water.

New bubble analyses seem to confirm that only a few percent of the original molten aluminum globule actually burned during the ignition-type steam explosion. This information is included in an appendix added after this report was completed. 


\section{INTRODUCTION}

In 1988 , at the request of the Savannah River Laboratory, Sandia National Laboratories began a program designed to study the steam-explosion behavior of single drops of molten aluminum-based alloys. As part of this program, we report here the effects of elevated melt temperatures on steam explosions of pure aluminum. Our program forms part of the Severe Accident Analysis Program for the Savannah River nuclear production reactors (Hyder 1991).

One objective of our work was to compare our laboratory-scale experiments using single drops of molten pure aluminum with other laboratory-, intermediate-, and large-scale experiments, particularly those in which metal/water combustion is known or suspected to have accompanied the more common thermal-type explosions.

During a steam explosion of molten aluminum, the melt can ignite, accompanied by the emission of bright light and the generation of hydrogen. This effect has been reported by, a number of authors, including Higgins and Schultz (1957), Hess and Brondyke (1969), Lemmon (1980), Anderson and Armstrong (1981), and Beck and Rightley. ${ }^{1}$ It was shown later by Rightley et al. (1993) that for a given set of experimental conditions and a given melt mass, there is a threshold temperature below which only thermal-type explosions occur, and above which ignition-type explosions occur. The ignition-type explosions are about an order of magnitude more energetic than the thermal-type and probably account for most of the serious "Force $3^{\prime \prime}$ explosive incidents observed in the aluminum industry (Epstein and Miller 1987). To our knowledge, the ignition-type explosion had never been observed clearly in laboratory-scale experiments, although Anderson and Armstrong (1981) reported several experiments in a small tank in which the exploding aluminum emitted both a "ruddy glow" and light of color temperature between 2600 and $3000 \mathrm{~K}$.

In the work described in this report, we progressively increased the release temperatures of nominally $10 \mathrm{~g}$ of molten aluminum in 100 degree steps from $1000^{\circ} \mathrm{C}(1273 \mathrm{~K})$ to nominally $1500^{\circ} \mathrm{C}(1770 \mathrm{~K})$ until an ignition-type steam explosion occurred. Even when the ignition-type steam explosion occurred, it was still necessary to apply a triggering pressure transient to the surrounding water to initiate the explosion. Each interaction involved the growth of a small first bubble, attributed to steam generated during "coarse breakup" of the molten mass, followed by the collapse of the first bubble and then the growth of a larger second bubble, attributed to water vaporized during the further breakup of the coarse mixture of melt and water. For the thermal-type interactions, the maximum volume of the second bubble was only several times larger than the first bubble; for the ignition-type interaction, however, the maximum volume of the second bubble was many times larger.

In the ignition-type experiment, the flash of light lasted about 1 ms and caused considerable "blooming" (overexposure) of the photographic image.

1 Beck, D. F., and Rightley, M. J., FCI Test NPR-1: Preliminary Report, SAND90-2715, Sandia National Laboratories, Albuquerque, NM. In preparation. 
After the light emission terminated, the second bubble grew steadily for about 4 ms until it broke through the water surface and the chamber failed. In the subsequent flooding, a small amount of the debris from the interaction may have been lost.

We compared the bubble produced by the ignition-type steam explosion with the bubbles formed when high-explosive detonators were fired underwater. The bubble growth rates were approximately the same for the ignition-type steam explosion and the explosion of a commercial detonator that contained $0.6 \mathrm{~g}$ of high explosive. From this comparison and the assumption that both the HE and $A I$ bubbles grow to the same maximum volumes we estimate the ignition-type interaction released 1 to 2 percent of the thermal and chemical energy available in the Al globule.

(In an appendix added after this report was completed, new bubble analyses seem to confirm that only a few percent of the original molten aluminum globule actually burned during the ignition-type steam explosion.) 


\section{EXPERIMENTAL}

\subsection{Melt Delivery}

The apparatus used here was derived from that used in earlier baseline experiments with pure aluminum and 6061 alloy drops. 1 We used the same bottom-drain crucible and release procedures.

The major difference between the apparatus of the previous lower melt-temperature experiments and these higher melt-temperature experiments was the replacement of the resistance furnace with a Westinghouse $450-\mathrm{kHz}$, $20 \mathrm{~kW}$, radio-frequency (RF) generator to heat the coaxial high-alumina crucible and plunger tubes. We used a five-turn coil of $1 / 2$-inch copper tubing, $16.5-\mathrm{cm}$ ID and $14 . \mathrm{cm}$ tall to couple power to the susceptors. As susceptors, we used two size 0000 "Plumbago" graphite crucibles, approximately $60-\mathrm{mm}$ OD at the top and 75-mm tall. These crucibles were placed in the coil of the RF generator, one inverted on top of the other on a graphite base plate. Holes, were drilled in the bottoms of the graphite crucibles to admit the aluminum-oxide crucible.

We placed a $11.5-\mathrm{cm}$ OD by $24.2-\mathrm{cm}$ tall, transparent, fused-quartz sheathtube around the graphite for atmosphere control. The quartz sheath-tube also rested on the graphite base plate and had a loose fitting

graphite-disk cover resting on the top of it. Gaseous argon was flushed through the quartz sheath-tube from bottom to top by means of a $6-\mathrm{mm}$ diameter, transparent, fused-quartz tube passed through a hole in the upper graphite cover. The argon flow was monitored with a floating-ball flow meter. For insulation and reduction of radiant emission, silica cloth was wrapped around the sheath-tube. The apparatus is shown in Figures 1 and 2 .

A Pyro Photomatic, automatic, optical pyrometer, Serial No. Al27 (Pyrometer Instrument Co., Bergenfield, NJ), was used to measure temperatures. With a windowless sight path through a $13-\mathrm{mm}$ diameter hole drilled in the sheath-tube, the pyrometer viewed a hohlraum formed by drilling a second $13-\mathrm{mm}$ diameter hole in the upper graphite susceptor. Within their respective temperature ranges, it was also possible to use both Type $R$ and Type $K$ thermocouples inside the central alumina tube of the crucible assembly. The Type $R$ thermocouple operated in essential agreement with the optical pyrometer up to a temperature of $1497^{\circ} \mathrm{C}$ $(1770 \mathrm{~K})$, almost $600 \mathrm{~K}$ higher than the highest melt temperature studied in the baseline experiments by Nelson et al. 1

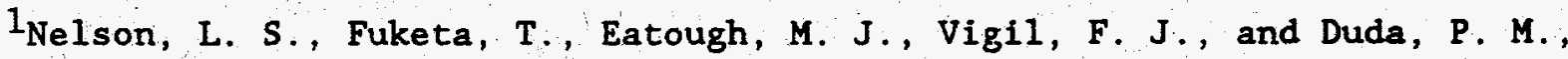
The Triggering of Steam Explosions of Single Drops of Pure and Alloyed Molten Aluminum, SAND90-0131, Sandia National Laboratories, Albuquerque, NM. In preparation.
} 


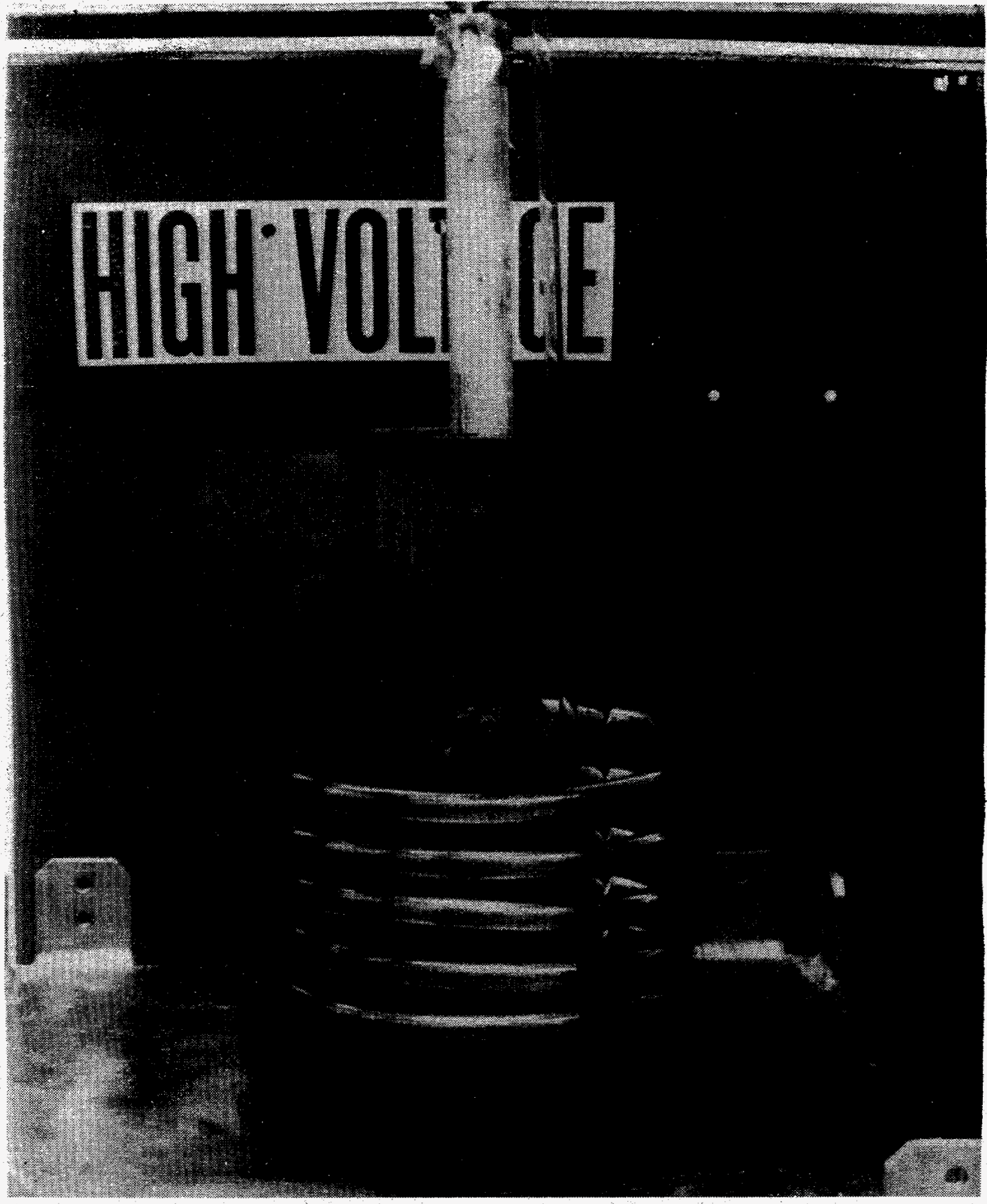

Figure 1. Apparatus used to produce drops of molten aluminum at elevated temperatures. The radio-frequency heater coll surrounds a transparent, fused-quartz sheath-tube which in turn surrounds two graphite crucibles used as susceptors to heat the central alumina crucible arrangement. The argon inlet quartz tube is shown to the right of the crucible. 


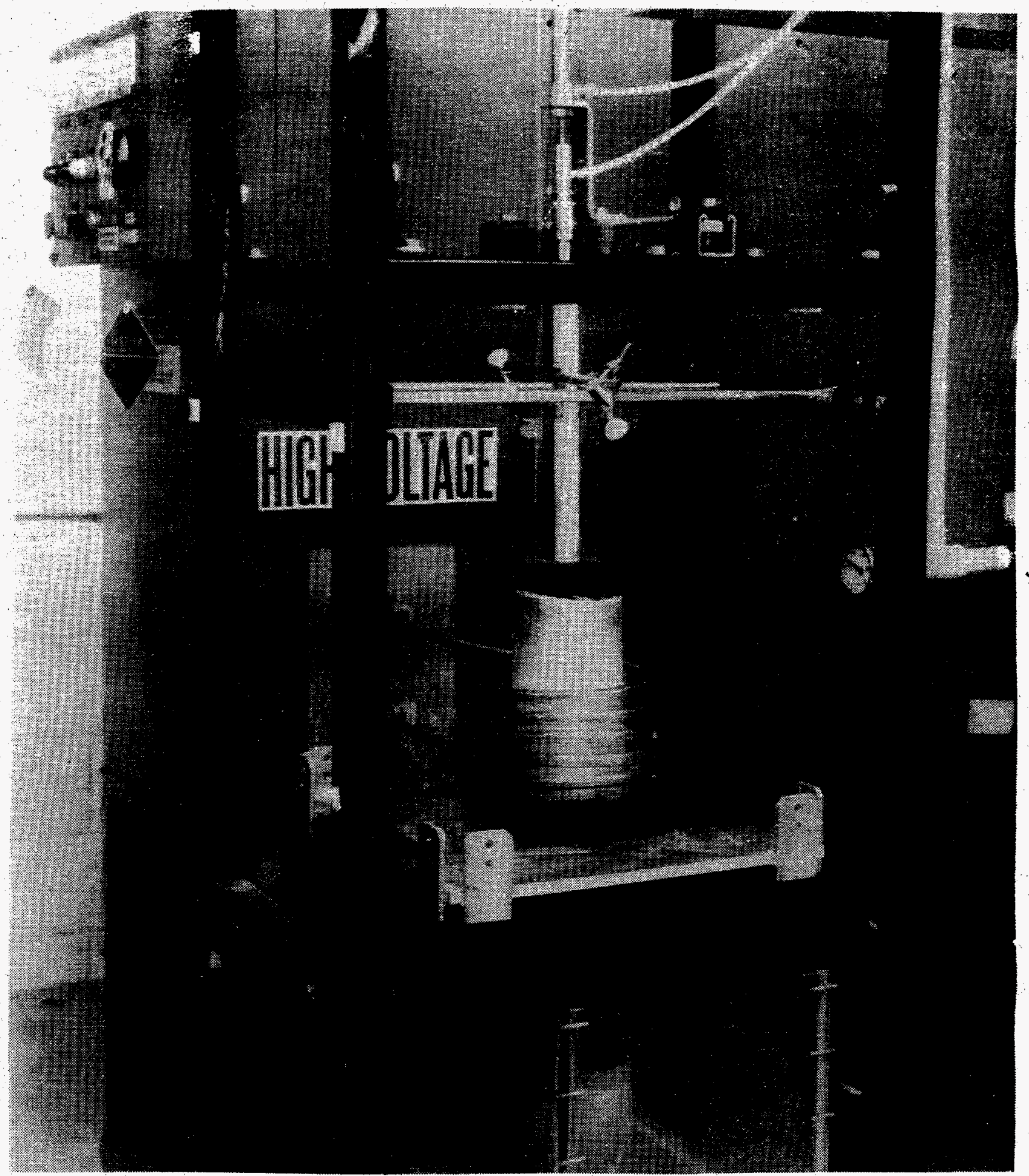

Figure 2. Another view of the apparatus used to produce drops of molten aluminum at elevated temperatures. The transparent, fusedquartz sheath-tube has been wrapped with silica cloth for insulation. The argon inlet tube has been moved to the left of the crucible tube. A water chamber different from that shown in the figure was used for the actual experiments (see Section 2.4). 


\subsection{Materials}

The aluminum, water, and argon were the same as those used by Nelson et al. 1 The aluminum was Marz grade of purity 99.999 percent Al, obtained from the Materials Research Corporation, Orangeburg, NY. Deionized water was obtained in bottles from a local supplier. Argon was taken from cylinders of commercial high-purity gas.

\subsection{Diagnostics}

The diagnostics were the same as those used by Nelson et al. ${ }^{1}$

Images of the aluminum-water interactions were recorded by high-speed photography [Hycam 16-mm camera, 4000 frames per second (Redlake Corp., Morgan Hill, CA)] and standard video tape on 1/2" VHS format. Four, 1-kw, quartz-halogen photographic lights provided illumination.

Selected frames from the $16-\mathrm{mm}$ films were analyzed with a Jandel (Corte Madera, CA) JAVA automatic digitizing video analysis system that used hand-tracings from projected Hycam frames. Bubble volumes were estimated by assuming the images could be represented as the sum of many rightcircular cylindrical slices at all positions along the vertical axis of the bubble. Plots were prepared using a Harvard Graphics Software package. (Software Publishing Corp., Mountain View, CA).

The fragmented aluminum debris produced during the interactions was separated from the water by filtration and after drying was divided into logarithmic fractions with a stack of sieves. The sieving was performed by hand; weights were determined with an analytical balance accurate to $10^{-5} \mathrm{~g}$.

\subsection{Water Chamber}

The water chamber used here was constructed of $12.7-\mathrm{mm}$ thick Lexan sheet instead of the polymethylmethacrylate used by Nelson et al. ${ }^{1}$ The chamber had the dimensions of $30-\mathrm{cm}$ front-to-back by $60-\mathrm{cm}$ wide by $30-\mathrm{cm}$ tall (volume was $0.06 \mathrm{~m}^{3}$ ). The melt fall path was located approximately $15 \mathrm{~cm}$ from the back and one side of the chamber (that is, centered in one half of the chamber). The top of the chamber was not covered.

\subsection{Triggering}

Underwater gold bridgewire explosions were used to initiate the interactions, as in Nelson et al. 1 : The bridgewire was always exploded with a $63 \mu \mathrm{F}$ capacitor charged to $3 \mathrm{kV}$. The face of the bridgewire was placed a horizontal distance of $57 \mathrm{~mm}$ from the fall path of the aluminum

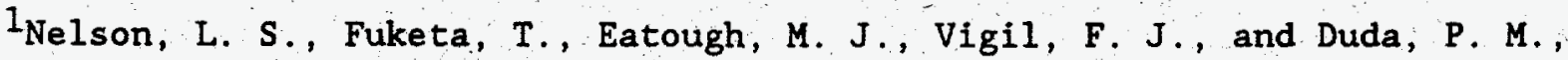
The Triggering of Steam Explosions of Single Drops of Pure and Alloyed Molten Aluminum, SAND90-0131, Sandia National Laboratories, A1buquerque, NM. In preparation. 
drop. The bridgewire explosions produced transients in the water with peak pressures of approximately $3 \mathrm{MPa}$ and impulses of approximately $4 \mathrm{~Pa} \cdot \mathrm{s}$ at the location of the drop.

Unlike some of the experiments of Nelson et al. (1992), shock wave reflectors were not used in the experiments described in this report.

\subsection{Safety Shielding}

The entire experiment was performed in a manned laboratory. For safety, a three-sided shield made of vertical $25-\mathrm{mm}$ thick Lexan plates was positioned around the experimental setup via a mobile carriage just before each experiment. 


\section{RESULTS}

During this work we performed 17 new experiments with single 2 to $10 \mathrm{~g}$ drops of molten high-purity aluminum with the melt released at temperatures between $1200^{\circ} \mathrm{C}(1473 \mathrm{~K})$ and nominally $1500^{\circ} \mathrm{C}(1773 \mathrm{~K})$. Bridgewire triggers were applied in eight of these experiments; seven of these produced steam explosions. The experiments are summarized in Table 1. Two earlier experiments (numbered 38-3-1 and 38-6-1) with melt release temperatures of $1000^{\circ} \mathrm{C}$ and $1200^{\circ} \mathrm{C}(1273 \mathrm{~K}$ and $1473 \mathrm{~K})$ are also included in Table 1. Although the experiments are reported elsewhere, 1 they form a natural extension of the experiments reported here because their triggering and other experimental parameters were essentially identical.

\subsection{Video and Photographic Images}

The video and Hycan images recorded during these experiments showed the complete path of the molten aluminum globule as it fell through the water. No bubbles were released from the falling globule prior to triggering (e.g., $\mathrm{H}_{2}$ bubbles). After triggering, some bubbles attributable to $\mathrm{H}_{2}$ were seen (see Section 3.6 ) and provided considerable qualitative and quantitative information about the nature of the interactions.

In Figure 3, we show selected frames from the Hycam record of a thermal-type explosive interaction (experiment 30-78-1). This interaction was triggered with a bridgewire fired underwater at $3 \mathrm{kV}$ and $63 \mu \mathrm{F}$ at a distance of $57 \mathrm{~mm}$ from the drop's fall path. The melt release temperature was $1400^{\circ} \mathrm{C}(1673 \mathrm{~K})$. The images shown in Figure 3 are typical of the explosions initiated with melt release temperatures at or below $1400^{\circ} \mathrm{C}$ (1673 K).

In Figure 4, we reproduce Hycam frames for the experiment analogous to that shown in Figure 3, except that the melt temperature had been raised to a nominal $1500^{\circ} \mathrm{C}(1773 \mathrm{~K})$. Note in Frame 33 of Figure 4 that a brilliant flash of light is present which is absent in all frames in Figure 3. Notice also that after the flash of light, bubble growth was very rapid and reached a large volume that ultimately exceded the chamber dimensions and led to the failure of the water chamber.

\subsection{Bubble Behavior}

In Figures 5 through 14, we show the bubble growth history as a function of time recorded during nine triggered steam explosions produced with single drops of pure aluminum released at melt temperatures increasing from $970^{\circ} \mathrm{C}\left(1243^{\mathrm{K}}\right)$ to $1525^{\circ} \mathrm{C}(1798 \mathrm{~K})$. Other than variations between melt masses, the triggering and other experimental parameters were held essentially constant. (The data in Figures 5 and 6 were taken from our earlier work. ${ }^{1}$ ) These plots were obtained from the Hycam film images with the automatic video digitizing system. Each figure is comprised of

(a) the bubble volume (left ordinate scale) and (b) the pressure-volume

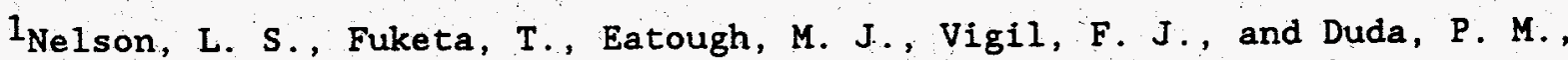
The Triggering of Steam Explosions of Single Drops of Pure and Alloyed Molten Aluminum, SAND90-0131, Sandia National Laboratories, Albuquerque, NM. In preparation. 
Table 1. Steam Explosion Experiments With Pure Aluminum at Elevated Temperatures

\begin{tabular}{|c|c|c|c|c|c|c|c|c|c|c|c|c|c|c|c|}
\hline $\begin{array}{c}\text { Expt. } \\
\text { No. }\end{array}$ & Date & $(\cdot c)^{\mathrm{T}}$ & (K) & $r(m x)$ & kv & $\mu f$ & Expl: & $\begin{array}{l}\text { Debris } \\
\text { Texture }\end{array}$ & $\begin{array}{c}\text { Weight } \\
\text { (g) }\end{array}$ & $\begin{array}{l}\text { Frame } \\
\text { No. }\end{array}$ & $\begin{array}{l}t-t_{b w} \\
\text { (ms) }\end{array}$ & $\begin{array}{l}\text { Maxim } \\
d_{\text {ax }} \\
\text { (cm) }\end{array}$ & $\begin{array}{c}u \text { Bubble } \\
v_{m} \\
\text { (L) }\end{array}$ & $\frac{P V_{\min }}{(\mathrm{J} / \mathrm{s})}$ & Remarks \\
\hline $38-3-1$ & $08 / 24 / 89$ & 970 & 1243 & 57 & 3 & 63 & Yes & v. fine & 6.54 & 43 & 12.90 & .12 .6 & 1.05 & 13.9 & \\
\hline $38-6-1^{6}$ & $09 / 18 / 89$ & 1195 & 1468 & 57 & 3 & 63 & Yes & v. fine & 4.50 & 54 & 13.01 & 12.8 & 1.10 & 21.0 & \\
\hline $30-64-1$ & $01 / 15 / 91$ & 12,00 & 1473 & -- & - & -- & Ho & $\begin{array}{l}\text { Several } \\
\text { globules }\end{array}$ & 4.95 & $\therefore-$ & -- & -- & - & -- & Control \\
\hline $30-66-1$ & $02 / 04 / 91$ & 1310 & 1583 & -- & $\therefore$ & -- & No & A fow particles & N.R. & -- & $\cdots$ & -- & $\cdots$ & - & Control \\
\hline $30-68-1$ & $02 / 06 / 91$ & 1215 & 1488 & - & - & -- & No & Single globules & 3.14 & $\therefore$ & - & -- & $\because$ & -- & Control \\
\hline $30-73-1$ & $02 / 14 / 81$ & 1200 & 1473 & 57 & 3 & 63 & Mod. & $\begin{array}{l}\text { Torn melt; med. } \\
\text { fine }\end{array}$ & 5.22 & 26 & 12.82 & 11.3 & 0.75 & $12 \cdot$ & \\
\hline $30-78-1$ & $02 / 20 / 91$ & 1400 & 1673 & 57 & 3 & 63 & Mod. & $\begin{array}{l}\text { Torn melt; med. } \\
\text { fine }\end{array}$ & 4.69 & 40 & 8.96 & B. 0 & 0.27 & 4.9 & \\
\hline $30-80-1$ & $02 / 25 / 91:$ & $1500^{\circ}$ & $1773^{\circ}$ & 57 & 3 & 63 & v. 180 & Finetcoarse & $\sim 10$ & 53 & 13.30 & $>30^{4}$ & $>14^{4}$ & $>124^{\circ}$ & $\begin{array}{l}\text { White flash, } \\
\text { chember } \\
\text { failed }\end{array}$ \\
\hline $30-85-1$ & $03 / 01 / 81$ & 1395 & 1668 & 57 & 3 & 63 & No & Two lobs & $\begin{array}{l}6.45 \\
3.85\end{array}$ & $\therefore$ & - & -- & -- & $\because$ & $\begin{array}{l}\text { BW Elired } \\
\text { early }\end{array}$ \\
\hline $30-87-1$ & $03 / 04 / 81$ & 1410 & 1683 & 57 & 3 & 63 & Mod. & $\begin{array}{l}\text { Torn molt; mod. } \\
\text { fine }\end{array}$ & 6.33 & 42 & 10.67 & 10.3 & 0.52 & 7.1 & \\
\hline $30-88-1$ & $03 / 06 / 81$ & 1465 & 1738 & -- & $\cdots$ & $\cdots$ & No & Two slobs & 3.13 & -- & - & $\cdots$ & -- & $\cdots$ & \\
\hline $30-90-1$ & $03 / 08 / 81$ & 1500 & 1773 & $\because-$ & - & $\cdots$ & - & No drop & -- & - & $\cdots$ & -- & -- & - & \\
\hline
\end{tabular}

-d is calculated by assuming a spherical bubble of volume $v_{\text {mx }}$. Not all bubbles were exactly spherical.

Taken from Nolson, L. S., Fuketa, T., Eatough, M. J., Vigil, F. J., and Duda, P. M., The Iriggering of Stean Explogions of Single Drops of Pure and Alloyed Xolten Aluminum, SAlD90-0131, Sendie National Laboratories, Albuquerque, Nal. In proparation.

Tamperature misht heve been higher because of vaporization products in pyromoter's vien path.

Moasured just bofore the bubble broke through the water surface. 
Table 1. Steam Explosion Experiments with Pure Aluminum at Elevated Temperatures (continued)

\begin{tabular}{|c|c|c|c|c|c|c|c|c|c|c|c|c|c|c|c|}
\hline $\begin{array}{l}\text { Expt. } \\
\text { No. }\end{array}$ & Date & $\left({ }^{*} \mathrm{C}\right)^{\mathrm{T}_{\mathrm{m}}}$ & (K) & $r(\min )$ & $\begin{array}{l}\mathbf{s e g} \\
\mathbf{k V}\end{array}$ & $\mathrm{Bf}$ & Expl. & $\begin{array}{l}\text { Debris } \\
\text { Texture }\end{array}$ & $\begin{array}{l}\text { Weight } \\
(\mathrm{g})\end{array}$ & $\begin{array}{l}\text { Frame } \\
\text { No. }\end{array}$ & $\begin{array}{l}t-t_{b} \\
\text { (ms) }\end{array}$ & $\begin{array}{l}\text { Maxi } \\
\text { (cm) }\end{array}$ & $\begin{array}{l}\text { ande } \\
v_{\text {a }} \\
\text { (L) }\end{array}$ & $(\mathrm{J} / \mathrm{g})$ & Remarks \\
\hline $30-91-1$ & $03 / 11 / 91$ & 1525 & 1798 & 57 & 3 & 63 & Mod. & Fairly coarse & 2.54 & 19 & 4.75 & 9.6 & 0.46 & 15.5 & Long heating \\
\hline $30-93-1$ & $03 / 12 / 91$ & 1400 & 1673 & 57 & 3 & 63 & Strong & $\begin{array}{l}\text { Some spheres \& } \\
\text { fines }\end{array}$ & 9.10 & 50 & 12.45 & $11: 3$ & 0.75 & 7.1 & \\
\hline $41-4-1$ & $04 / 11 / 91$ & -- & - & - & $\therefore$ & -- & $\therefore$ & - & -- & -- & -- & -- & -- & -- & Abort \\
\hline $41-5-1$ & $04 / 12 / 91$ & 1525 & 1798 & 57 & 3 & 63 & Strong & Moderately fine & 7.59 & 56 & 14.56 & 12.0 & 0.90 & 10.2 & . \\
\hline $41-8-1$ & $04 / 16 / 81$ & 1560 & 1833 & $\therefore$ & -- & $\therefore$ & No & Several globs. & - & $\because$ & - & -- & -- & $\cdots$ & $\begin{array}{l}\text { Drop swerved: } \\
\text { no BW firing }\end{array}$ \\
\hline $41-10-1$ & $04 / 17 / 91$ & - & -- & $\because-$ & - & - & -- & Several globs & - & - & -- & $\cdots$ & - & $\therefore$ & Abort \\
\hline $41-11-1$ & $04 / 18 / 91$ & 1530 & 1803 & $\therefore$ & - & -- & No & Several globs & 8.3 & - & $\cdots$ & -- & -- & -- & Weak BW \\
\hline
\end{tabular}

da is calculated by assuming a spherical bubble of volume $v_{m a}$. Not all bubbles were exactly spherical.

Taken from Nelson, L. S., Fukota, T., Eatough, M. J., Vigil, F. J., and Duda, P. M., The Trisgering of Stien Explosions of Single Drops of Pure and Alloyed Molten Aluminum, SAMD90-0131. Sandia National Laboratories, Albuquerque, In. In proparation.

Tenperature might have been higher because of vaporization products in pyroneter's view path.

Measured just before the bubble broke through the water surface. 


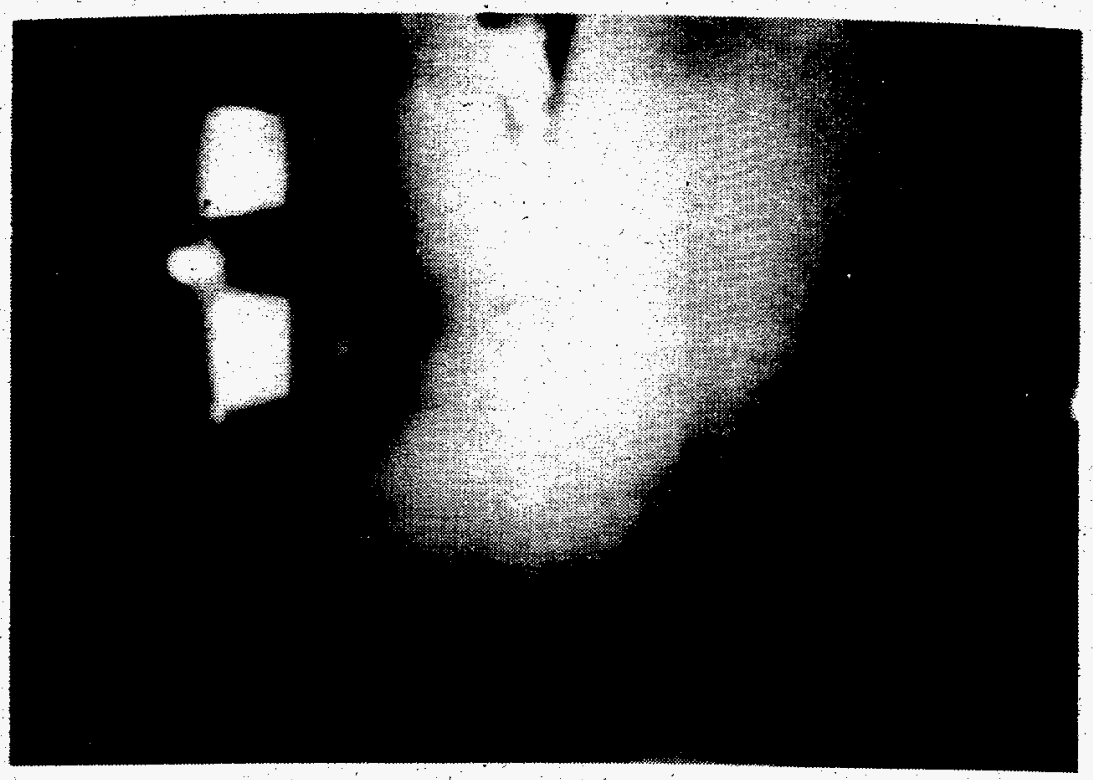

Frame $-1 ;-0.249$ ms. Melt drop falls through water.

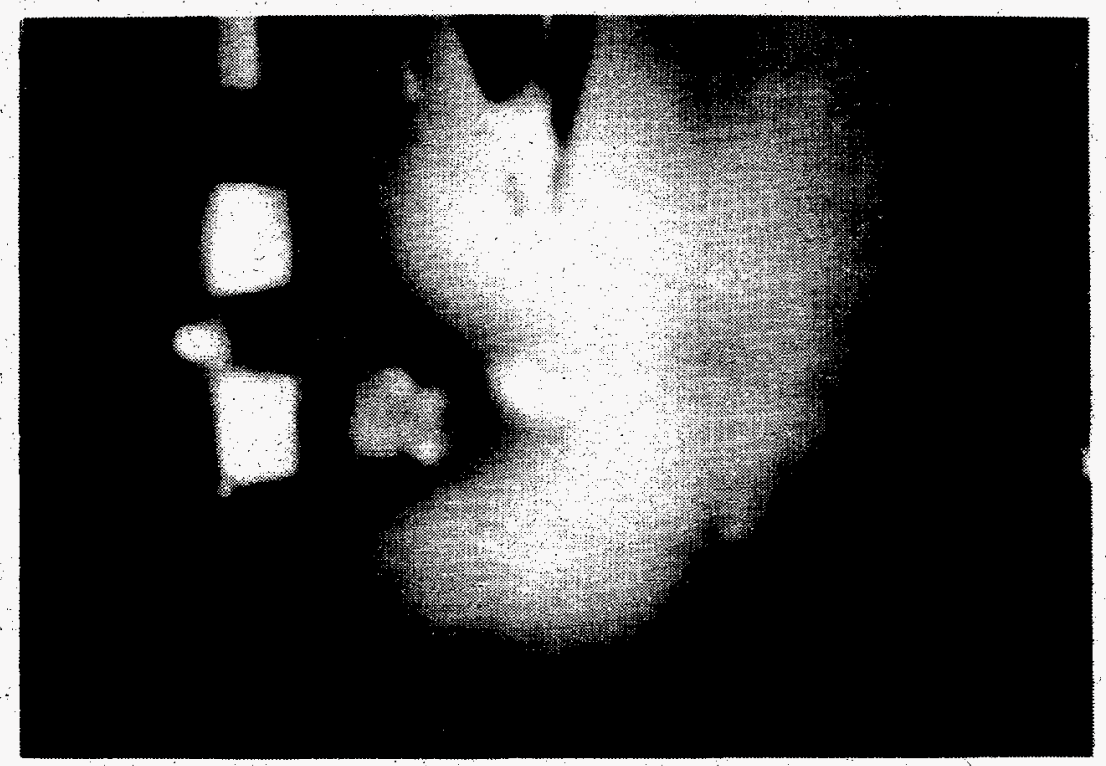

Frame $3 ; 0.747$ ms. Bridgewire has fired. Both bridgewire and interaction bubbles grow.

Figure 3. Selected frames reproduced from the high-speed photographs of experiment $30-78-1$. Temperature of the melt was $1400^{\circ} \mathrm{C}$

$(1673 \mathrm{~K})$ at time of release. 


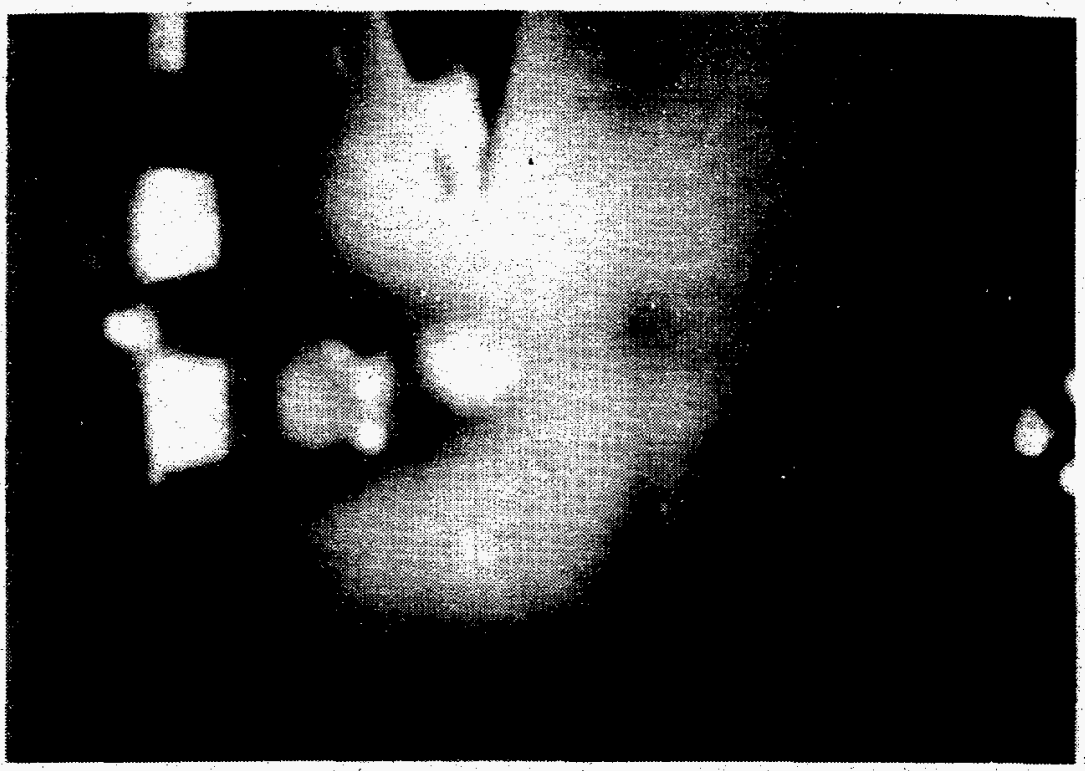

Frame $5 ; 1.245$ ms. Bridgewire and Interaction bubbles grow.

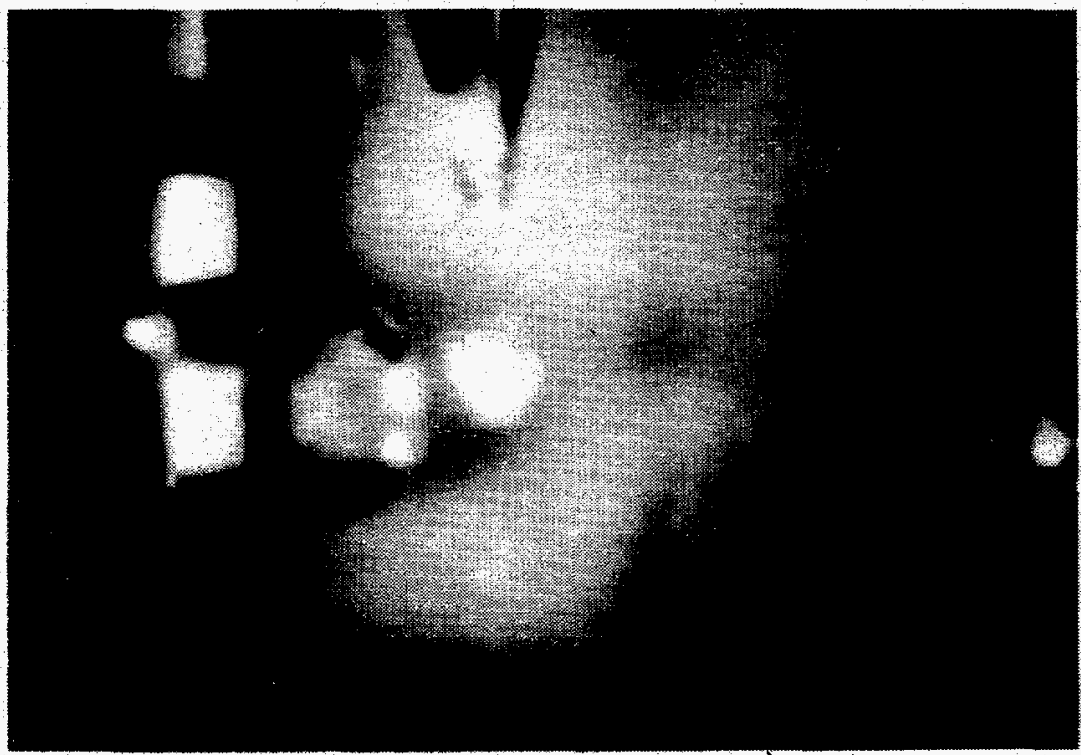

Frame $8 ; 1.992^{\circ} \mathrm{ms}$. Bridgewire and interaction bubbles begin to collapse.

Figure 3 (continued). Selected frames reproduced from the high-speed photographs of experiment 30-78-1. Temperature of the melt was $1400^{\circ} \mathrm{C}(1673 \mathrm{~K})$ at time of release. 


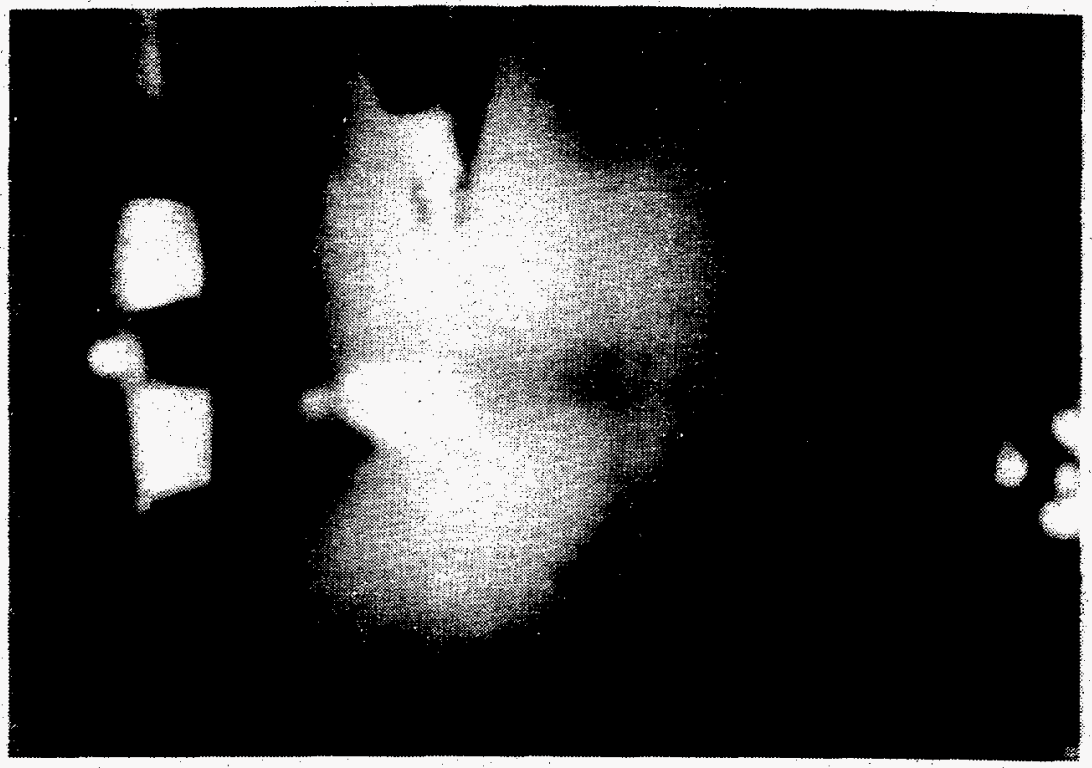

Frame $25 ; 6.225 \mathrm{~ms}$. Bridgewire and interaction bubbles are about to collapse completely.

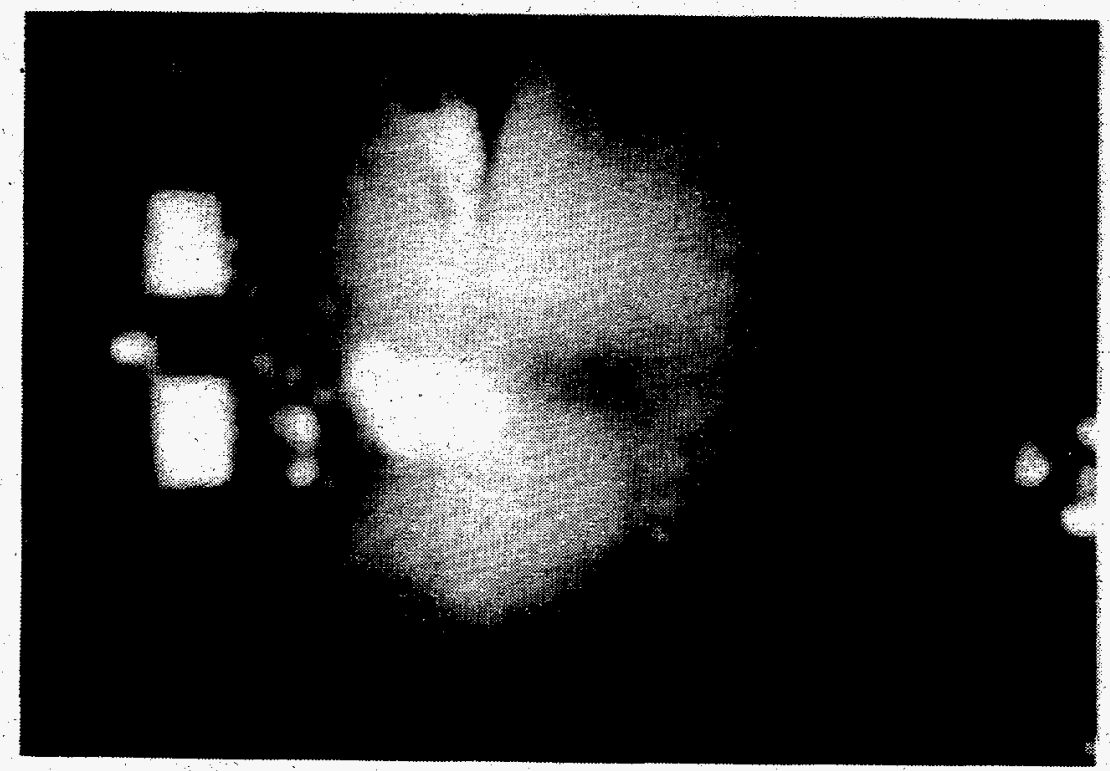

Frame $27 ; 6.723 \mathrm{~ms}$. Bridgewire and interaction bubbles have collapsed. Cavitation bubbles have formed.

Figure 3 (continued). Selected frames reproduced from the high-speed photographs of experiment 30-78-1. Temperature of the melt was $1400^{\circ} \mathrm{C}(1673 \mathrm{~K})$ at time of release. 


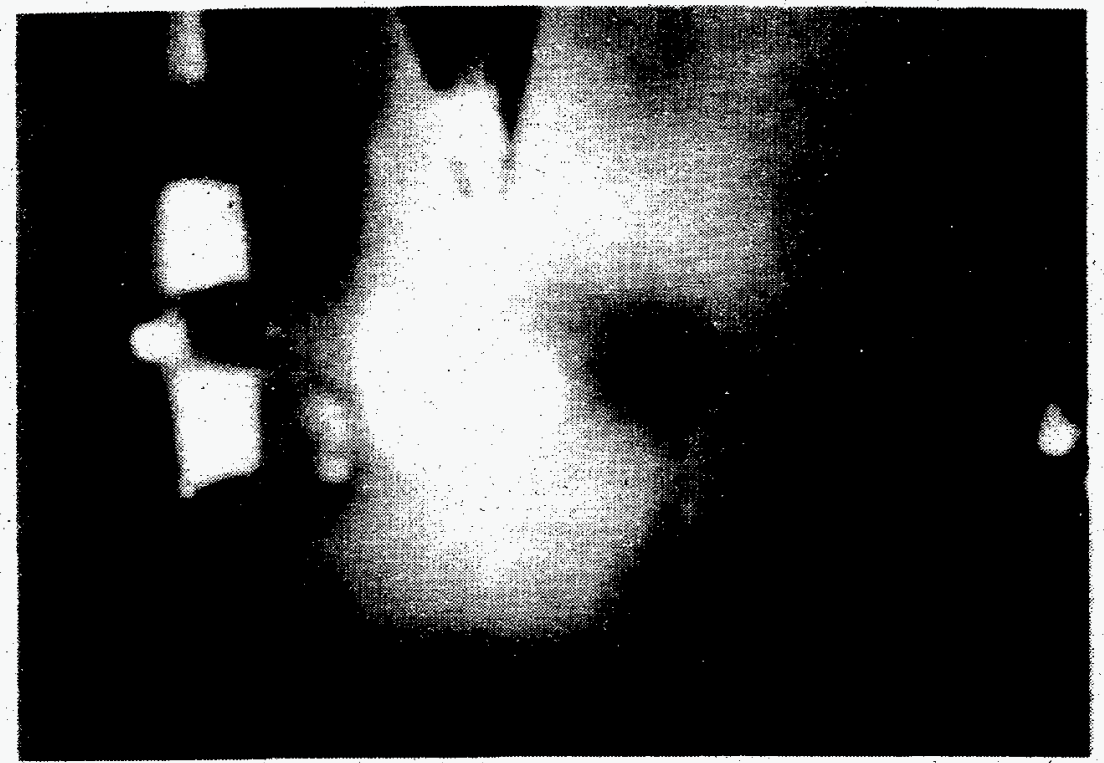

Frame $30 ; 7.470 \mathrm{~ms}$, Interaction bubble grows again.

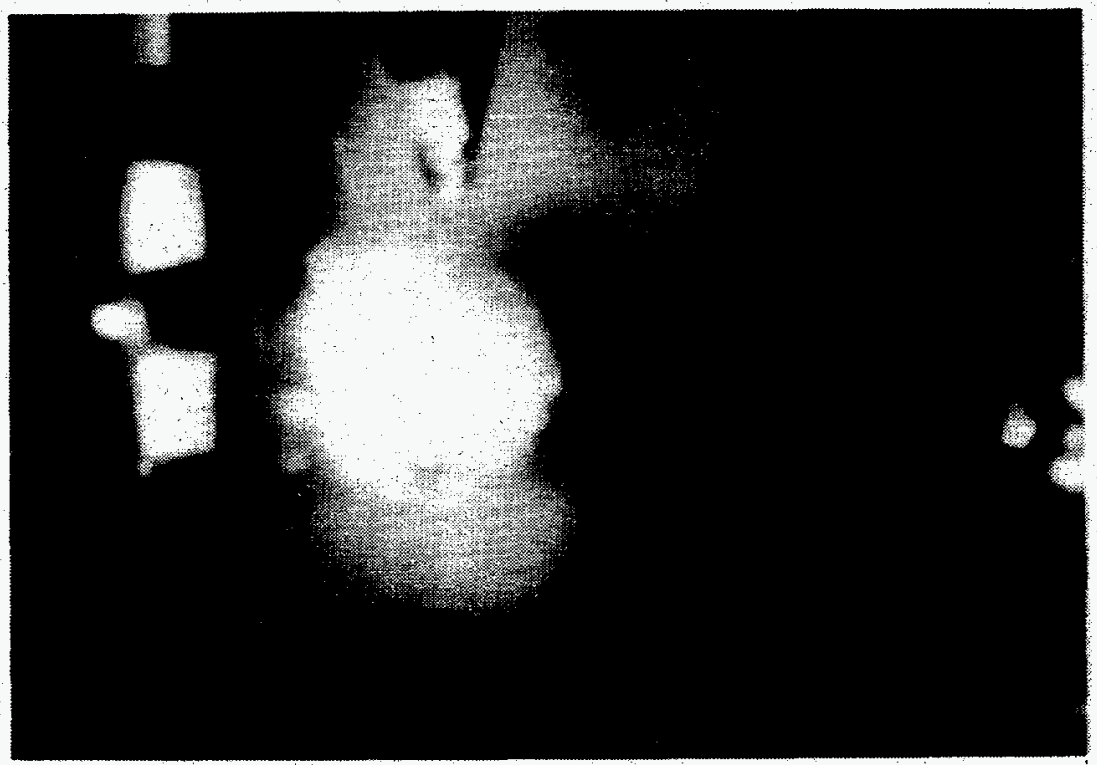

Frame $40 ; 9.960 \mathrm{~ms}$. Interaction bubble has grown to maximum volume.

Figure 3 (concluded). Selected frames reproduced from the high-speed photographs of experiment 30-78-1. Temperature of the melt was $1400^{\circ} \mathrm{C}(1673 \mathrm{~K})$ at time of release. 


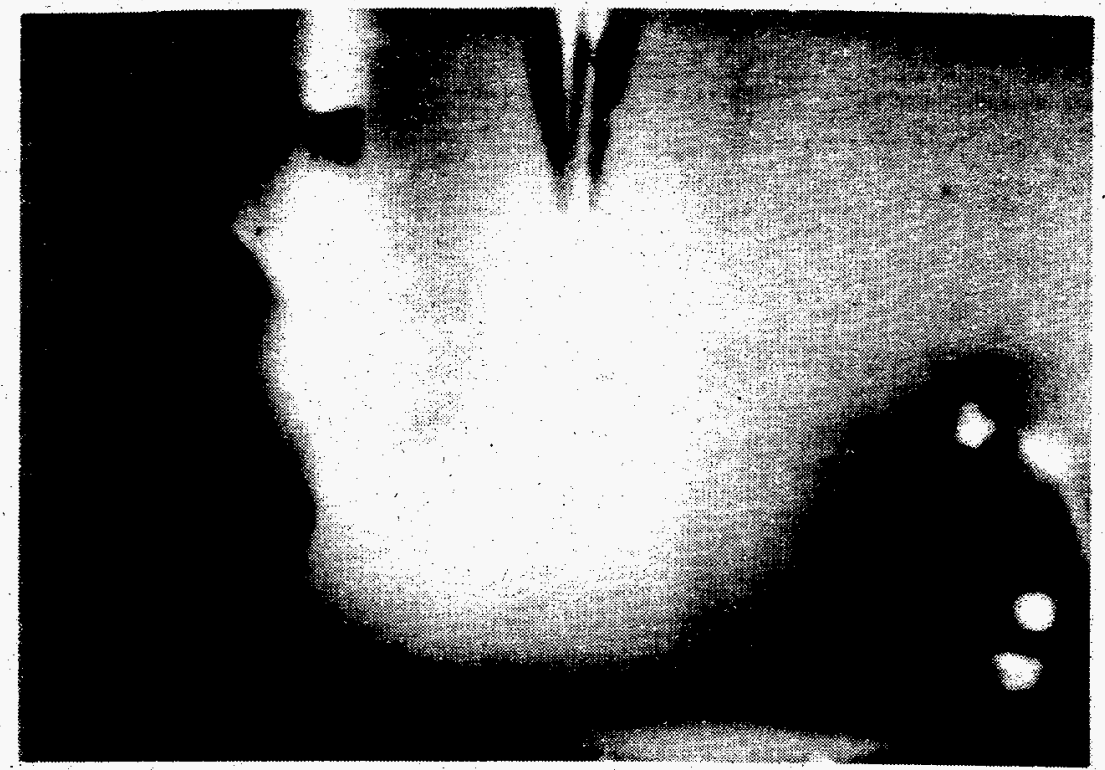

Frame $-2 ;-0.504$ ms. Melt drop and streamer fall through water.



Frame $9 ; 2.268 \mathrm{~ms}$. Bridgewire has fired. Bubbles from bridgewire, drop, and streamer grow.

Figure 4. Selected frames reproduced from the high-speed photographs of experiment $30-80-1$. Temperature of the melt was nominally $1500^{\circ} \mathrm{C}(1773 \mathrm{~K})$ at time of release. 


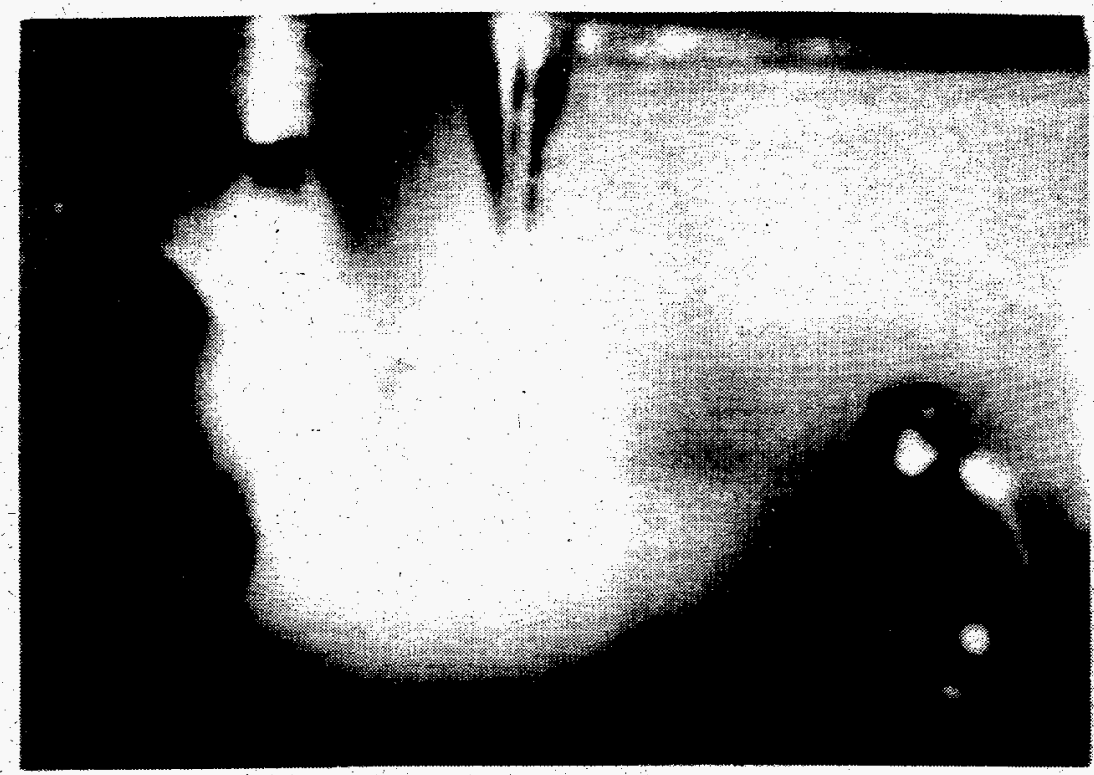

Frame 25; $6.300 \mathrm{~ms}$. Bubbles from bridgewire, drop, and streamer are collapsing.

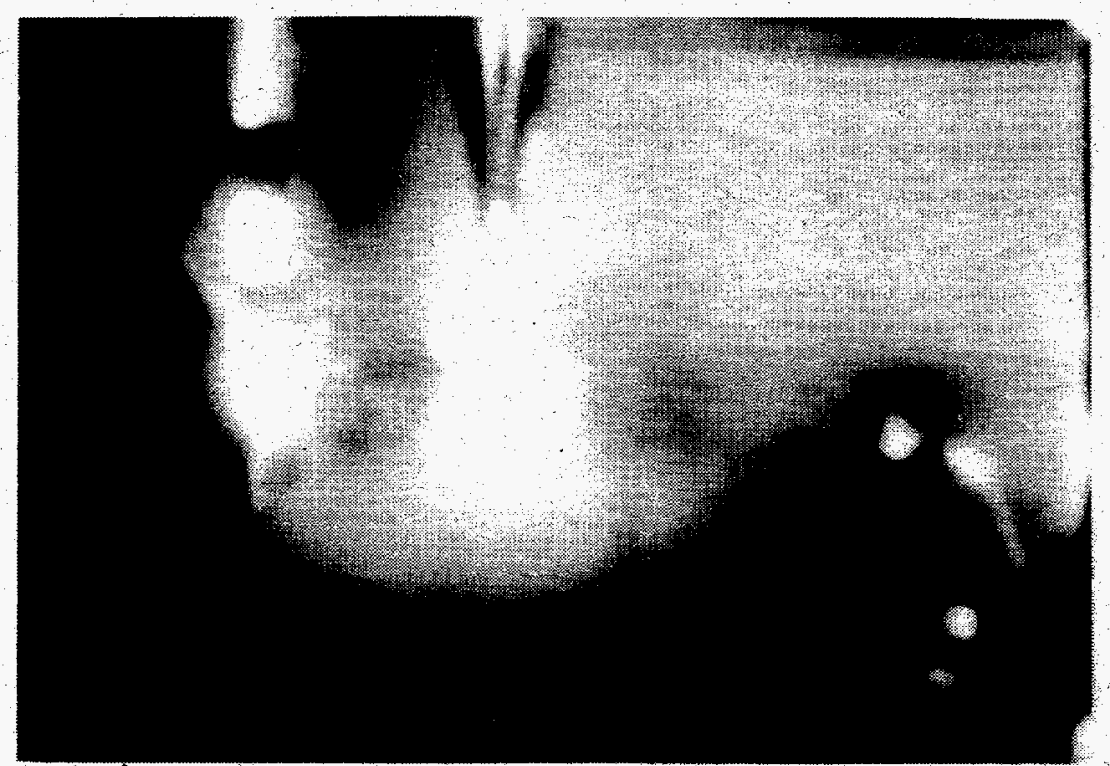

Frame $32 ; 8.064 \mathrm{~ms}$. Bubbles from drop and streamer coalesce, are about to collapse completely.

Figure 4 (continued). Selected frames reproduced from the high-speed photographs of experiment 30-80-1. Temperature of the melt was nominally $1500^{\circ} \mathrm{C}(1773 \mathrm{~K})$ at time of release. 


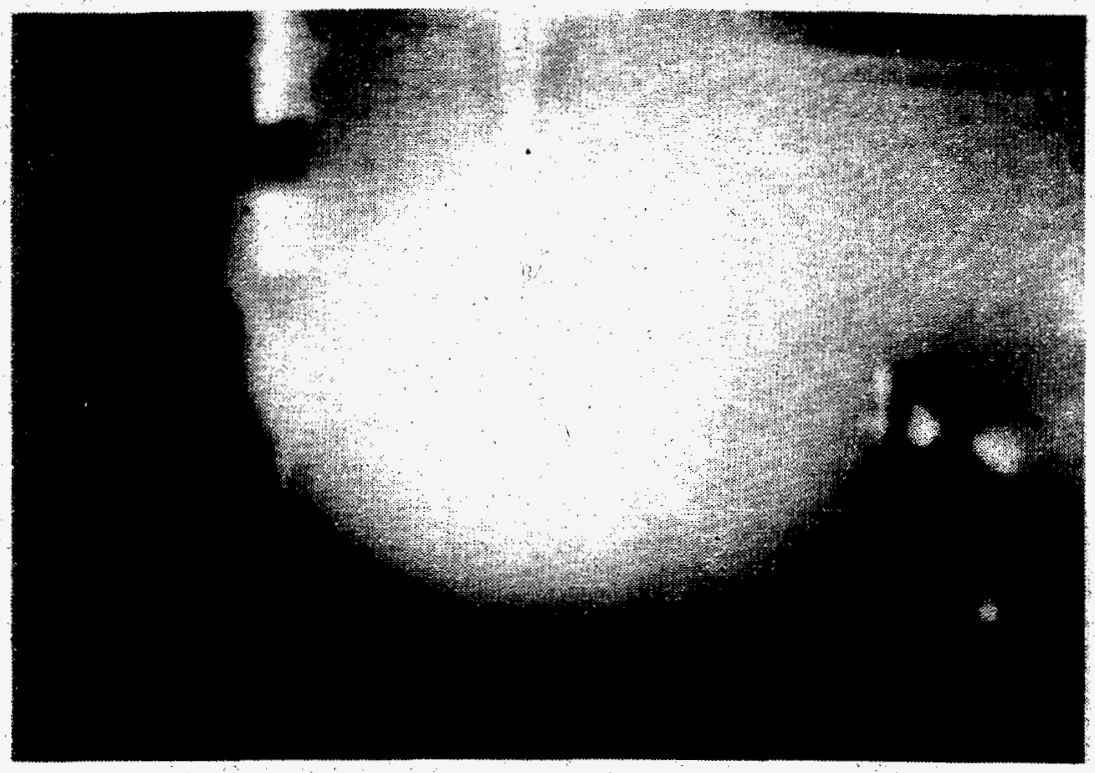

Frame $33 ; 8.316 \mathrm{~ms}$. Ignition indicated by bright flash of light.

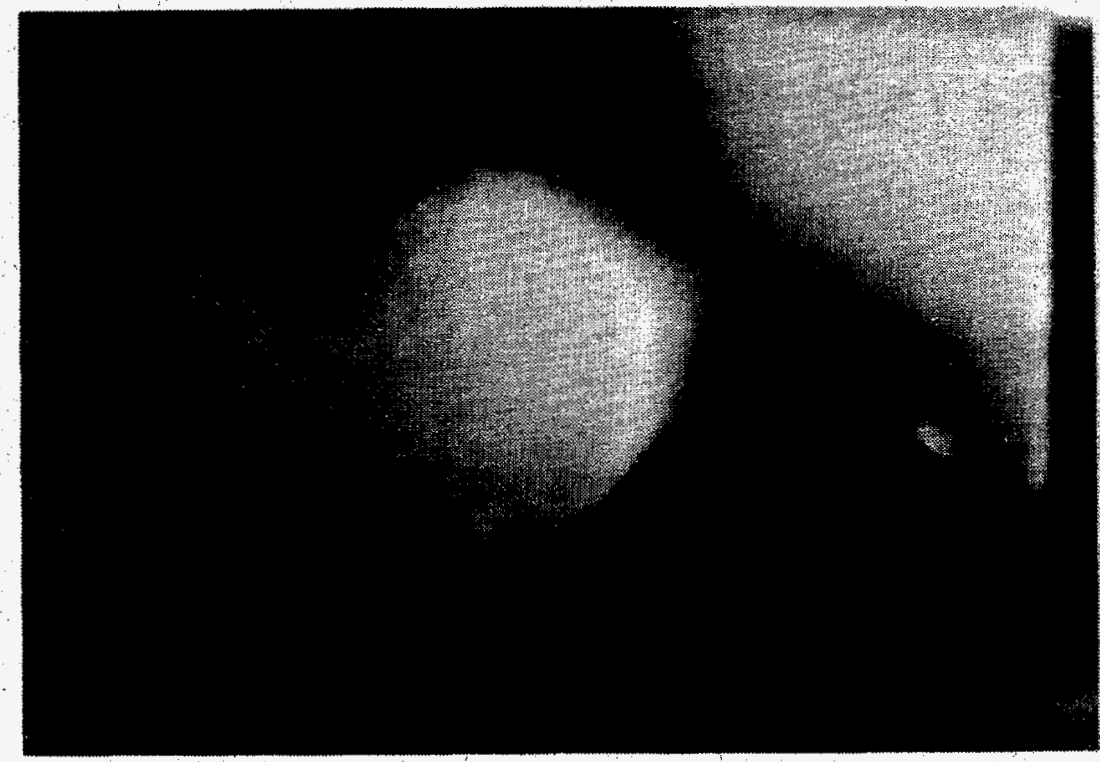

Frame 37 ; 9.324 ms. Luminosity has decayed; interaction bubble grows.

Figure 4 (continued). Selected frames reproduced from the high-speed photographs of experiment 30-80-1. Temperature of the melt was nominally $1500^{\circ} \mathrm{C}(1773 \mathrm{~K})$ at time of release. 


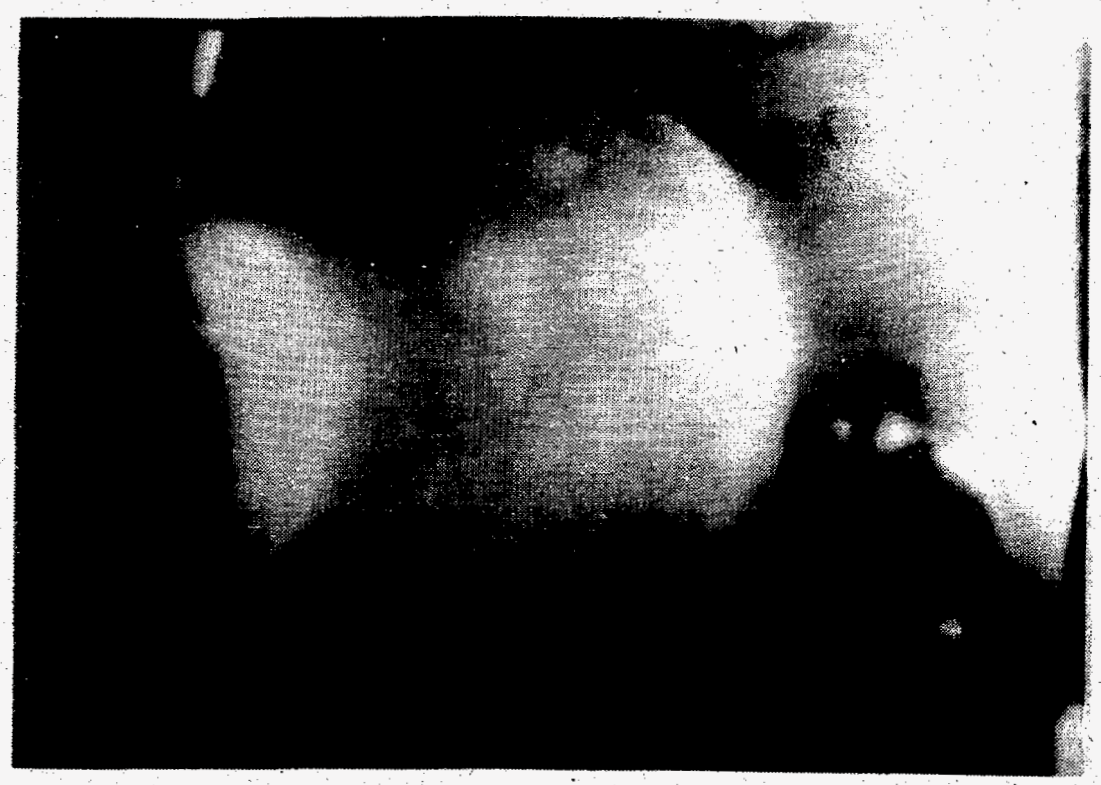

Frame $45 ; 11.340 \mathrm{~ms}$. Bubble grows; patches of debris appear on its surface. Spurious reflection, left.

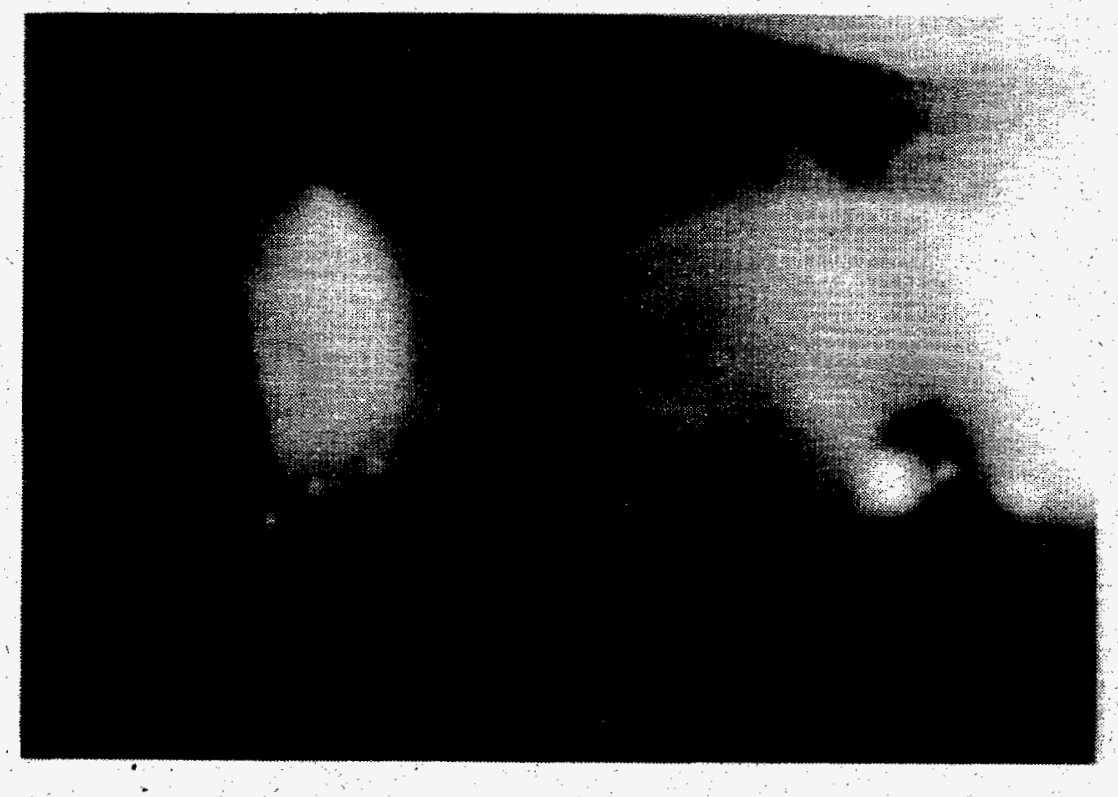

Frame $56 ; 14.112 \mathrm{~ms}$. Bubble grows, is about to burst through water surface. Spurious reflections.

Figure 4 (concluded). Selected frames reproduced from the high-speed photographs of experiment $30-80-1$. Temperature of the melt was nominally $1500^{\circ} \mathrm{C}(1773 \mathrm{~K})$ at time of release. 


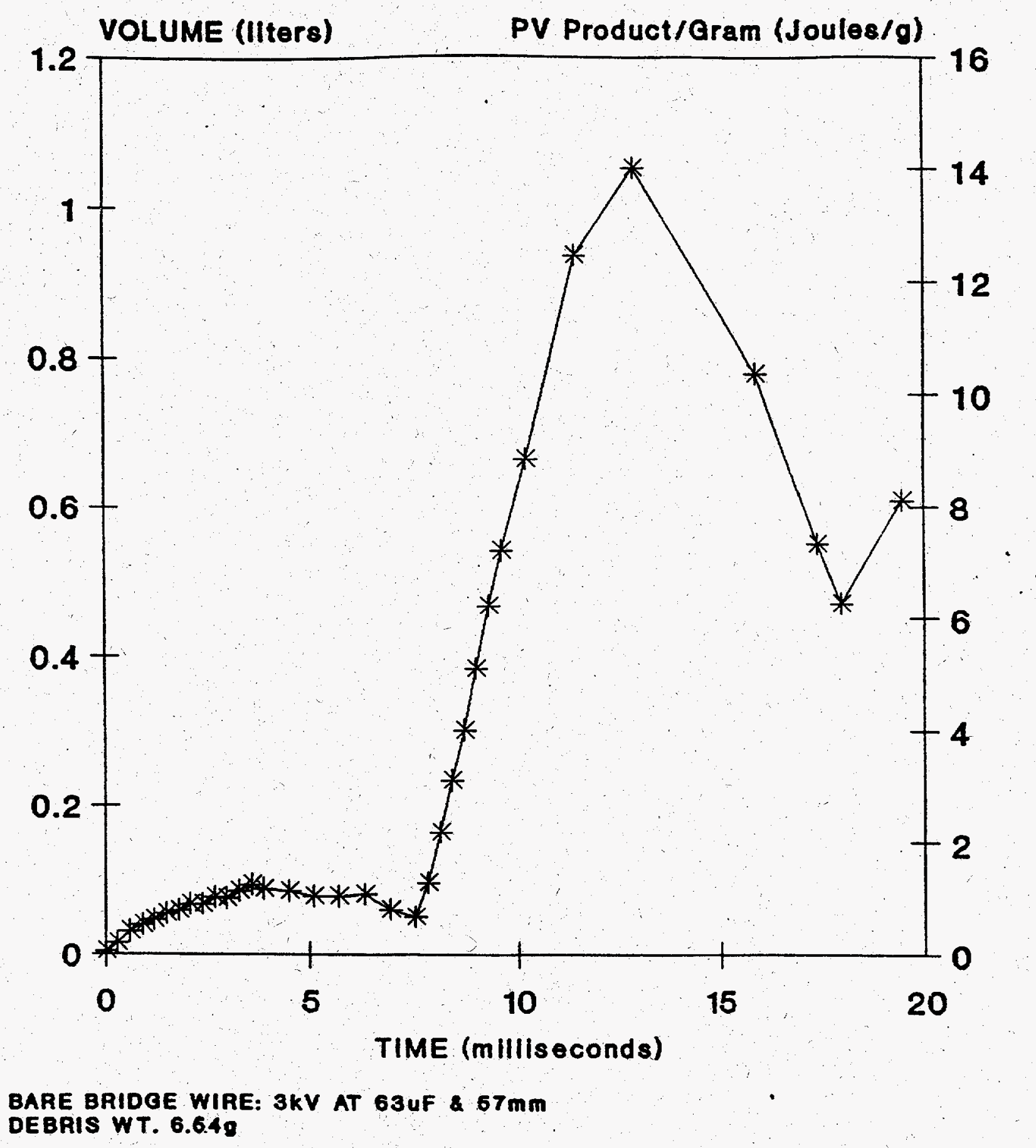

Figure 5. Bubble volume and PV product per gram of melt that participated in the triggered steam explosion of a drop of molten aluminum released at $970^{\circ} \mathrm{C}(1243 \mathrm{~K})$ as a function of time. (38-3-1). 


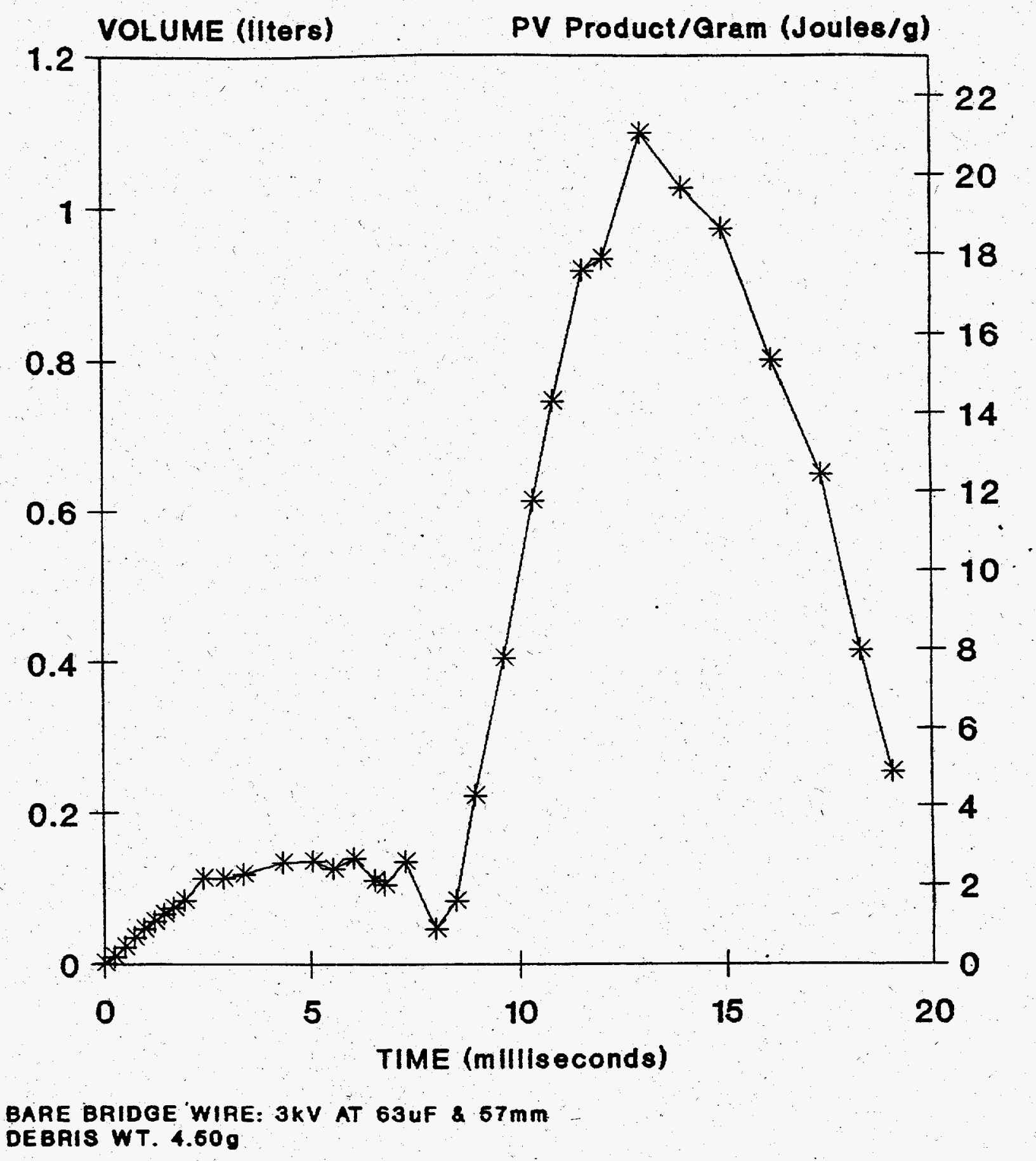

Figure 6. Bubble volume and PV product per gram of melt that participated in the triggered steam explosion of a drop of molten aluminum released at $1195^{\circ} \mathrm{C}(1468 \mathrm{~K})$ as a function of time. $(38-6-1)$. 


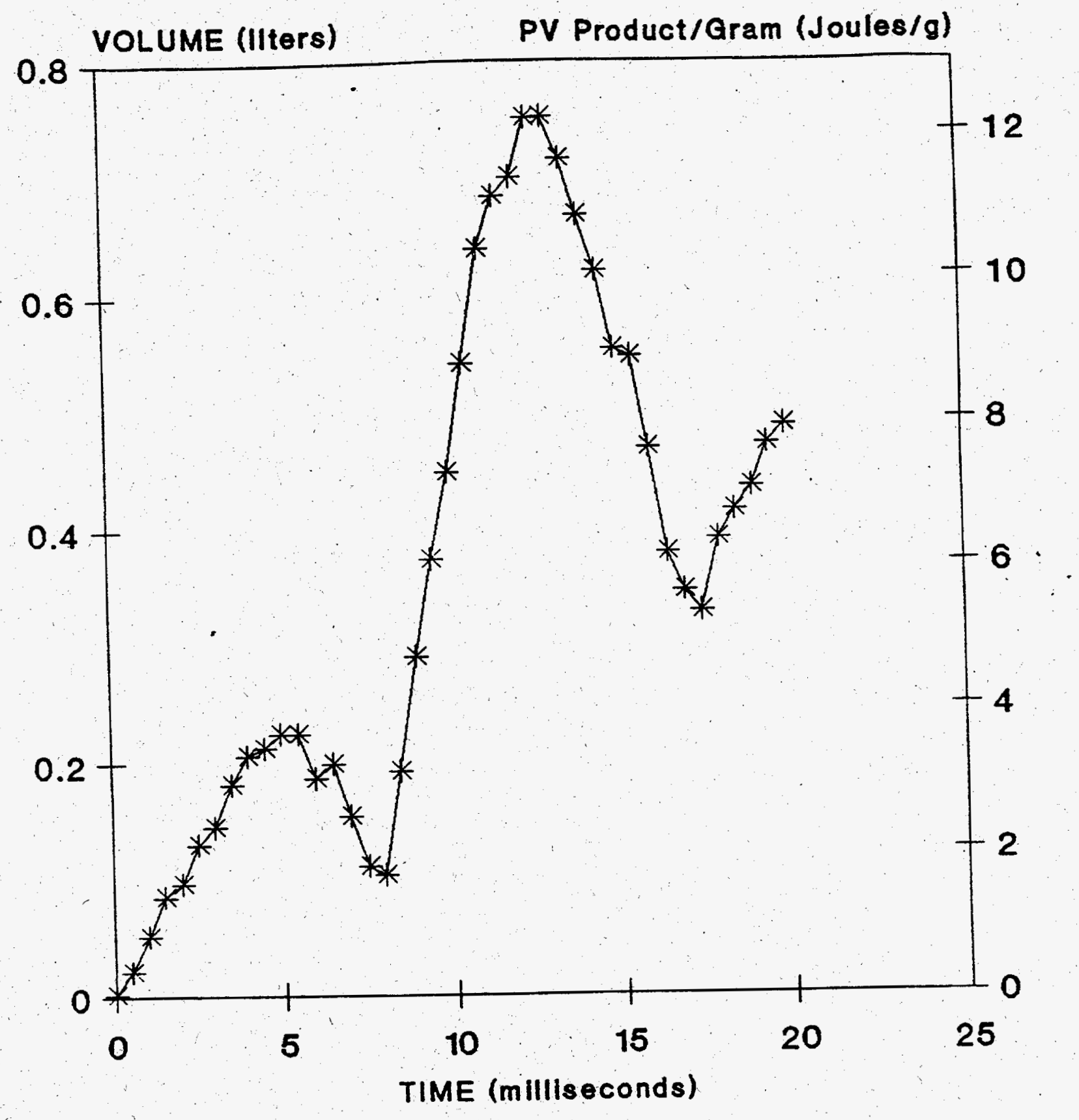

BARE BRIDGE WIRE 3KV AT 63 UF $857 \mathrm{~mm}$ DEBRIS WT. 6.229

Figure 7. Bubble volume and PV product per gram of melt that participated in the triggered steam explosion of a drop of molten aluminum released at $1200^{\circ} \mathrm{C}(1473 \mathrm{~K})$ as a function of time. $(30-73-1)$. 


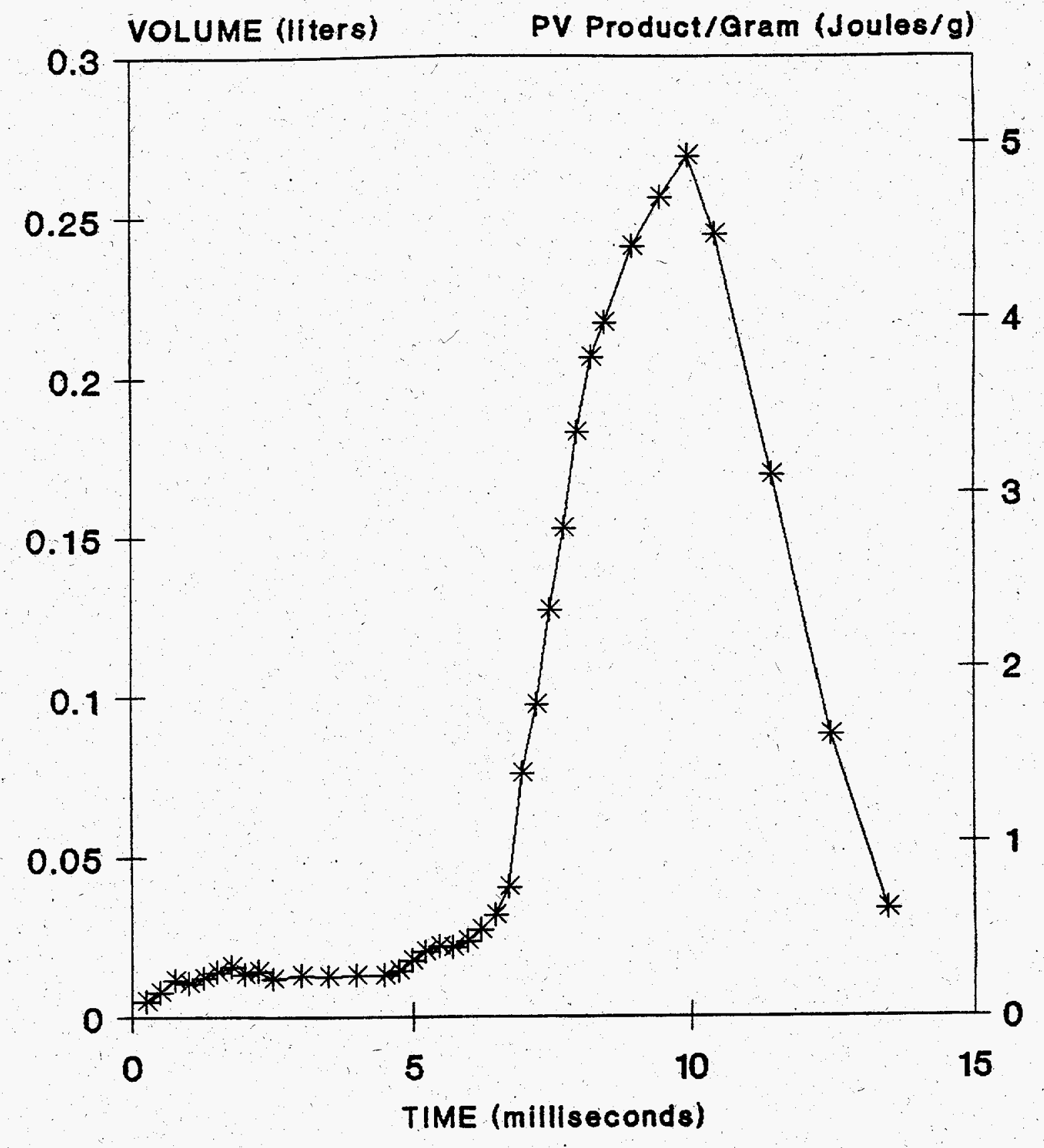

BARE BRIDGE WIRE $3 k V$ AT $63 U F \& 67 \mathrm{~mm}$ DEBRIS WT. $4.69 \mathrm{~g}$

FIgure 8. Bubble volume and PV product per gram of melt that participated in the triggered steam explosion of a drop of molten aluminum released at $1400^{\circ} \mathrm{C}(1673 \mathrm{~K})$ as a function of time. $(30-78-1)$. 


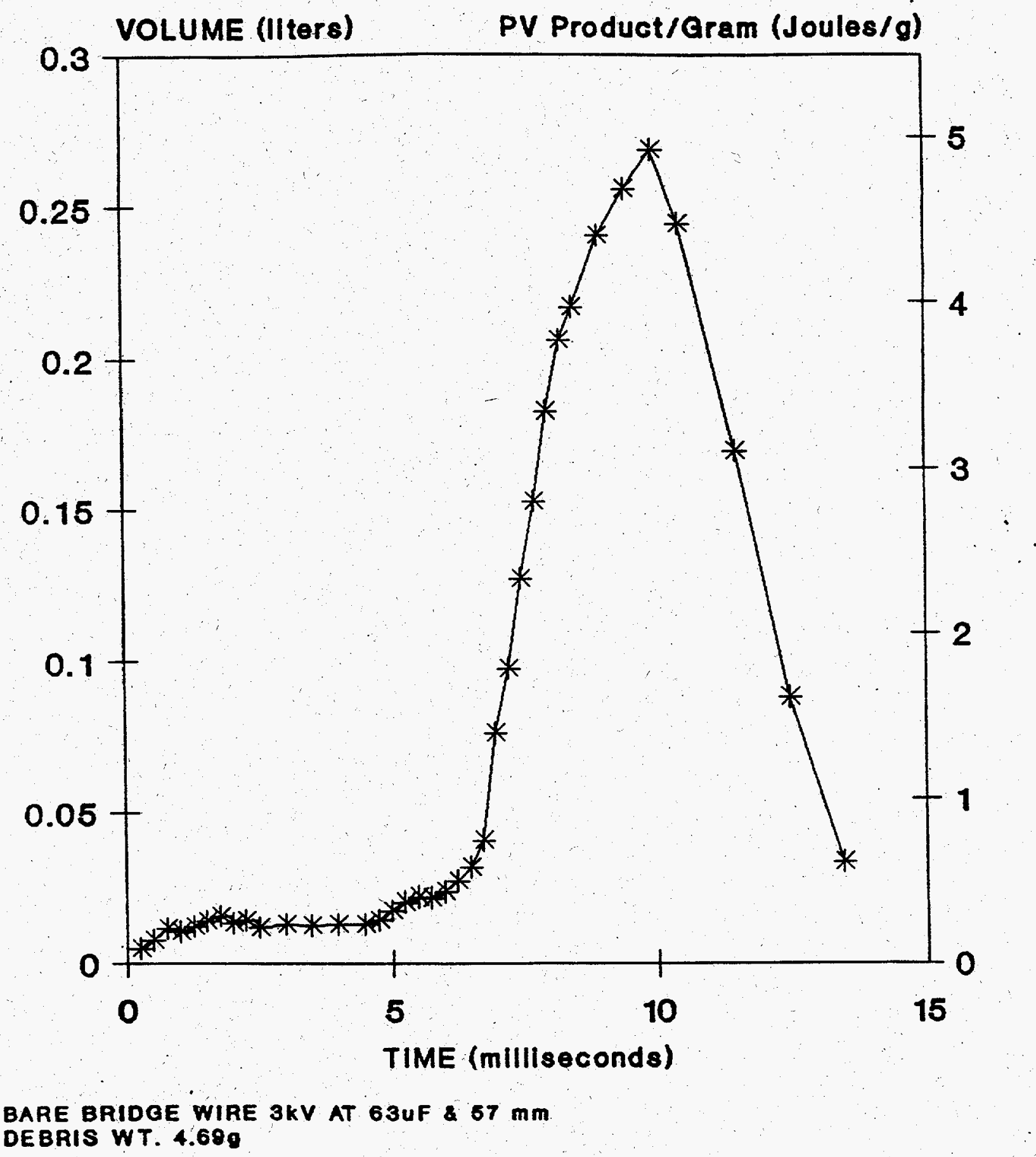

Figure 9. Bubble volume and PV product per gram of melt that participated in the triggered steam explosion of a drop of molten aluminum released at $1410^{\circ} \mathrm{C}(1683 \mathrm{~K})$ as a function of time. (30-87-1). 


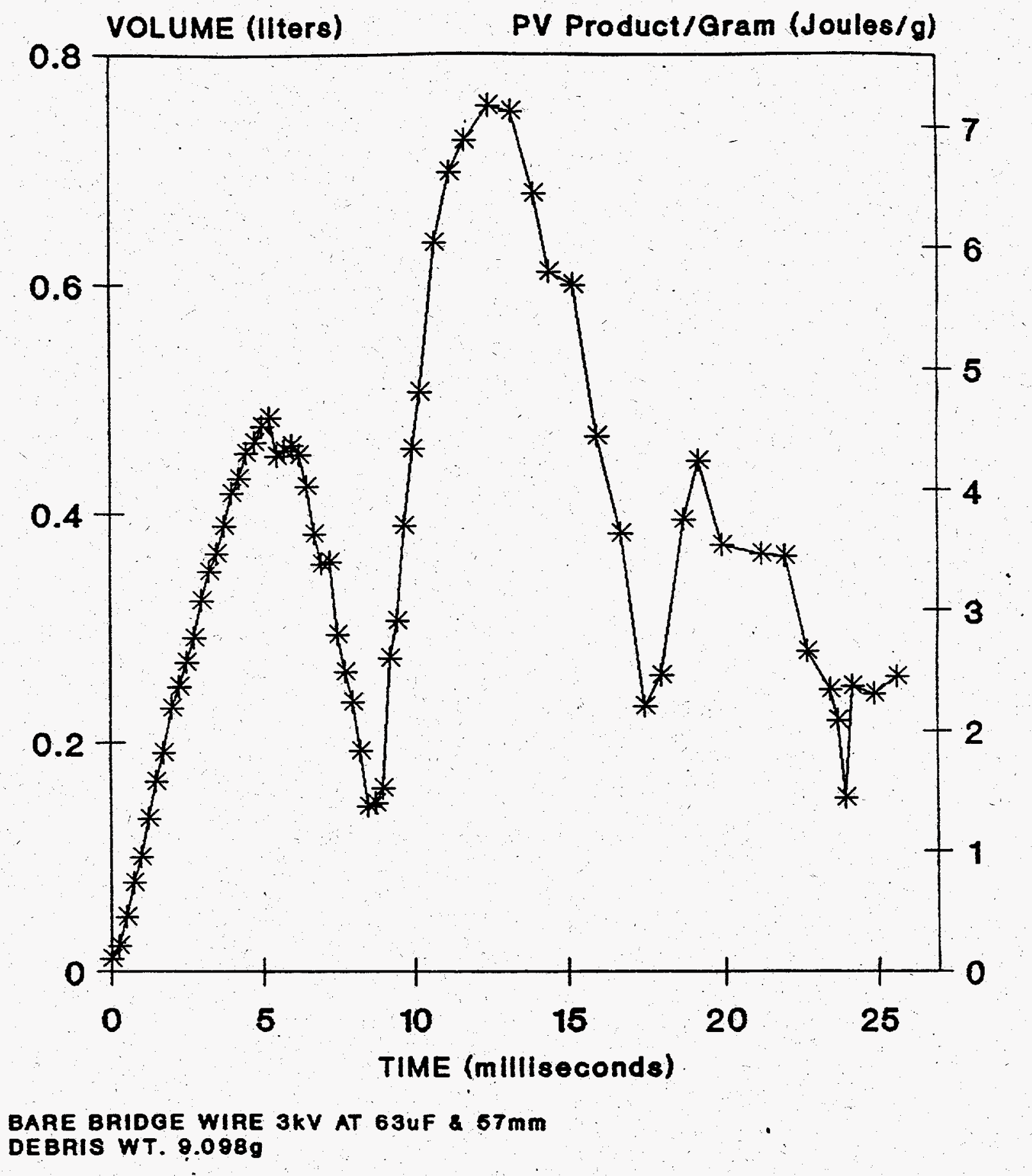

Figure 10. Bubble volume and PV product per gram of melt that participated in the triggered steam explosion of a drop of molten aluminum released at $1400^{\circ} \mathrm{C}(1673 \mathrm{~K})$ as a function of time. (30-93-1). 


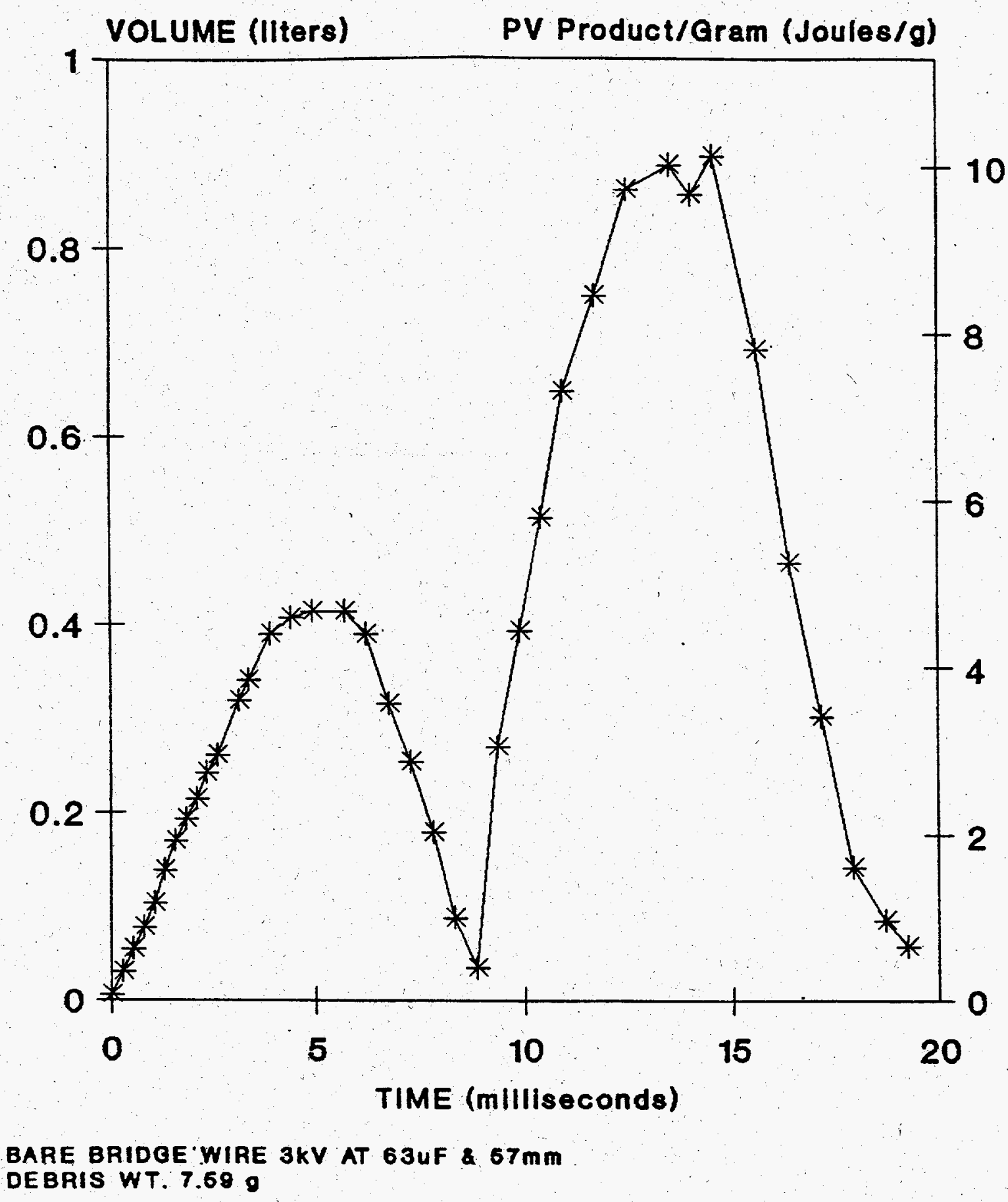

Figure 11. Bubble volume and PV product per gram of melt that participated in the triggered steam explosion of a drop of molten aluminum released at $1500^{\circ} \mathrm{C}(1773 \mathrm{~K})$ as a function of time. $(41-5-1)$. 


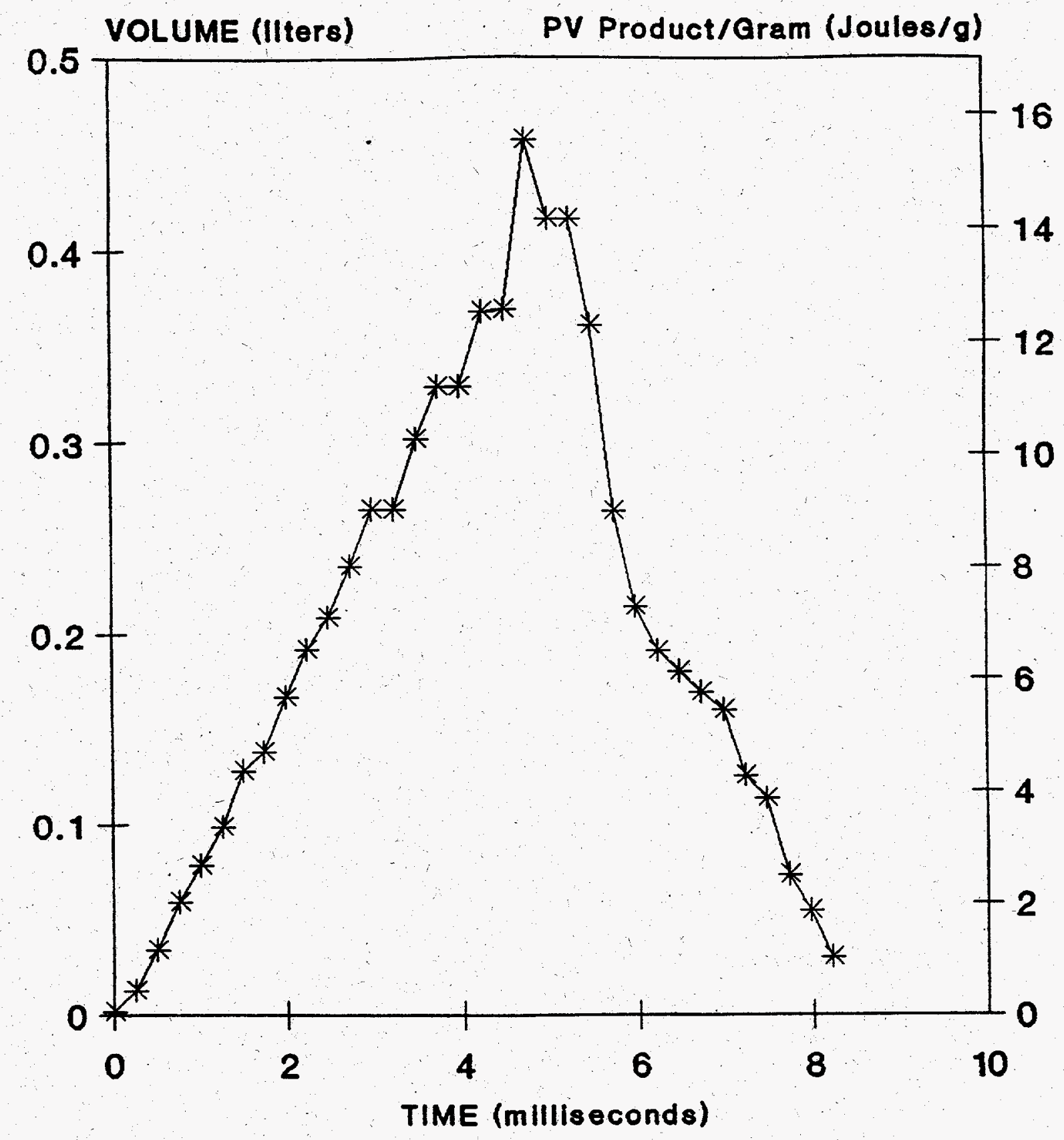

BARE BRIDQE WIRE $3 \mathrm{kV}$ AT $63 \mathrm{H}$ \& $67 \mathrm{~mm}$ DEBRIS WT. 2.640

Figure 12. Bubble volume and PV product per gram of melt that participated in the triggered steam explosion of a drop of molten aluminum released at $1525^{\circ} \mathrm{C}(1798 \mathrm{~K})$ as a function of time (30-91-1). After collapse of the first bubble at approximately $8 \mathrm{~ms}$, a poorly defined second bubble formed. This bubble could not be measured easily and was not included in this figure. 


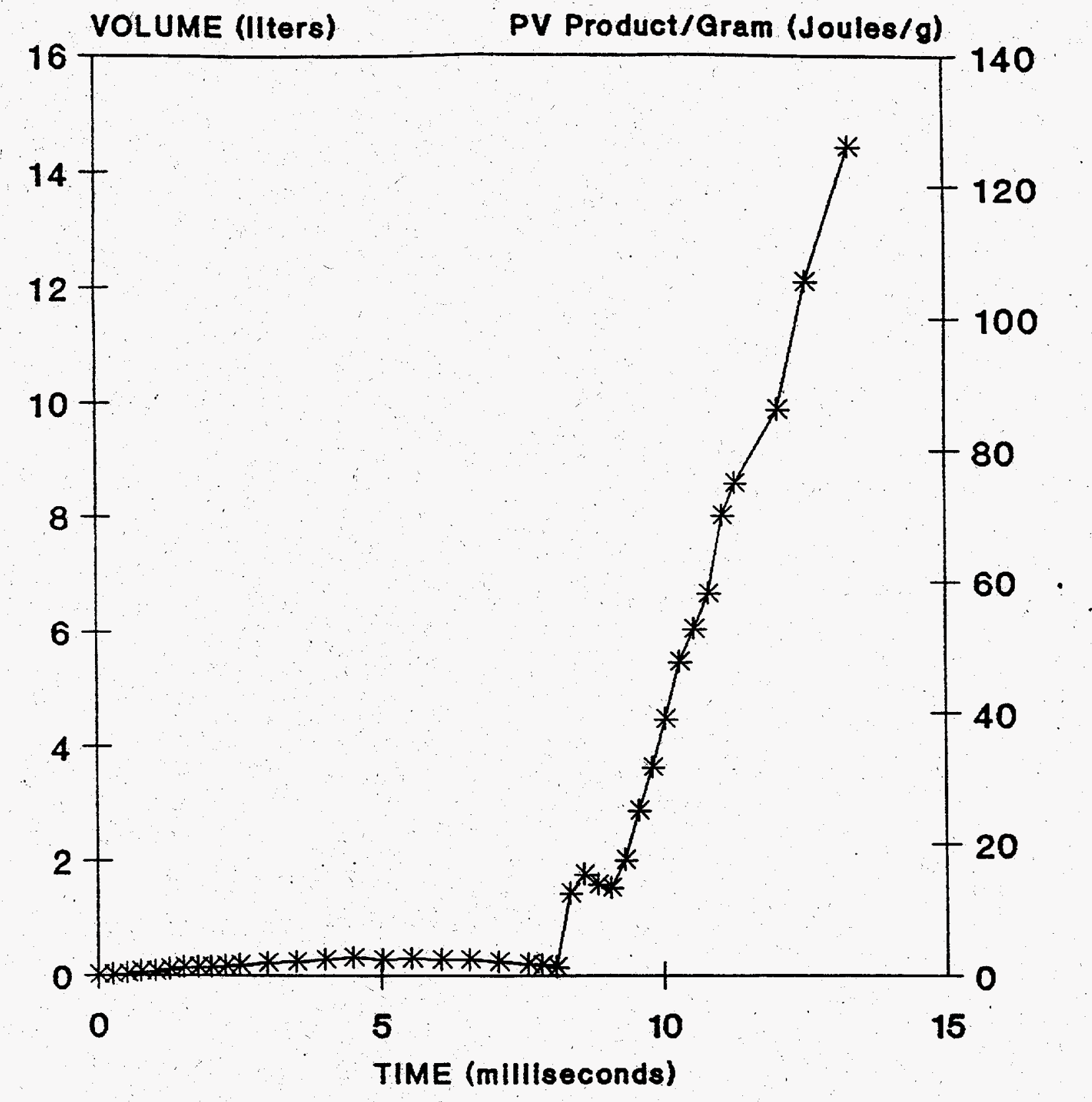

BARE BRIDGE WIRE $3 k V$ AT $63 U F \& 67 \mathrm{~mm}$

DEBRIS WT. appiox. $10 \mathrm{~g}$

IGNITION at 8.3 milliseconds

Figure 13. Bubble volume and PV product per gram of melt that participated in the triggered steam explosion of a drop of molten aluminum released at nominally $1500^{\circ} \mathrm{C}(1773 \mathrm{~K})$ as a function of time. $(30-80-1)$. 




Figure 14. Bubble volume and PV product per gram of melt that participated in the triggered steam explosions of drops of molten aluminum released at nominally $1500^{\circ} \mathrm{C}(1773 \mathrm{~K})$ as a function of time. $(30-80-1)$. The data for the first $10 \mathrm{~ms}$ of Figure 13 are shown here at enlarged scale. 
product per gram of melt (right ordinate scale), plotted as a function of time. We have normalized the bubble volume plots point-by-point to the amount of melt that participated in the interaction (assumed equal to the weight of debris retrieved after the interaction and neglecting. oxidation), and converted bubble volumes in liters to pressure-volume product in joules by the equation

$$
\text { PV (joules) } \left.=1013\left(P_{\text {atm }}(\mathrm{MPa})\right)(\mathrm{V} \text { (1iters })\right) \text {, }
$$

where $P_{a t m}=0.085 \mathrm{MPa}$, the average local atmospheric pressure.

The plots in Figures 5 through 11 are essentially similar, showing the formation of an initial small bubble that collapses in about $8 \mathrm{~ms}$, followed by the growth of a second larger bubble to a maximum volume at 10 to $12 \mathrm{~ms}$. However, the plot in Figure 12 differs from those in the previous figures because only one fairly large bubble formed and then collapsed. A second small bubble formed but was difficult to see clearly and was not measured. The plot for experiment 30-80-1 in Figure 13 shows the growth and collapse of a small first bubble during approximately the first $8 \mathrm{~ms}$ (similar to those in Figures 5 through 11), and then shows a small inflection about 1 -ms wide followed by a steep linear rise in volume: for about $4 \mathrm{~ms}$ more, after which the images were lost. The initial behavior of the bubble during the first $10 \mathrm{~ms}$ of the interaction is shown more clearly in the enlarged plot in Figure 14. The last observed volume in Figure 13 was about $14 \mathrm{~L}$, with no indication of the bubble growth "tapering off"; its ultimate volume would have been much larger if the chamber had been large enough to hold a sufficient volume of water to accommodate the bubble's complete growth.

We interpret Figures 5 through 14 as follows:

- For all experiments except 30-91-1 (Figure 12), an initial smal1 bubble grew and collapsed during approximately the first $8 \mathrm{~ms}$. We attribute this to prefragmentation of the melt on the basis of the baseline experiments with focused shockwave triggering. 1

- For the experiments at melt release temperatures up to and including $1500^{\circ} \mathrm{C}(1763 \mathrm{~K})$, except experiments $30-91-1$ and $30-80-1$, a second moderate bubble grew to 0.2 to $1.1 \mathrm{~L}$, which we attribute to mostly thermal-type explosions.

- Experiment 30-91-1 in Figure 12 is probably a transition-type interaction at a melt release temperature of $1525^{\circ} \mathrm{C}(1798 \mathrm{~K})$, perhaps a precursor of the ignition-type experiment shown in Figures 13 and 14 . (Note: One of the experimenters observed the melt to have a reddish glow as it fell between the crucible and the water surface in experiment $30-91-1$. This glow was also

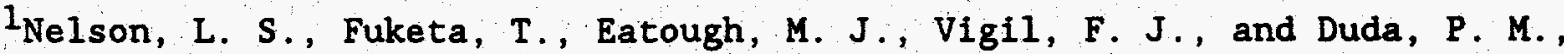
The Triggering of Steam Explosions of Single Drops of Pure and Alloyed Molten Aluminum, SAND90-0131, Sandia National Laboratories, Albuquerque, NM. In preparation.
} 
apparent on the high-speed film after the drop entered the water, prior to triggering.)

- After the initial 8-ms long bubble growth and collapse, the film from experiment 30-80-1 showed a small upward deviation (inflection) that lasted about $1 \mathrm{~ms}$ (Figures 13 and 14). This deviation corresponds to three overexposed Hycam images of the bright flash of light emitited by the interaction (apparent increase in image size [blooming] normally accompanies overexposed film). One of the photographic images that corresponds to this flash is reproduced in Figure 4, Frame 33. We interpret this flash of light to be the ignition and combustion of aluminum vapor and the generation of high-temperature gaseous reaction products within the bubble.

- The expansion of the gaseous combustion products at high temperature caused the bubble to grow to about $14 \mathrm{~L}$ before the chamber failed and the bubble broke through the surface of the water (an approximately $31-\mathrm{cm}$ diameter bubble formed just as the $30-\mathrm{cm}$ wide and $30-\mathrm{cm}$ deep chamber was falling).

- At the final bubble volume in the ignition-type steam explosion, the pressure-volume product had increased to about 124 joules per. gram of melt. At this point, the bubble had achieved roughly half the Hicks-Menzies (HM) value for maximum conversion of thermal energy for molten pure aluminum (Anderson and Armstrong 1981; Rightley et al. 1993). To our knowledge, this is the first time an energy conversion anywhere near this large has ever been measured in a laboratory-scale experiment with a single drop of melt falling freely in water; the conversions usually have been no greater than 1 or 2 percent of HM. Moreover, because there was no apparent tendency toward "tapering off". when the bubble burst, the actual conversion probably was much higher than the value reported above.

- An interesting trend was observed in $\mathrm{PV}_{\max } / \mathrm{g}$, the maximum pressure-volume product per gram of aluminum that participated in the interactions. In Table 2, those experiments from Table 1 in which steam explosions occurred (the experiments that correspond to Figures 5 through 14 ) are arranged in order of increasing meit release temperature. We note a dip in the $P V_{\max } / g$ values when the melt release temperature was nominally $1400^{\circ} \mathrm{C}(1673 \mathrm{~K})$. Neither the significance of the dip nor its validity (because of the small number of experiments) is known at this time.

In Figure 15 we have placed the bubble volume-time plots of a representative thermal-type explosion (30-93-1, melt release temperature of $1400^{\circ} \mathrm{C}$ [ $\left.1673 \mathrm{~K}\right]$ ) on the same ordinate scale as the ignition-type explosion (30-80-1, melt release temperature of approximately $1500^{\circ} \mathrm{C}$ $[1773 \mathrm{~K}])$. With a linear regression, we have determined the slope of the linear portion (a-b) of the plot in Figure 15 to be approximately 26 joules per millisecond per gram, that is, $26 \mathrm{~kW}$ per gram of melt. (This should be compared with a maximum slope observed for the triggered 
Table 2. Bubble Volume Analyses of Steam Explosions of Drops of Pure Aluminum Arranged in Order of Increasing Melt Release Temperature

\begin{tabular}{|c|c|c|c|c|c|c|}
\hline Expt. No. & Fig. No. & $\left({ }^{\circ} \mathrm{C}\right)^{\mathrm{T}_{\text {mol }}}$ & (K) & $\begin{array}{l}v_{\operatorname{mix}} \\
(L)\end{array}$ & $\begin{array}{c}\mathrm{PV}_{\max } / \mathrm{g}^{*} \\
(\mathrm{~J} / \mathrm{g})\end{array}$ & Remarks \\
\hline $38-3-1^{b}$ & 5 & 970 & 1243 & $0.08 / 1.05$ & $1.1 / 13.9$ & \\
\hline $38-6-1^{b}$ & 6 & 1195 & 1468 & $0.15 / 1.10$ & $2.9 / 21.0$ & \\
\hline $30-73-1$ & 7 & 1200 & 1473 & $0.22 / 0.75$ & $3.6 / 12.4$ & $\therefore$ \\
\hline $30-78-1$ & 8 & 1400 & 1673 & $0.02 / 0.27$ & $0.4 / 4.9$ & \\
\hline $30-87-1$ & 9 & 1410 & 1683 & $0.02 / 0.52$ & $0.3 / 7.1$ & \\
\hline $30-93-1$ & 10 & 1400 & 1673 & $0.48 / 0.75$ & $4.5 / 7.1$ & • \\
\hline $30-91-1$ & 11 & 1525 & 1798 & $0.46 /-$ & $15.5 /$ & $\begin{array}{l}\text { Only one measureable } \\
\text { bubble was generated }\end{array}$ \\
\hline $41-5-1$ & 12 & 1525 & 1798 & $0.41 / 0.90$ & $4.7 / 10.2$ & \\
\hline $30-80-1$ & 13,14 & $1500^{\circ}$ & $1773^{\circ}$ & $0.35 / \geq 14$ & $3.1 / \geq 124$ & \\
\hline
\end{tabular}

The values before and after the slash refer to the first and second bubbles generated in each interaction.

Baseline experiments from Nelson L. S., Fuketa, T., Eatough, M. J., Vigil, F. J., and Duda, P. M., The Triggering of Steam Explosions of Single Drops of Pure and Alloyed Molten Aluminum, SAND90-0131, Sandia National Laboratories, Albuquerque, NM. In preparation.

'Temperature may have been higher because of vaporization products in pyrometer's view path. 




BARE BRIDGE WIRE: $3 k V$ at $63 U F$ and $67 \mathrm{~mm}$

Figure 15. Comparison of the volume and pressure-volume product per gram of melt that participated in the triggered ignition-type $(30-80-1)$ and thermal-type $(30-93-1)$ steam explosions of single drops of molten aluminum. The upper curve is for aluminum at a nominal temperature of $1773 \mathrm{~K}$; the lower curve is for a nominal temperature of $1673 \mathrm{~K}$. The blooming caused by the flash of light is indicated at about $8 \mathrm{~ms}$. The slope of the curve between points (a) and (b) is indicated. 
steam explosion of an aluminized thermite drop of approximately $6 \mathrm{~kW}$ per gram [Nelson et al., 1992], the largest slope previously observed in our laboratory.)

\subsection{Damage to the Chamber}

The damage to the chamber during the ignition-type steam explosion, experiment $30-80-1$, is shown in Figures 16 and 17 .

The chamber was made from $12.7-\mathrm{mm}$ thick Lexan held together by $2.5-\mathrm{cm}$ long, 10-24 machine screws and silicone adhesive. In the high-speed films the chamber was observed to bulge significantly and to crack in two places: on the end of the chamber farthest from the explosion and at a steel cross truss, part of the framework on which the chamber rested. This truss was located roughly midway between the ends of the chamber. Also, the bottom corners of the chamber separated and the machine screws either tore from their threads or pulled chunks of Lexan from the chamber walls. In addition to the damage to the chamber, the steel framework below the chamber was significantly tilted because of the torque produced by the explosion, which occurred approximately $15 \mathrm{~cm}$ from the left side of the chamber (as viewed by the camera).

\subsection{Temperature Measurements}

The melt release temperatures were measured with an optical pyrometer that viewed an unobstructed (i.e., windowless) sight path through the walls of the sheath tube and the susceptors into a hohlraum created between the susceptors and the alumina tube used as the crucible. For all experiments except 30-80-1 there was good agreement between the pyrometer readings and the readings of the Type $K$ or Type $R$ thermocouples inserted in the inner alumina plunger tube of the crucible arrangement. The temperature measurement during experiment $30-80-1$ is uncertain because some vapor and aerosols were being ejected from the RF-heated susceptor at approximately $1500^{\circ} \mathrm{C}(1773 \mathrm{~K})$. The actual release temperature that would have been recorded with a clear view path might have been somewhat in excess of $1500^{\circ} \mathrm{C}(1773 \mathrm{~K})$.

\subsection{Debris}

The debris produced in the ignition-type steam explosion of pure aluminum, experiment 30-80-1, was recovered as carefully as possible after the flooding had been stabilized. Instead of the quantitative recovery accomplished in each of the thermal-type explosions, a small portion of the debris was probably lost when the chamber failed. We recovered about $8 \mathrm{~g}$ of the initial $12 \mathrm{~g}$ of the aluminum charge in the crucible. To account for the lost debris, we conservatively estimated the mass that participated in the interaction to be approximately $10 \mathrm{~g}$ (the value entered in Table 1).

In both the thermal-and ignition-type experiments, the debris was transferred from the interaction chamber by repeated rinsing with streams of deionized water to a fluted filter paper held in a large funnel. After the debris was separated from the water by filtration, it was dried and 


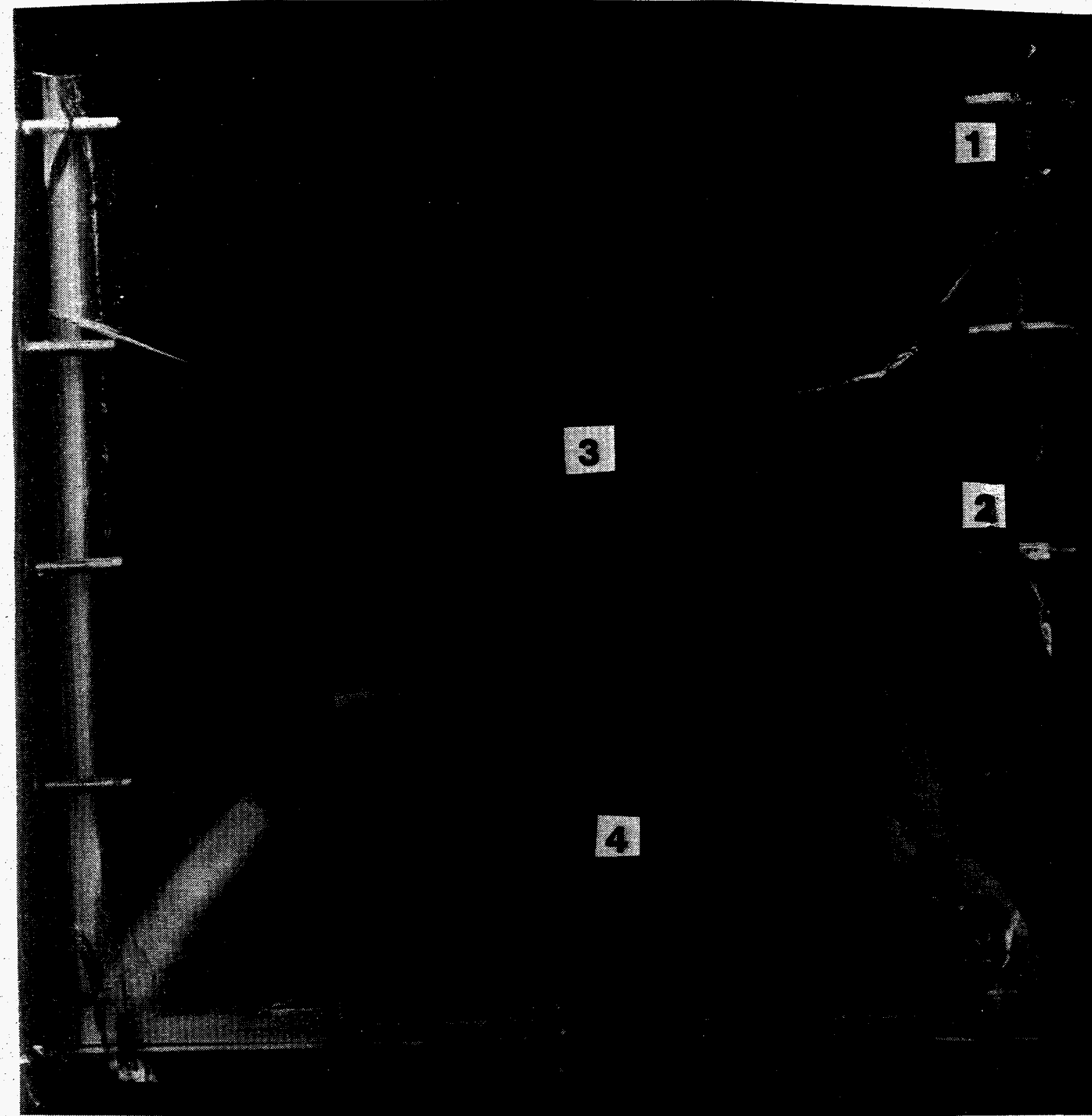

Figure 16. Lexan water chamber damaged in experiment 30-80-1. Note the $2.5 \mathrm{~cm}-1$ ong, 10-24 machine screws that pulled from threads in the Lexan (1) and pulled off chunks of Lexan (2). Note also the fractured end of the chamber (3) and the crack in bottom of the chamber (4). 


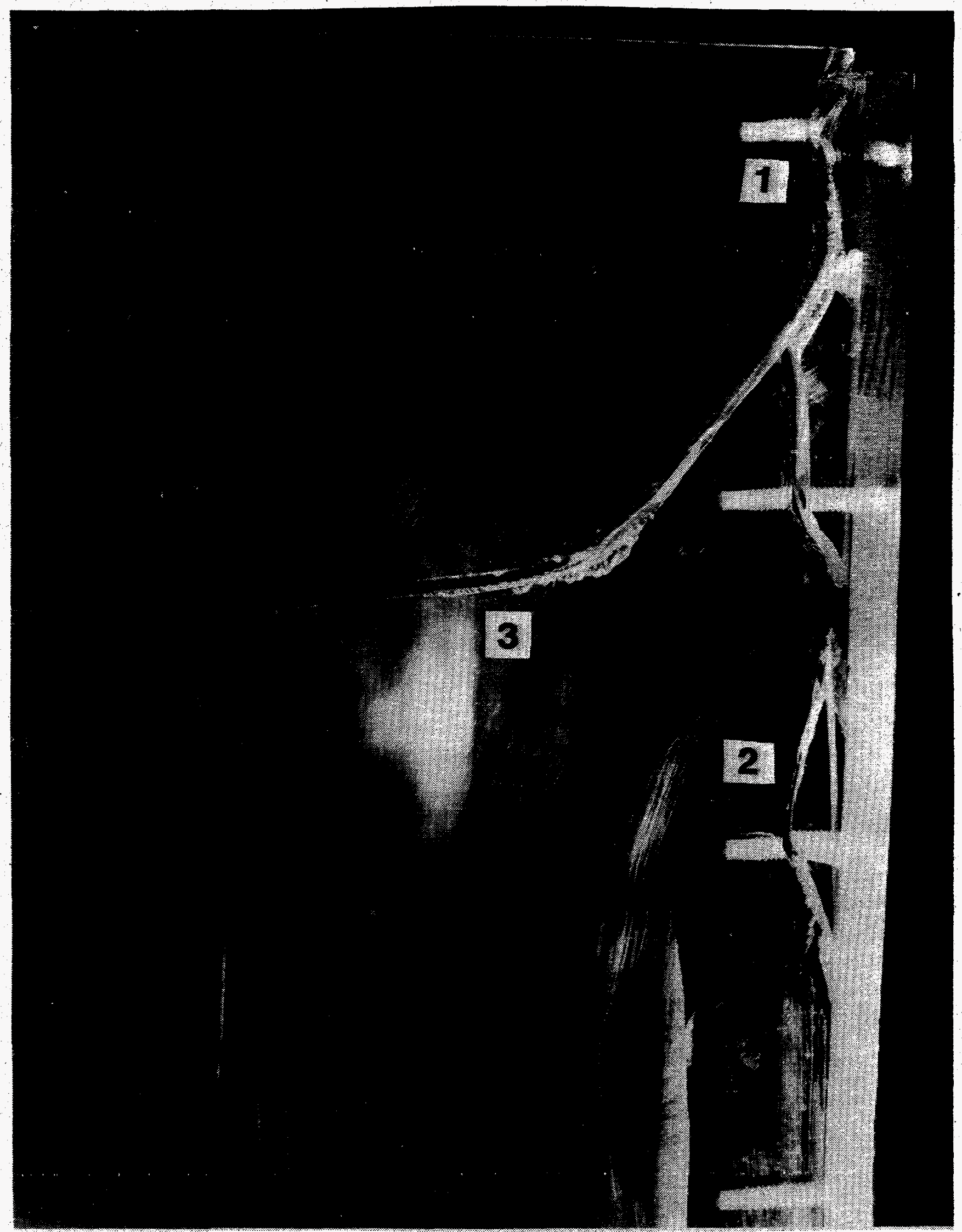

Figure 17. Enlarged view of the upper right corner of the damaged Lexan chamber shown in Figure 16. The numbering is the same as in Figure 16. 
sieved as in the baseline experiments. 1 The sieve analysis for the ignition-type steam explosion, experiment $30-80-1$, is presented in Table 3a. These results should be compared with those for a typical. thermal-type explosion (experiment 38-6-1, melt release temperature $1200^{\circ} \mathrm{C}$ $[1473 \mathrm{~K}])$ reported earlier ${ }^{1}$ and reproduced in Table $3 \mathrm{~b}$. Both sieve analyses are plotted in Figure 18. It should be noted that there is apparently little difference between the particle size distributions obtained in the two experiments.

We also performed careful (blind) stereomicroscopic comparisons of the debris retrieved from experiment $30-80-1$ and that retrieved from experiment 38-6-1. With up to $10 \mathrm{X}$ magnification, we were unable to visually observe any differences (e.g., oxide coatings) between the debris retrieved from the ignition-type steam explosion and the thermal-type steam explosion with molten high purity aluminum. We concluded that little combustion of aluminum occurred in either experiment.

$X$-ray diffraction analyses were performed on portions of the sieved samples of debris shown in Figure 18. Three sieve fractions (\#14 [coarse], \#80 [fine] and pan [finest]) were submitted for each sample for the analyses. The analyst's report is quoted here:

"The predominant phase in each fraction of both samples is aluminum . metal. The trace phases for each are listed below.

30-80-1: \#14; Gamma-alumina

\#80; Gamma-alumina with lesser alpha-alumina

Pan; Mostly alpha-alumina with gamma-alumina and quartz or graphite.

38-6-1: \#14 and 80; Gamma-alumina is the only additional phase

Pan; Gamma-alumina was detected plus other phases which I suspect are quartz and feldspars but are otherwise unidentified."

Both the stable alpha-alumina and the metastable gamma-alumina have been observed previously in triggered steam explosions of melt drops generated by the thermite reaction of two mixtures of iron oxide and aluminum powders (Nelson et al. 1992). In the thermite mixtures before ignition, the aluminum powder was present at either $25 \mathrm{w} / 0$ (the normal stoichiometric composition) or $50 \mathrm{w} / 0$ (a mixture significantly enriched in aluminum). After the interactions, the alpha-alumina was found in both mixtures, while the gamma-alumina was detected mostly in the finest debris from the most vigorous explosions, that is, the colloid-like fines that remained suspended in the water after the interaction. Since vapor-phase combustion of excess aluminum is presumed to have occurred with the aluminum-enriched thermite, it is possible that both alpha- and

${ }^{1}$ Nelson, L. S., Fuketa, T., Eatough, M. J., Vigil, F. J., and Duda, P. M., The Triggering of Steam Explosions of Single Drops of Pure and Alloyed Molten Aluminum, SAND90-0131, Sandia National Laboratories, Albuquerque, NM. In preparation. 
Table 3a. Particle Size Weight Data Obtained by Sleving Debris Recovered from Ignition-Type Molten Aluminum-Water Interaction

\begin{tabular}{|c|c|c|c|c|c|c|c|c|}
\hline $\begin{array}{c}\text { Expt. } \\
\text { No. }\end{array}$ & Melt & $\begin{array}{r}\text { Rel } \\
\text { Tempe } \\
\left({ }^{\circ} \mathrm{C}\right)\end{array}$ & $\begin{array}{r}\text { ease } \\
\text { rature } \\
\quad(K) \\
\end{array}$ & $\begin{array}{c}\text { Sieve } \\
\text { No. } \\
\end{array}$ & $\begin{array}{c}\text { Sieve } \\
\text { Opening } \\
\text { (mm) }\end{array}$ & $\begin{array}{l}\text { Weight } \\
\text { (g) }\end{array}$ & $\begin{array}{l}\text { Cumulative } \\
\text { Weight (g) }\end{array}$ & $\begin{array}{c}\text { Cumulative } \\
\text { Weight Percent }\end{array}$ \\
\hline \multirow[t]{14}{*}{$30-80-1$} & Pure Al & -1500 & -1773 & 5 & 4.00 & 0.2468 & 7.0080 & 100.00 \\
\hline & & & & 7 & 2.80 & 0.0772 & 6.7612 & 96.48 \\
\hline & & & & 10 & 2.00 & 0.1517 & 6.6840 & 95.38 \\
\hline & & & & 14 & 1.41 & 0.5980 & 6.5323 & 93.21 \\
\hline & & & & 18 & 1.00 & 1.0064 & 5.9343 & 84.68 \\
\hline & & & & 25 & 0.71 & 0.8654 & 4.9279 & 70.32 \\
\hline & & & & 35 & 0.50 & 1.0561 & 4.0625 & 57.97 \\
\hline & & & & 45 & 0.35 & 0.7797 & 3.0064 & 42.90 \\
\hline & & & & 60 & 0.25 & 0.6038 & 2.2267 & 31.77 \\
\hline & & & & 80 & 0.18 & 0.5317 & 1.6229 & 23.16 \\
\hline & & & & 120 & 0.125 & 0.4268 & 1.0912 & 15.71 \\
\hline & & & & 170 & 0.040 & 0.2694 & 0.6642 & 9.48 \\
\hline & & & & 230 & 0.063 & 0.1849 & 0.3948 & 5.63 \\
\hline & & & & Pan & $<0.063$ & 0.2099 & 0.2099 & 2.99 \\
\hline
\end{tabular}


Table 3b. Particle Size Weight Data Obtained by Sieving Debris Recovered from Therma1-Type Molten Aluminum-Water Interaction ${ }^{a}$

\begin{tabular}{|c|c|c|c|c|c|c|c|c|}
\hline \multirow{2}{*}{$\begin{array}{c}\text { Expt. } \\
\text { No. }\end{array}$} & \multirow{2}{*}{ Melt } & \multicolumn{2}{|c|}{$\begin{array}{c}\text { Release } \\
\text { Temperature }\end{array}$} & \multirow{2}{*}{$\begin{array}{l}\text { Sieve } \\
\text { No. }\end{array}$} & \multirow{2}{*}{$\begin{array}{c}\text { Sieve } \\
\text { Opening } \\
\text { (mm) }\end{array}$} & \multirow{2}{*}{$\begin{array}{l}\text { Weight } \\
\text { (g) }\end{array}$} & \multirow{2}{*}{$\begin{array}{l}\text { Cumulative } \\
\text { Weight (g) }\end{array}$} & \multirow{2}{*}{$\begin{array}{c}\text { Cumulative } \\
\text { Weight Percent }\end{array}$} \\
\hline & & $\left({ }^{\circ} \mathrm{C}\right)$ & (K) & & & & & \\
\hline \multirow[t]{14}{*}{$38-6-1$} & Pure Al & 1195 & 1467 & 5 & 4.00 & 0.0320 & 4.5957 & 100.00 \\
\hline & & & & 7 & 2.80 & 0.0000 & 4.5637 & 99.30 \\
\hline & & & & 10 & 2.00 & 0.0806 & 4.5637 & 99.30 \\
\hline & & & & 14 & 1.40 & 0.3070 & 4.4831 & 97.55 \\
\hline & & & & 18 & 1.00 & 0.6465 & 4.1761 & 90.87 \\
\hline & & & & 25 & 0.710 & 0.6720 & 3.5296 & 76.80 \\
\hline & & & & 35 & 0.500 & 0.8555 & 2.8576 & 62.18 \\
\hline & & & & 45 & 0.355 & 0.6248 & 2.0021 & 43.56 \\
\hline & & & & 60 & 0.250 & 0.4594 & 1.3773 & 29.97 \\
\hline & & & & 80 & 0.180 & 0.3258 & 0.9179 & 19.97 \\
\hline & & & & 120 & 0.125 & 0.2343 & 0.5921 & 12.88 \\
\hline & & & & 170 & 0.090 & $0: 1425$ & 0.3578 & 7.79 \\
\hline & & & & 230 & 0.063 & 0.0893 & 0.2153 & 4.68 \\
\hline & & & & Pan & $<0.063$ & 0.1260 & 0.1260 & 2.74 \\
\hline
\end{tabular}

These data are reproduced from Nelson, L. S., Fuketa, T., Eatough, M. J., Vigil, F. J., and Duda, P. M., The Triggering of Steam Explosions of Single Drops of Pure and Alloyed Molten Aluminum, SAND90-0131, Sandia National Laboratories, Albuquerque, NM. In preparation. 


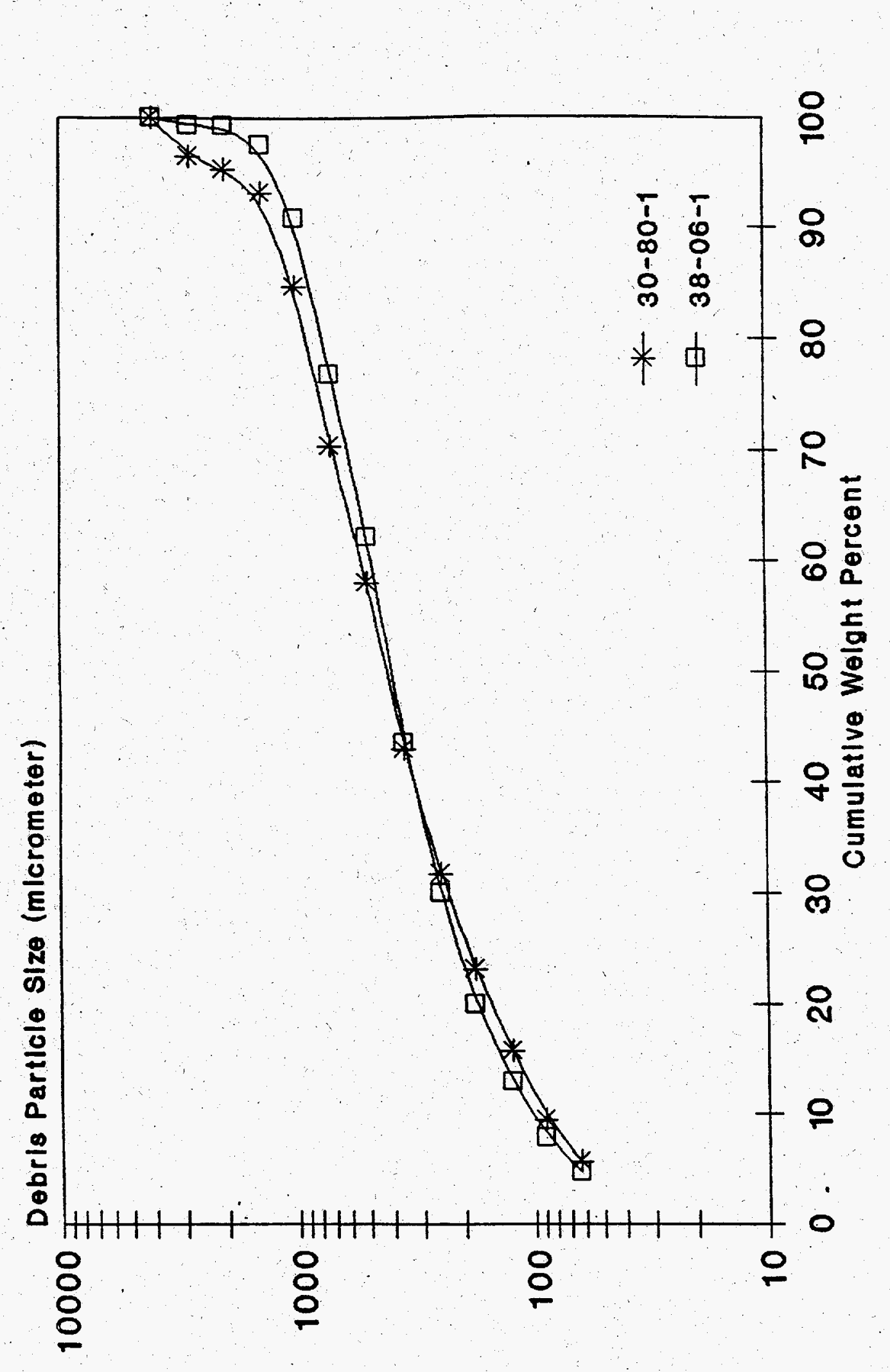

\section{荣}

幚出

ज幽

$\rightarrow 3$

牙嵒

哭

क्ष

ㄱ. 용

ฮ ने चे

$\rightarrow \infty$

首京里

4 近

ชั

ลे

소

주

出

บ 0

20

웅

in

表

정

글

길

ज

ज.

क्ष

虫

बे

感范

30

每出

可

on

热曋

$0-1$

岁品字

俒

굴

प

氙它总

og

武

$\stackrel{\infty}{\rightarrow}$

点 
gamma-alumina are produced during vapor phase combustion in the ignition-type explosions while only the stable alpha-alumina is formed during the lower temperature thermal-type explosions. (Rightley et al. [1993] also detected both alpha- and gamma-alumina in the debris recovered from their ignition-type steam explosions of approximately $10 \mathrm{~kg}$ of molten aluminum. They did not report similar analyses for the debris recovered from their thermal-type interactions, however.) Unfortunately the finest debris from our ignition-type explosion of aluminum was lost and did not appear in the pan sample as it did in the thermal-type explosion. The relationships of alpha- and gamma-alumina to the nature of the explosions of aluminum drops merit further study.

Note, however, that only trace amounts of either form of alumina were found by the $X$-ray diffraction analyses (normal levels of detectability by $X$-ray diffraction are usually about 5 percent). This is consistent with the limited extent of the metal/water reaction, as will be discussed further below. It is also consistent with our Inability to visually detect differences between the debris from the thermal-type $(38-6-1)$ and ignition-type $(30-80-1)$ steam explosions of pure aluminum. A possible explanation for this inability is that if the ignition and combustion had been only $1 \mathrm{~ms}$ long (as indicated in Figures 13 and 14) and had occurred in the vapor phase (as suggested by Baker [1965]), there might not have been sufficient time for the deposition of appreciable amounts of oxidic material on the debris particles as observed in the underwater ignition of . aluminum by laser heating (Liebowitz and Mishler 1967). Moreover, the products of the gas phase combustion probably would preferentially condense in the water phase as fine suspended material. (Products suspended in the water were not observed by Llebowitz and Mishler [1967], but were observed in aluminum drop ignition experiments described by Baker [1965]; suspended products have also been observed in both aluminized and stoichiometric thermite steam explosions by Nelson et al. [1992].) It is likely that this suspended material would not form at all in the thermal-type explosions, and if it had formed in our ignition-type explosion it probably would have been lost during the flooding.

\subsection{Metal/Water Reaction}

We explored the possibility that metal/water reactions had occurred during thermal-type steam explosions with molten aluminum drops. By examining our Hycam films carefully we discovered a single bubble that remained long after the steam explosion bubble had collapsed and disappeared. This appeared to be a bubble of noncondensible gas, presumably hydrogen: By measuring this bubble we were able to estimate approximately the extent of metal/water reaction in the thermal-type laboratory explosions.

In Figure 19, we show an image reproduced from the Hycam high-speed film of the interaction that occurred in experiment 38-3-1, in which the molten aluminum release temperature was $1000^{\circ} \mathrm{C}(1273 \mathrm{~K})$. The arrow in the figure points to the bubble that was ejected from the interaction center about $100 \mathrm{~ms}$ after the interaction was initiated. (In single drop studies, thermal-type steam explosion bubbles normally collapse and disappear by about $20 \mathrm{~ms}$ after the interactions are initiated [cf. Figures 5 through 11].) We have estimated the volume of this bubble to be $80 \mathrm{~cm}^{3}$. 


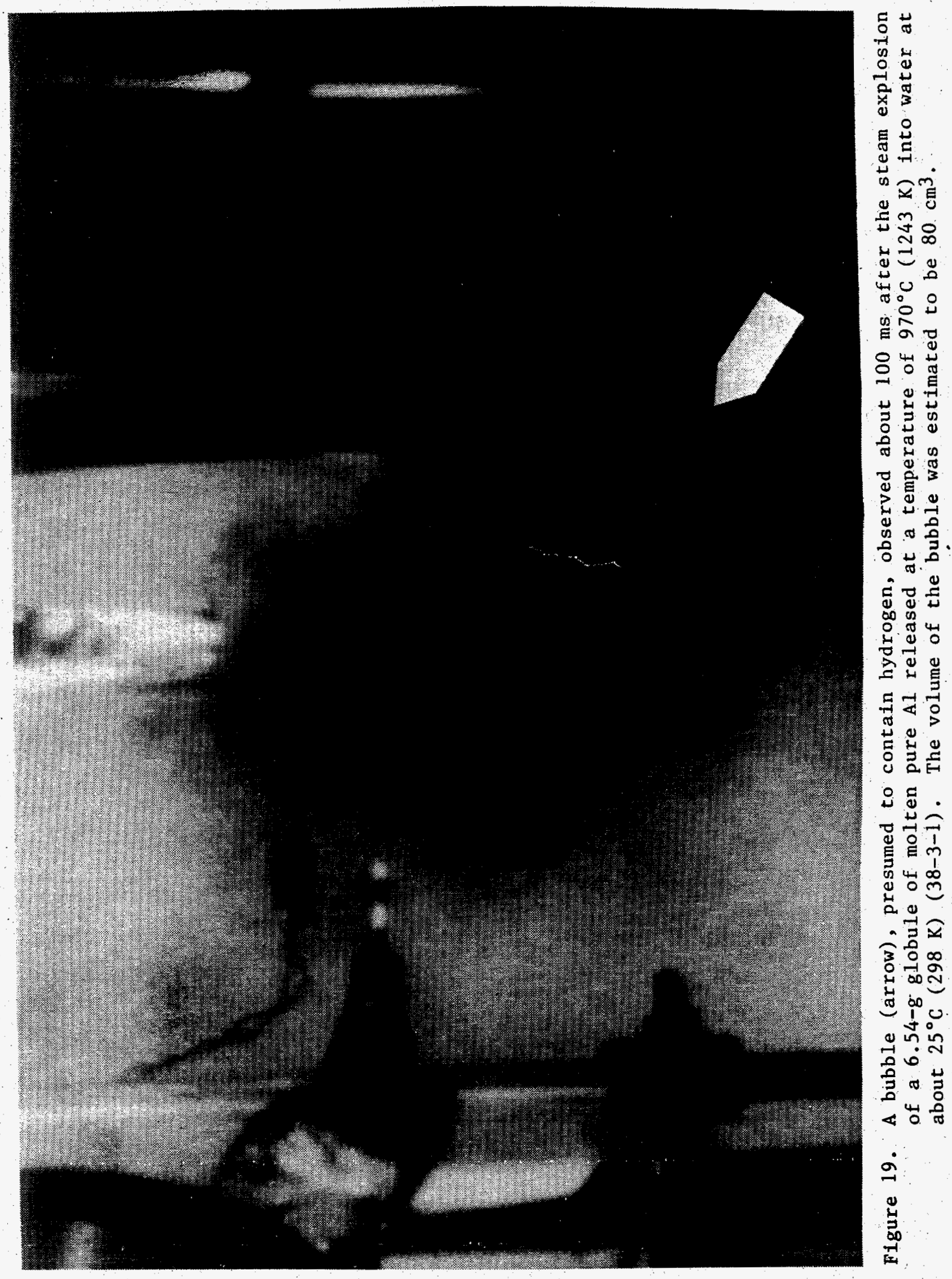


In Figure 20, we show a comparable photograph reproduced from the Hycam high-speed film from experiment 38-6-1 in which the melt release temperature was $200 \mathrm{~K}$ higher, namely, $1200^{\circ} \mathrm{C}(1473 \mathrm{~K})$. Again the arrow indicates the bubble. This image was recorded about $160 \mathrm{~ms}$ after the interaction was initiated. The volume of this bubble was estimated to be $267 \mathrm{~cm}^{3}$.

If we assume the bubbles contained only hydrogen, we can estimate both the total amount of hydrogen and the amount produced per gram of aluminum participating in the interaction, if we also assume a temperature for the gas. Upper and lower limits can be placed on the gas temperature, namely, the release temperature of the melt (assumes negligible heating from combustion) and the temperature of the water. The corresponding limiting values of the extent of metal/water reaction are compared for experiments 38-6-1 and 38-3-1 in Table 4. These values are based on the assumption that the aluminum in the debris was not oxidized appreciably. Note that the estimated maximum extents of metal/water reaction are less than 1 percent for the $970^{\circ} \mathrm{C}(1243 \mathrm{~K})$ aluminum and less than 4 percent for the $1195^{\circ} \mathrm{C}(1468 \mathrm{~K})$ aluminum.

In recent related work (Nelson et al. 1993; Hyder et al. 1993; Nelson et al. 1994), the amounts of hydrogen were estimated similarly from Hycam bubble images recorded during the untriggered (non-exploding) interactions of molten Al-Li drops as they fell through water with the assumption that. the gas was at the temperature of the water. These amounts have been shown to be about twice those measured after equilibrium with the water was achieved. The equilibrium volumes were measured by a volumetric/mass spectrometric procedure. By analogy, then, the actual extent of metal/water reaction shown in Table 4 might be about half those indicated for gas temperatures assumed to be equal to the temperature of the water.

(The extent of aluminum/water reaction in the ignition-type explosion, experiment $30-80-1$, could not be estimated this way because of the failure of the water chamber.) 


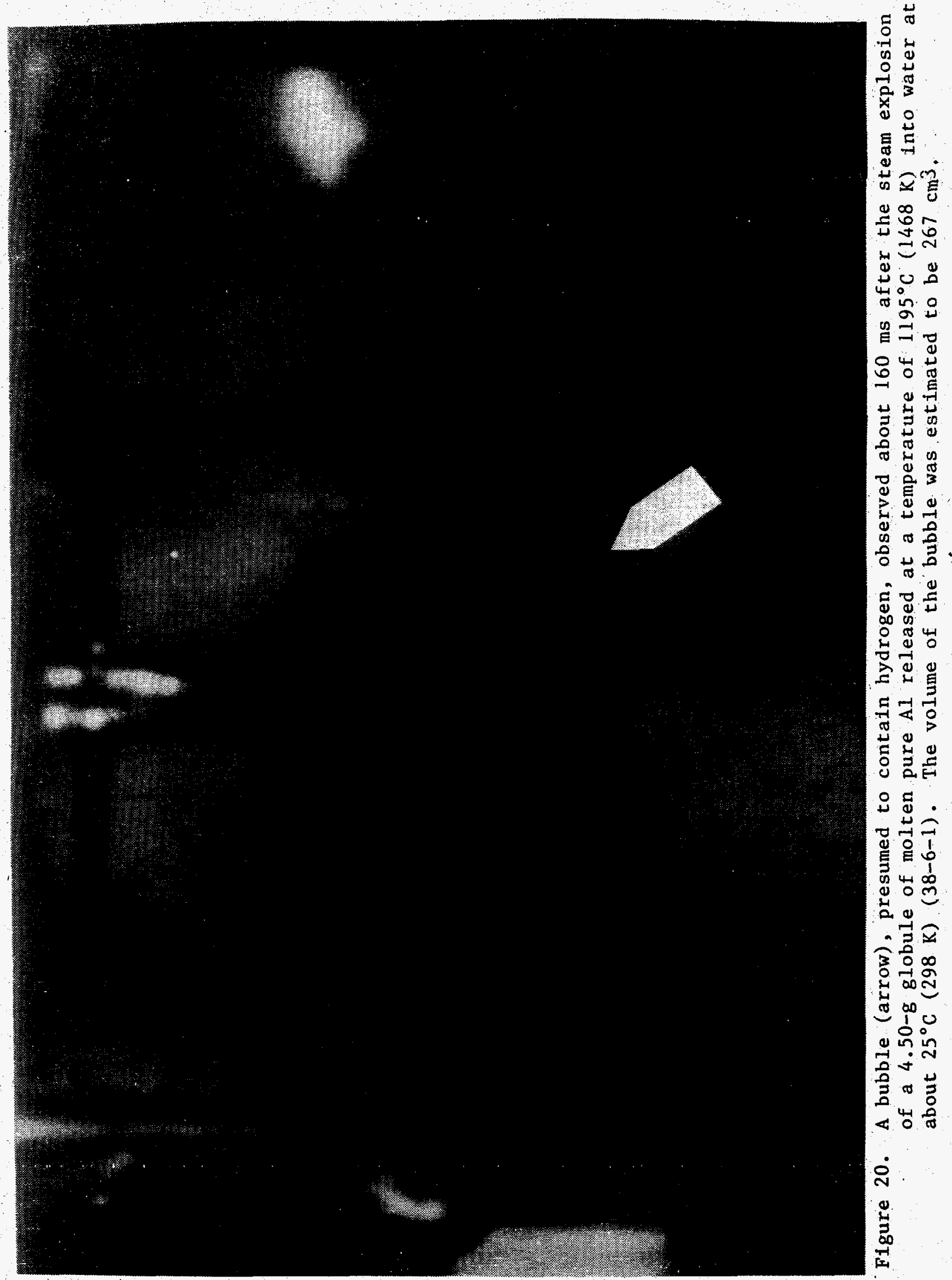


Table 4. Metal-Water Reaction for Steam Explosions of Pure Aluminum Drops Determined From Hycam Bubble Images

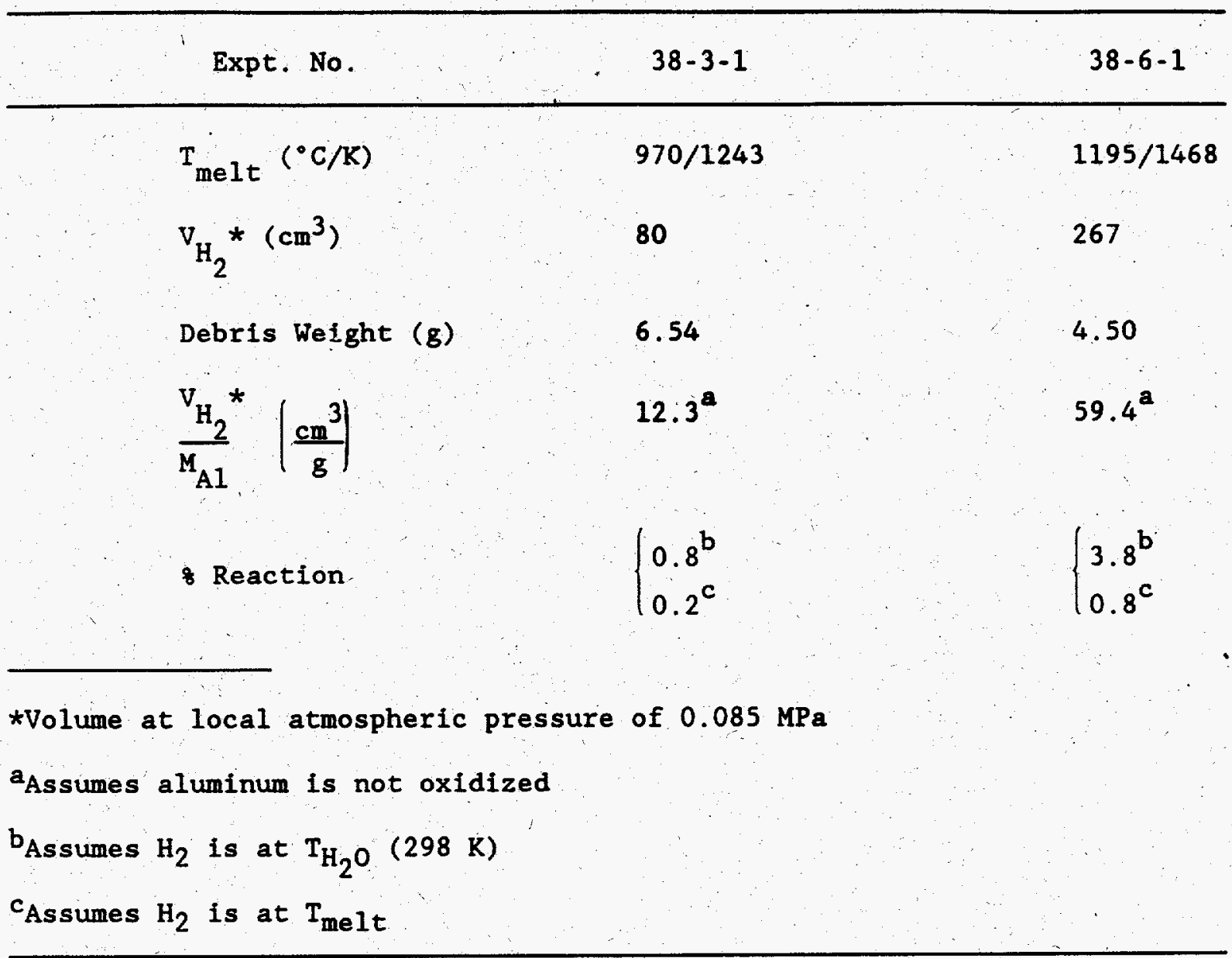




\subsection{DISCUSSION}

\subsection{Comparisons With Earlier Work}

The thermal-type steam explosions of 2 to $10 \mathrm{~g}$ drops of molten aluminum observed in this work resembled those observed in earlier studies, both by other experimenters (for example, Anderson and Armstrong 1981) and by us 1 (see also Nelson et al. 1989). Without applying a trigger, spontaneous explosions did not occur, in contrast to drops of molten tin and other low-melting metals released into water at similar melt temperatures (for example, Dullforce et al. 1976, Flory et al. 1969, Shoji and Takagi 1983). When triggered, the interactions of the aluminum drops normally would initially form a small bubble that collapsed after a few milliseconds, followed by a moderate second bubble, the volume of which did not exceed about 1 L. Sometimes a third or even a fourth smaller bubble formed after the second and largest bubble collapsed. (Similar multi-bubble interactions were observed in other thermal-type explosions [Nelson and Duda 1981].) Overall, the interactions with drops of molten aluminum were relatively mild, with only small conversions of the thermal energy to mechanical work. These conversions were seldom over one percent.

The one ignition-type explosion reported in this work, however, differed significantly (and unexpectedly) from the many thermal-type explosions produced earlier in our laboratory. The interaction began similarly to the thermal-type explosion by initially forming a small bubble that collapsed $8 \mathrm{~ms}$ after the bridgewire trigger was fired. The maximum volume of this initial bubble was about $0.3 \mathrm{~L}$ (see Figures 13 and 14).

After the collapse of the initial bubble, however, the interaction was very different. There was a brilliant flash of light that lasted about $1 \mathrm{~ms}$, followed by the very rapid growth of a large bubble that achieved a volume of about $14 \mathrm{~L}$ after about $5 \mathrm{~ms}$, at which time the chamber failed. The increase in volume was linear with time, with no apparent slowing of the growth during the $4 \mathrm{~ms}$ period after the flash ended. This suggests that the bubble possibly would have grown at least several times larger before it began to collapse.

The unfortunate failure of the interaction chamber lost important information. The flooding that resulted probably carried away the finest of the particles, perhaps those with the most information about the combustion reaction. And finally, if the chamber had been larger and had not failed, we would have been able to follow the bubble growth further, and also might have obtained information about both the total thermal energy released and the amount of hydrogen generated in the explosion.

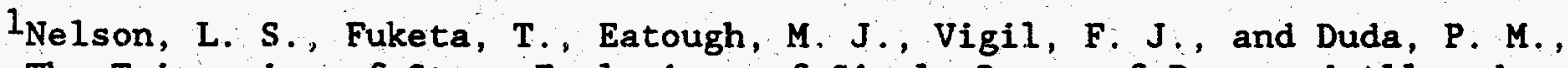
The Triggering of Steam Explosions of Single Drops of Pure and Alloyed Molten Aluminum, SAND90-0131, Sandia National Laboratories, Albuquerque, NM. In preparation. 
(Severe damage caused by the unexpected vigor of ignition-type steam explosions of molten aluminum has also been reported by others [Higgins and Schultz 1957; Hess and Brondyke 1969; Lemmon 1980; Anderson and Armstrong 1981; Beck and Rightley ${ }^{1}$; and Rightley et al. 1993].)

Despite the experimental difficulties described here, we believe we have obtained the clearest images and the best, albeit incomplete, information reported to date about the debris produced during an ignition-type steam explosion of molten aluminum.

\subsection{Comparisons With High Explosives}

The vigor of the ignition-type steam explosion and the damage it produced (e.g., the cracking of $12.7-\mathrm{mm}$ thick Lexan [Figures 16 and 17]) qualitatively resembles the action associated with the underwater detonation of high explosives. Therefore, we compared the initial few milliseconds of growth of our bubble with the growth of bubbles produced by firing two types of commercial detonators about $50 \mathrm{~cm}$ beneath the surface in approximately $100 \mathrm{~cm}$-deep water. The information for the comparisons was obtained from bubble growth films provided by D. F. Beck 2 for his experiments DET 55 and LASER DEMO\#3.

The two types of commercial high-explosive detonators are shown in Figures 21 and 22. The detonators are designated Types RP-1 and RP-2, respectively. Type RP-1 contains 606 milligrams and Type RP-2 contains 64 milligrams of PETN/RDX explosive. The detonators were obtained from Reynolds Industries Systems, Inc., San Ramon, CA.

The bubble volume-time plots for the two types of detonators (Type RP-1 from film DET 55; Type RP-2 from film LASER DEMO\#3) and the ignition-type aluminum explosion $(30-80-1)$ for about $5 \mathrm{~ms}$ are compared in Figure 23 . Using Equation ( 1 ), these volumes have been converted to the corresponding pressure-volume products in joules as indicated by the right-hand

ordinate. In this figure, we have taken zero time to be the start of the flash of light (the "blooming" of the image) for the ignition-type explosion (cf. Figures 13, 14, and 15). It can be seen in Figure 23 that the initial rate of bubble growth is essentially identical for the aluminum ignition and the Type RP-1 high explosive detonator. A considerably smaller initial bubble growth rate was observed with the Type RP-2 detonator with its order-of-magnitude smaller mass of high explosive.

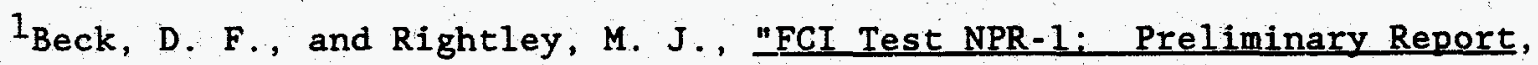
SAND90-2715, Sandia National Laboratories, Albuquerque, NM. In preparation.

${ }^{2}$ Beck, D. F., personal communication, 19.91.
} 


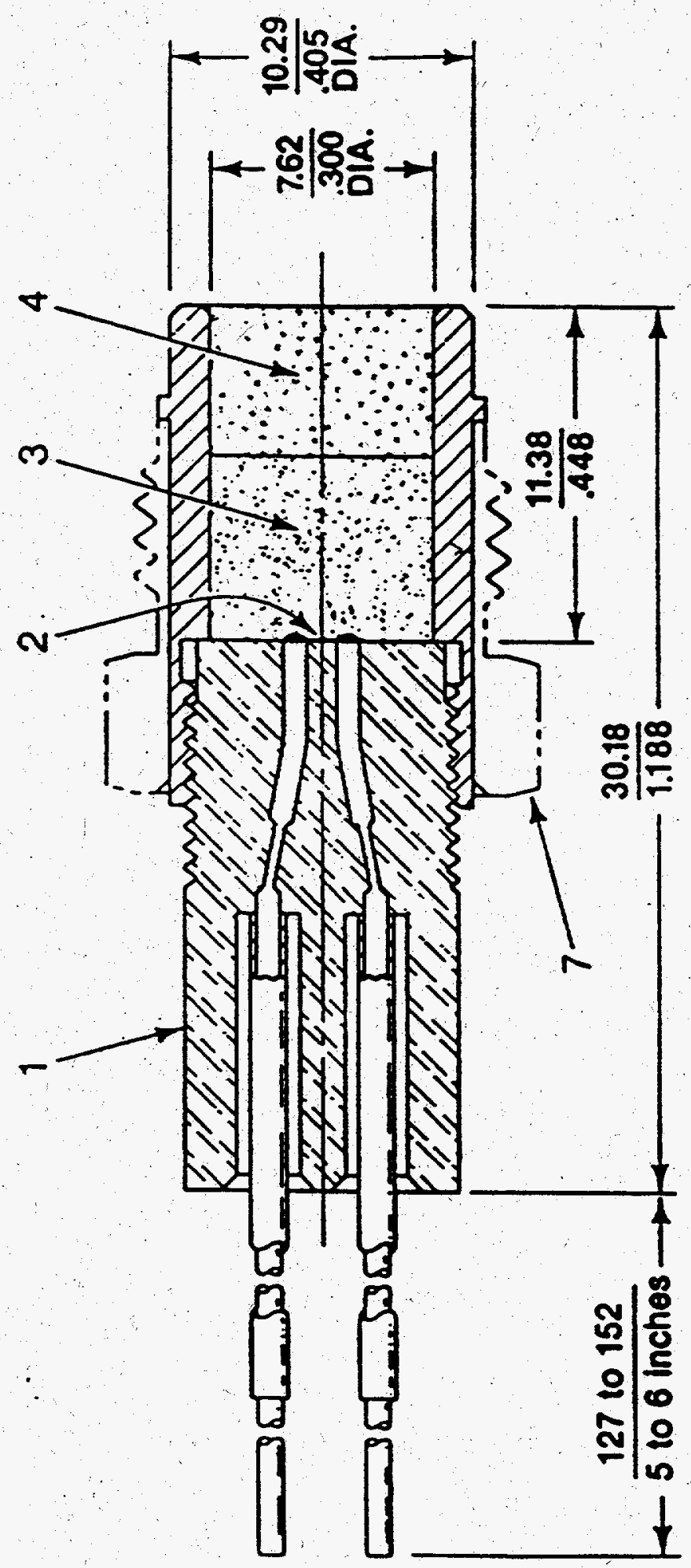

这

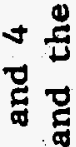

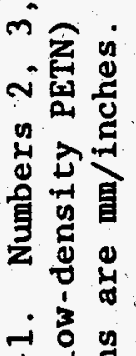

D $己$

(1)

내의

-

0

造

요 4

요 出

ชै

(1)

点豆焉

娄

号㝴

म 2

000

吾势

웅 웅



0 0

4 등

얼

站

㟧六

\&

Ð

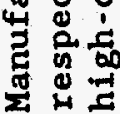

a

$\sum_{0}^{0}$ 


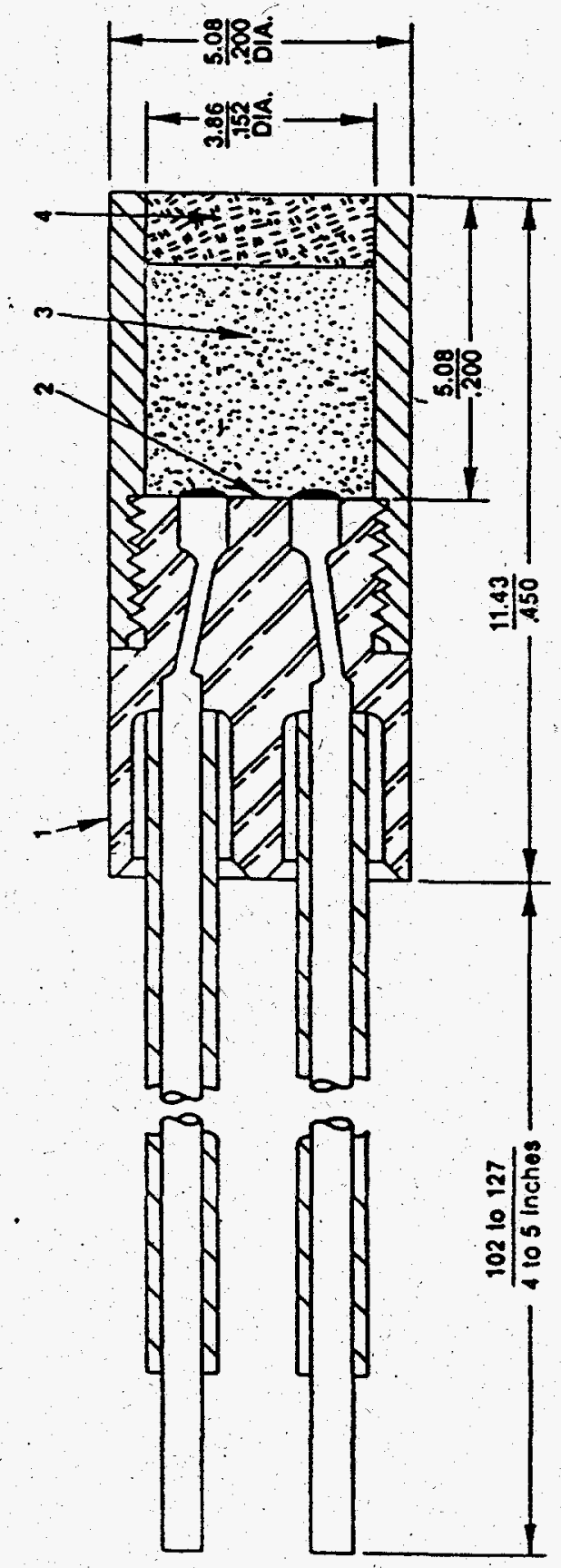

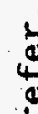

$\checkmark \frac{\mathscr{Z}}{\nu}$

急

m

N 畄

幽 슝

目盟宣

造总

i

럼

\&

으욤

芹合?

ป 0

过

品

o 4 ?

걸 돌

年

号总希

-

$\infty \stackrel{4}{4}$

告

7800

这选

(1) 口

4. 멍

bo

告 总

出 80

(2)

is 2 군

可

का स

娄 U

年

赵 站

จ

$\approx$

岁 


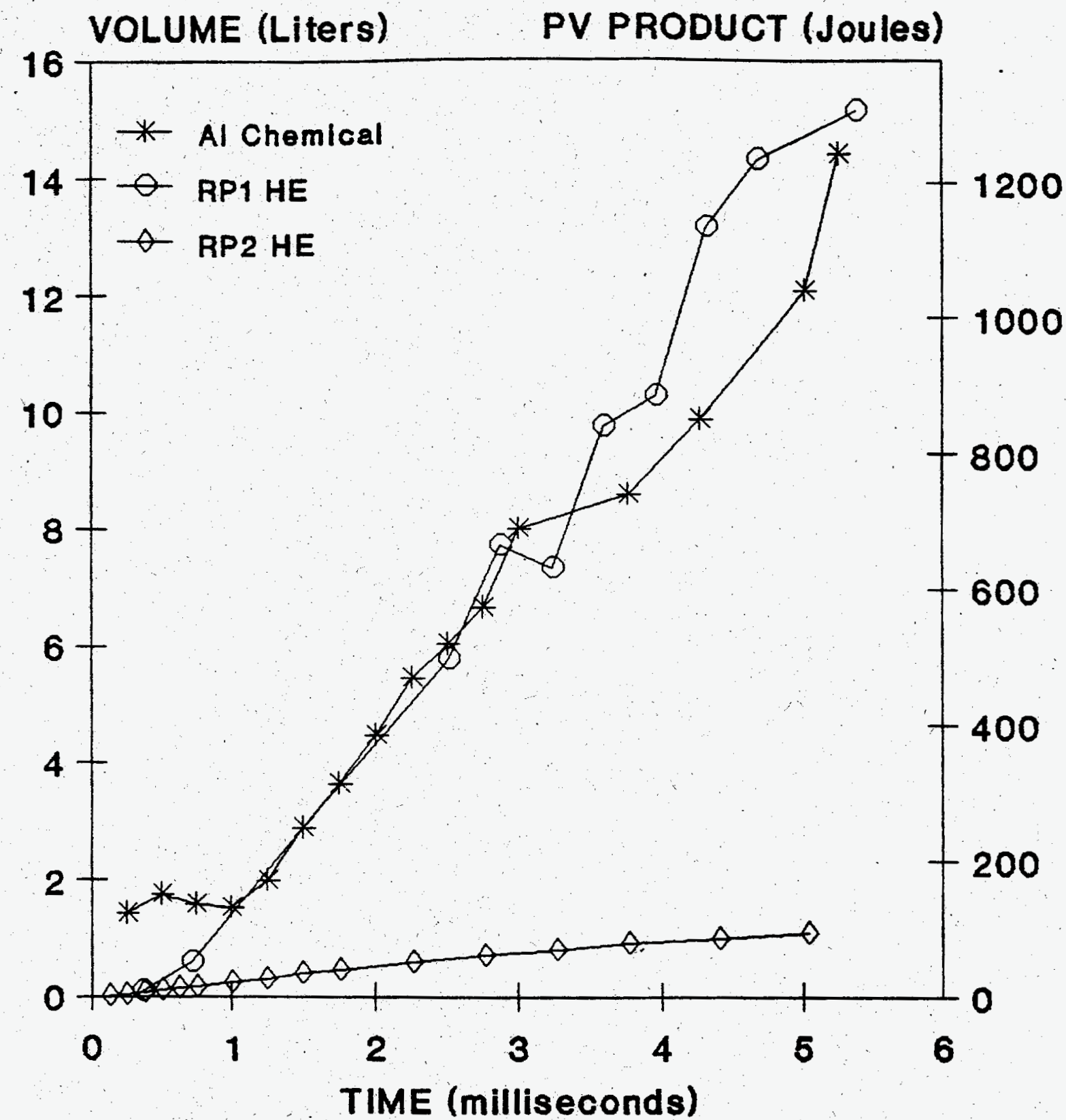

AL: Aprox. 10 grama debrio

RP 1: $606 \mathrm{mg} \mathrm{HE}$

RP 2: $64 \mathrm{mg} \mathrm{HE}$

Figure 23. Comparison of bubble volumes (left ordinate) and pressurevolume products (right ordinate) versus time for an ignitiontype steam explosion of molten pure aluminum $(30-80-1)$ and exploding bridgewire detonators Types RP-1 and RP-2. The release temperature of the molten aluminum was nominally $1500^{\circ} \mathrm{C}\left(1773^{\circ} \mathrm{K}\right)$. 
In Figure 24 , we have replotted the bubble growth data from Figure 23 on a per-gram-of-exploding-material basis. Here it can be seen that the two amounts of high explosive produce similar bubble pressure-volume growth rates on per-gram bases $(310$ and $450 \mathrm{~kW} / \mathrm{g}$ ) that are more than an order of magnitude greater than the pressure-volume growth rate per gram of aluminum $(26 \mathrm{~kW} / \mathrm{g})$. This slope was calculated assuming that all metal released into the water participated in the millisecond-long ignition and combustion reaction. The amount of aluminum involved was conservatively estimated to be $10 \mathrm{~g}$, with uncertainty due to the flooding loss (the true value lies between the $12 \mathrm{~g}$ initial charge in the crucible and the $8 \mathrm{~g}$ weight of recovered material).

However, we believe the amount of aluminum that actually oxidized to produce the flash of light shown in Figure 4, Frame 33, and the blooming indicated in Figures 13,14 , and 15 was much less than the $10 \mathrm{~g}$ cited above. We base our conclusion primarily upon the visual examination and $X$-ray diffraction and sieve analyses of the debris recovered from the interaction, and the likelihood that the light-emitting reaction involved vapor-phase combustion of the aluminum (Baker 1965).

The absence of significant amounts of oxidized aluminum in the debris suggests that little metal had burned. This absence was first noted visually by comparing debris recovered from our ignition-type explosion with photographs of debris recovered from a known ignition-type explosion reproduced in the paper by Leibowitz and Mishler (1967). Their photographs showed significant coatings of oxide on debris recovered from laser-initiated ignition of aluminum particles underwater. The virtual absence of oxide from our debris was confirmed later by X-ray diffraction analyses that indicated only trace amounts of aluminum oxide in the debris samples recovered from either the thermal-or ignition-type interactions.

Moreover, the similarity between the particle size distributions of the ignition- and thermal-type explosions determined by sieve analyses as shown in Figure 18 is, in our opinion, another indicator that there was no significant alteration of the fragmented metal by chemical or other hightemperature processes during the energetic portion of the ignition-type explosion.

The absence of appreciable oxidized aluminum in the debris is also consistent with the self-sustained burning rate of aluminum of $0.96 \mathrm{~g} / \mathrm{min} / \mathrm{cm}^{3}$ at temperatures above $1750^{\circ} \mathrm{C}(2023 \mathrm{~K})$ reported by Baker (1965). If we assume the nominal $10 \mathrm{~g}$ of aluminum recovered from experiment 30-80-1 consisted entirely of spherical particles $400 \mu \mathrm{m}$ in diameter (the mass median taken from Figure 18), the amount of aluminum burned in the vapor phase during the 1-ms-long flash of 1ight would have been approximately $8 \times 10^{-3} \mathrm{~g}$. (This corresponds to a volume of $\mathrm{H}_{2}$ of approximately $10 \mathrm{~cm}^{3}$ [STP]; cf. Table 4.)

Returning, then, to the PV-product-per-gram-of-aluminum plots shown in Figures 14, 15, and 24 , it seems likely that the linear portion of these plots was generated by the ignition and combustion of one or two orders of magnitude less metal than the 10 grams assumed originally. Thus the slope of the PV-product curve of $26 \mathrm{~kW} / \mathrm{g}$ might more realistically be approximately $10^{3} \mathrm{~kW} / \mathrm{g}$; which is comparable to the slopes of 450 and $310 \mathrm{~kW} / \mathrm{g}$ for the bubbles generated by the Types RP-1 and RP-2 detonators. 


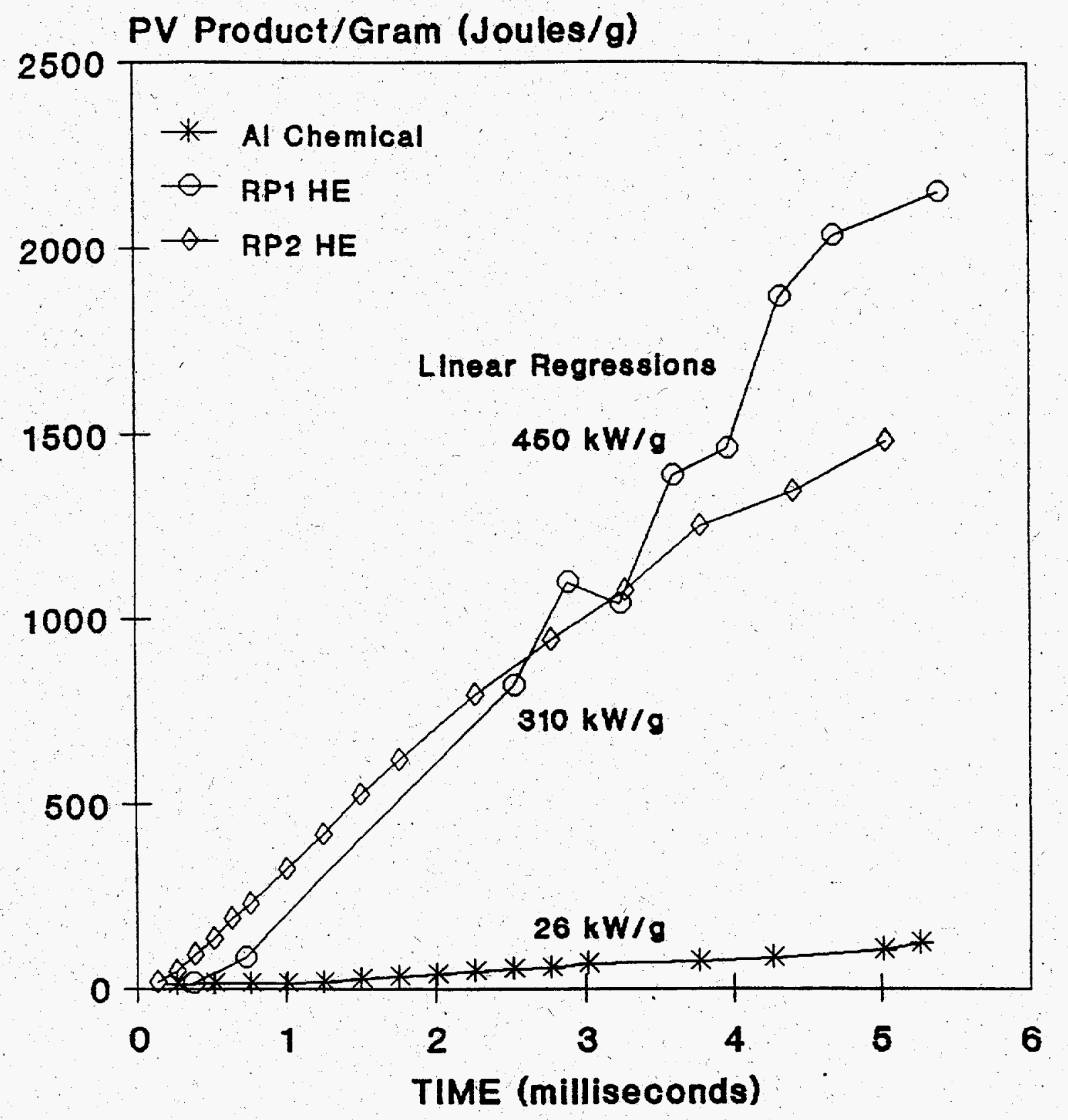

AL: Aprox. $10 \mathrm{~g}$ RP 1: $606 \mathrm{mg} \mathrm{HE}$ RP 2: $64 \mathrm{mg} \mathrm{HE}$

Figure 24. Comparison of pressure-volume product per gram of aluminum or explosive versus time for an ignition-type steam explosion of molten pure aluminum $(30-80-1)$ and exploding bridgewire detonators Types $R P-1$ and $R P=2$. The release temperature of the molten aluminum was nominally $1500^{\circ} \mathrm{C}(1773 \mathrm{~K})$. 
This is consistent with estimates of the total energy of about $17 \mathrm{~kJ} / \mathrm{g}$ that can be released in theory from molten aluminum steam explosions with complete metal/water reactions (Chase et al. 1985), and about $4 \mathrm{~kJ} / \mathrm{g}$ for conventional high explosives (Rightley et al. 1993).

(In Appendix $C$, added after this report was completed, new bubble analyses seem to confirm that only a few percent of the original molten aluminum globule actually burned during the ignition-type steam explosion in experiment $30-80-1$.

\subsection{Calculations for Future Ignition-Type Experiments}

If future ignition-type steam explosion experiments are to be performed with aluminum, it is important to calculate the maximum dimensions of fully contained bubbles expected from ignition-type steam explosions of the sort observed in experiment 30-80-1. We have estimated the bubble diameters and volumes that might be produced during experiments with $10 \mathrm{~g}$ of high-purity aluminum at elevated melt temperatures undergoing a steam explosion where combustion occurs along with the transfer of enthalpy of the melt to the water. These values are presented in Table 5. The volumes and diameters are estimated from the maximum chemical plus thermal energy obtainable (Chase et al. 1985) and also empirically on the basis of recent intermediate-scale field tests (Rightley et al. 1993), assuming the, best estimate of explosive energy release (about 30 percent overall conversion) and the lower and upper limits of the 95 percent confidence levels.

Table 5 shows that for $10 \mathrm{~g}$ of molten aluminum a bubble with a maximum diameter as large as $1.5 \mathrm{~m}$ might form for 100 percent conversion, and perhaps a meter in diameter for an experiment with the estimated efficiency of the Beck and Rightley tests. This indicates the need for a significant redesign of our experimental apparatus to have at least a $1-m$ diameter chamber compared to the nominally $0.3 \mathrm{~m}$ dimensions of our current water chamber. (The mass of water in this larger chamber would be on the order of $10^{3} \mathrm{~kg}$ !)

In the fifth line of Table 5, we have entered values of the maximum bubble volume and diameter calculated for the underwater explosion of the Type RP-1 detonator containing $0.6 \mathrm{~g}$ of high explosive, using the energy release of $4 \mathrm{~kJ} / \mathrm{g}$ cited by Rightley et al. (1993). For comparison, we have entered in the last line of Table 5 the corresponding experimental values for this detonator taken from the extended plot of bubble volume vs. time shown in Figure 25. Figure 25 was prepared from the high-speed film of experiment DET 55 supplied by D. F. Beck. 1 The horizontal line indicates the portion of the plot used to prepare Figures 23 and 24.

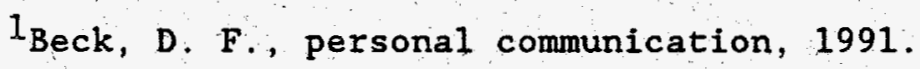


Table 5. Comparison of Estimated Maximum Bubble Volumes and Diameters for Ignition-Type Steam Explosions of Molten Aluminum and for Underwater Explosions of the Type RP-1 High Explosive Detonator

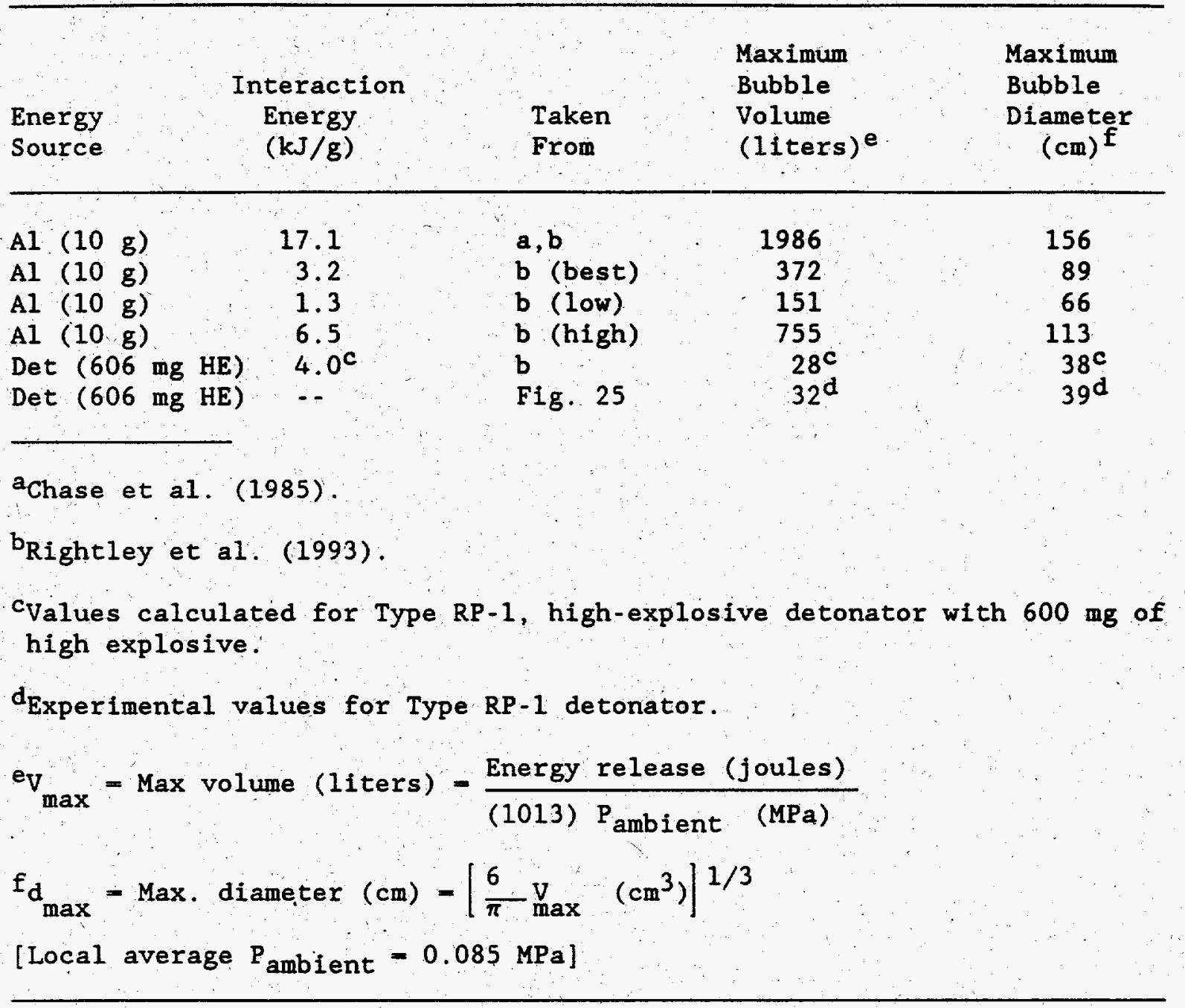

\subsection{Temperature Thresholds for Ignition-Type Explosions}

It is interesting to compare data from the literature for the temperatures at the onset of ignition-type steam explosions of molten aluminum as a function of metal mass. Nine ignition temperature thresholds are shown as a function of metal mass in Figure 26. (These data points are taken from reports by Baker [1965], Hess and Brondyke [1969], Higgins and Schultz [1957], Lemmon [1980], Rengstorff et al. [1969], Rightley et al. [1993] Tao et al. [1989], and from this work. Each data point is discussed further in Appendix A.)

It can be seen from this figure that as melt mass increases, the threshold ignition temperature decreases, until at approximately $10^{5} \mathrm{~g}$ (and presumably above) it approaches the melting temperature of aluminum. This plot may have great significance for the metalworking industries, where large quantities of molten aluminum are often handled just above their melting temperature in close proximity to liquid water. 


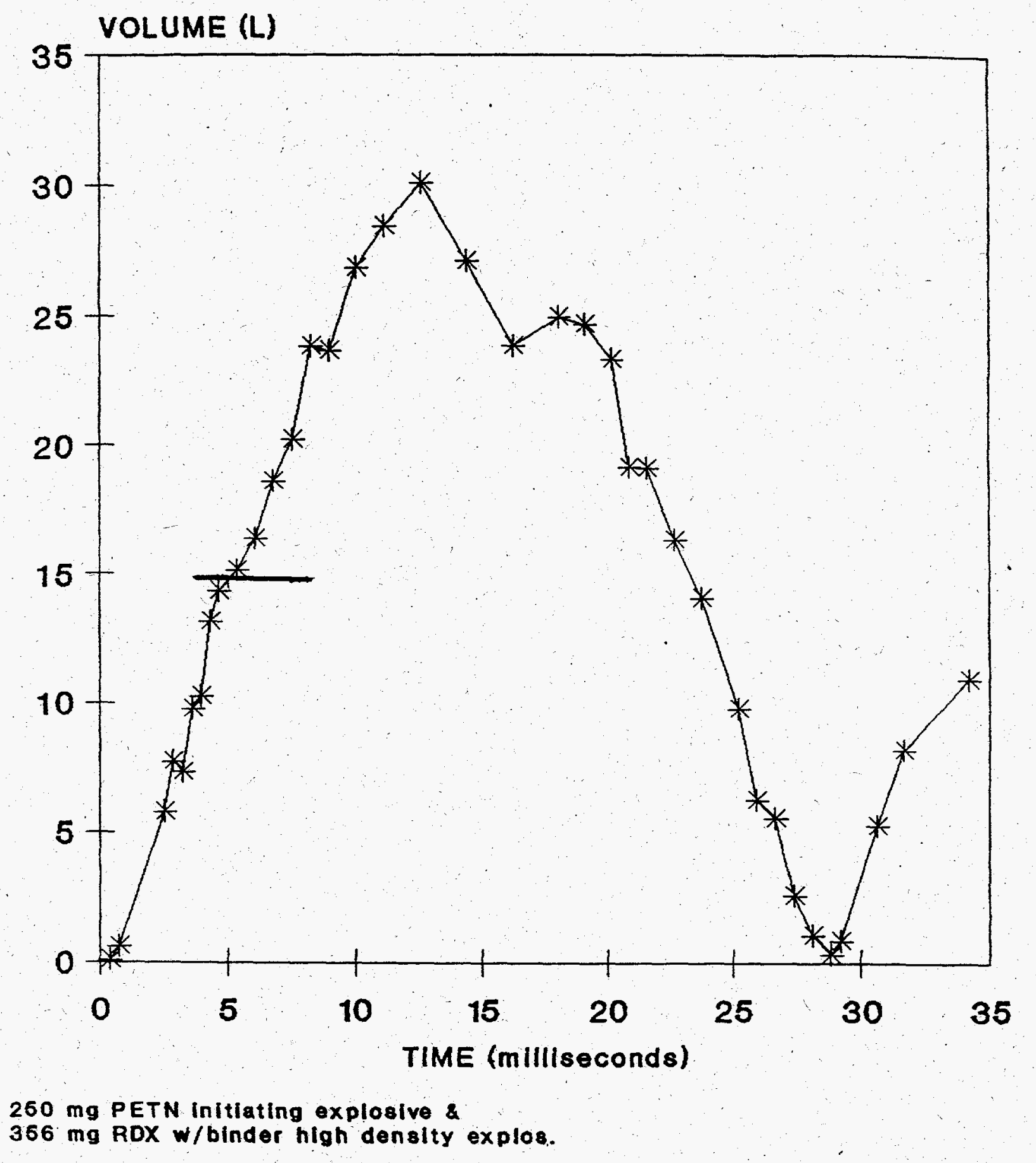

Figure 25. Extended bubble volume as a function of time for the Type RP-1 high-explosive detonator fired underwater. The horizontal line indicates the portion of the plot used to prepare Figures 23 and 24. 


\section{AL IGNITION TEMPERATURE VS. MELT MASS}

\section{Minimum Ignition Temperature (K)}

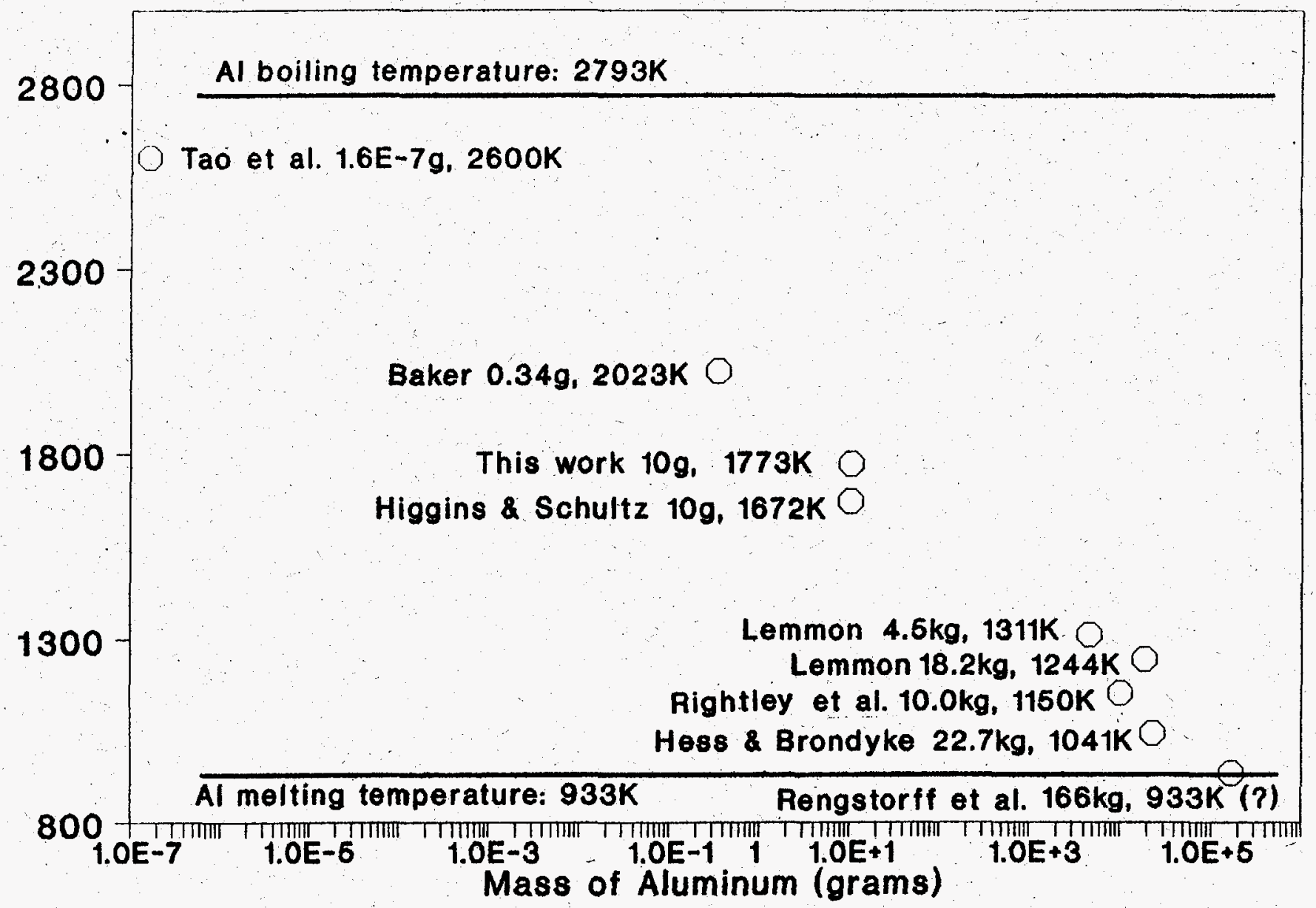

Figure 26. Plot of melt temperatures for onset of ignition-type steam explosions of molten aluminum plotted as a function of mass of molten metal. Note the steady decrease in ignition temperature as melt mass increases. (See Appendix A for further discussion of the data.) 
It is possible that the failure to produce ignition-type steam explosions of two of three experiments performed at nominally $1500^{\circ} \mathrm{C}(1773 \mathrm{~K}$ ) (30-91-1 and 41-5-1 did not produce ignition while $30-80-1$ did) is explained by the trend shown in Figure 26. In the two experiments where ignition did not occur, the mass of melt released was significantly smaller than in the experiment where ignition occurred (cf. Tables 1 and 2). 


\section{CONCLUSTONS}

We have investigated the effect upon triggered steam explosions of progressively increasing the melt release temperature of 2 - to $10-\mathrm{g}$ drops of molten pure aluminum. At a melt release temperature of nominally $1500^{\circ} \mathrm{C}(1773 \mathrm{~K})$, we performed a single experiment in which there was a very vigorous explosion accompanied by a flash of light; the explosion seriously damaged the water chamber of our test apparatus. This explosion was at least an order-of-magnitude more vigorous than the hundred or more triggered explosions of aluminum performed earlier in this chamber or similar apparatus. We conclude that the milder explosions were thermal-type explosions driven primarily by enthalpy transfer, while the very vigorous explosion was an ignition-type explosion that involved both enthalpy transfer and metal-water combustion.

High-speed films showed the flash of light to be $1 \mathrm{~ms}$ long, followed by the very rapid growth of a bubble for about $4 \mathrm{~ms}$ more before the chamber failed. Its growth rate was equivalent to that of a bubble generated by the underwater detonation of $0.6 \mathrm{~g}$ of high explosive. Moreover, examining the debris indicated that very little metal had oxidized, suggesting that the energy released per gram of metal that actually had participated in the interaction may have been very large. 1

We believe this to be the first clear observation of an ignition-type steam explosion of molten aluminum in the laboratory. With proper analyses and theoretical extrapolation, this and other similar experiments should help us understand the very violent steam explosions with flashes of light observed with masses of molten aluminum greater than about $4 \mathrm{~kg} \cdot 2,3$

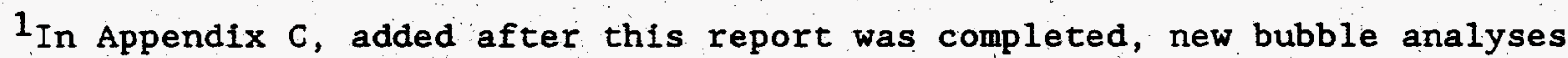
seem to confirm that only a few percent of the original molten aluminum. globule actually burned during the ignition-type steam explosion in experiment $30-80-1$.

${ }^{2}$ Recently, Epstein (1991) theoretically analyzed the underwater vapor phase ignition and combustion of molten aluminum observed in this and earlier work.

${ }^{3}$ After completing our experiments and preparing this report, we became aware of the work of Ciccarelli (1991). His research seems to explain the bubble dynamics presented in Figures 3 through 15 of this report. We regret not having been able to use his work to interpret our observations. 


\section{REFERENCES}

Anderson, R. P., and Armstrong, D. R., 1981, "Experimental Study of Small-Scale Explosions in an Aluminum-Water System," presented at the Winter Annual Meeting of the American Society of Mechanical Engineering, Washington, DC, November 15-20, and published in Fuel-Coolant. Interactions, ASME HTD-Vol. 19, 31-40.

Baker, L., Jr., 1965, "Metal-Water Reactions," Nuclear safety, 7, 25-34.

Chase, M. W., Jr., Davis, C. A., Downey, J. R., Jr., Frurip, D. J., McDonald, R. A., and Syverud, A. N., 1985, "JANAF Thermochemical Tables, Third Edition," Journal of Physical Chemistry Reference Data, 14, Supplement No. 1.

Ciccarel1i, G., 1991, Investigation of Vapor Explosions with Single Molten Metal Drops in Water Using Flash X-ray, Thesis, Department of Mechanical Engineering, McGill University, Montreal; Quebec, Canada.

Dullforce, T. A., Buchanan, D. J., and Peckover, R. S., 1976, "SelfTriggering of Small-Scale Fuel-Coolant Interactions: I. Experiments," Journal of Physics D: Applied Physics, 9, 1295-1303.

Epstein, M., 1991, Underwater Vapor Phase Burning of Aluminum Particles and on Aluminum Ignition During Steam Explosions, WSRC-RP-91-1001, Westinghouse Savannah River Company, Aiken, SC.

Epstein, S. G., and Miller, R. E., 1987, "Causes and Prevention of Molten Aluminum-Water Explosions," Light Metals 1987. The Metallurgical Society of AIME, Warrendale, PA, 693-698.

Flory, K., Paoli, R., and Mesler, R., 1969, "Molten Metal-Water Explosions," Chemical Engineering Progress, 65, 12, December, 50-54.

Hess, P. D., and Brondyke, K. J.; 1969, "Causes of Molten Aluminum-Water Explosions and Their Prevention," Metal Progress, 95, 93-100.

Higgins, H. M., and Schultz, R. D., 1957, The Reaction of Metals With Water and Oxidizing Gases at High Temperatures, IDO-28000, Aerojet-General Corporation, Azusa, CA.

Hyder, M. L., 1991, "The Severe Accident Analysis Program for the Savannah River Nuclear Production Reactors," Nuclear safety, 32, 502-510.

Hyder, M. L. Nelson, L. S., Duda, P. M., and Hyndman, D. A., 1993, Interactions Between Drops of Molten Al-Li Alloys and Liquid Water, WSRC-TR-93-0178, Westinghouse Savannah River Company, Aiken, SC, August 1993.

Leibowitz, L., and Mishler, L. W., 1967, "A Study of Aluminum-Water Reactions by Laser Heating," Journal of Nuclear Materials, 23, 173.

Lemmon, A. W., Jr., 1980. "Explosions of Molten Aluminum and Water," Light Metals $1980, \mathrm{C}$. J. McMinn, ed., The Metallurgical Society of AIME, Warrendale, PA, 817-836. 
Nelson, L. S., and Duda, P. M., 1981, Steam Explosion Experiments With Single Drops of Iron Oxide Melted With a CO 2 Laser, NUREG/CR-2295, SAND81-1346, Sandia National Laboratories, Albuquerque, NM.

Nelson, L. S., Eatough, M. J., and Guay, K. P., 1989, Explosive Interactions Between Molten Aluminum and Aqueous Coolants, SAND88-2959, Sandia National Laboratories, Albuquerque, MM. Proprietary.

Nelson, L. S., Fuketa, T., Eatough, M. J., Vigil, F. J., Szklarz, D. D., Wong, C. C., and Hyndman, D. A., 1992, Steam Explosions of Single Drops of Thermite-Generated Melts: 25 and 50 Welght Percent Aluminum-Iron Oxide Initial Mixtures, SAND90-0511, Sandia National Laboratories, Albuquerque, NM, October 1992.

Nelson, L. S., Duda, P. M., and Hyndman, D. A., 1993, Interactions Between Drops of Molten A1-L1 Alloys and Llquid Water, SAND91-2191, Sandia National Laboratories, Albuquerque, NM, January 1993.

Nelson, L. S., Duda, P. M., and Hyndman, D. A., 1994, "Interactions Between Drops of a Molten Aluminum-Lithium Alloy and Liquid Water," Met. Matls. Trans, in press.

Rengstorff, G. W., Lemmon, A. W., Jr., and Hoffman, A. O., 1969, Review : of Knowledge on Explosions Between Molten Aluminum and Water, Battelle Memorial Institute, Columbus, $\mathrm{OH}$. Report to the Aluminum Association, April 11.

Rightley, M. J., Beck, D. F., and Berman, M., 1993, NPR/FCI EXO-FITS Experiment Series Report, SAND91-1544, Sandia National Laboratories, Albuquerque, NM, January 1993.

Shoji, M., and Takagi, N., 1983, "An Experimental Study of Small-Scale Vapor Explosions for Molten Tin Dropped Into Water," Bulletin of the Journal of the Society of Mechanical Engineers, 26, 215, 791-796.

Tao, W. C., Frank, A. M., Shepherd, J. E., and Clements, R. E., 1989, "The Fundamentals of Metal Combustion in Composite Explosives Revealed by Highspeed Micro Photography," Proceedings of the Ninth (International)

symposiun on Detonation, Portland, OR, August 28-September 1. 


\section{APPENDIX A}

Threshold Temperatures for Ignition-Type

Steam Explosions of Molten Aluminum:

Discussion of Individual Data Points

In this appendix we discuss each of the nine ignition threshold temperatures presented in Figure 26, because it was necessary to apply a degree of interpretation during the preparation of this figure. The data points are discussed according to literature citation.

\section{Baker (1965)}

The classic work of Baker and his co-workers describes the release of nominally $0.34 \mathrm{~g}$ drops of molten aluminum into liquid water. The drops were prepared by melting them while they were levitated in a radio-frequency field. When the drop temperatures were $1750^{\circ} \mathrm{C}(2023 \mathrm{~K})$ and above, the drops ignited and burned vigorously in the water, generating light, hydrogen, and a milky deposit of aluminum oxide. There were no triggers applied in this work, nor were there steam explosions.

Hess and Brondyke (1969)

These authors are not completely clear when they discuss the threshold temperatures for experiments in which flashes of light are observed. We have selected a typical experiment from their Table III. In this table the authors describe thermocouple readings near the bottom surface or directly at the interface between the molten aluminum and a clean steel tank that contained the water. The melt release temperature was stated to be $768^{\circ} \mathrm{C}(1041 \mathrm{~K})$ and the amount of incoming metal, $50 \mathrm{lbs}(22.7 \mathrm{~kg})$. We take as evidence that a chemical reaction occurred their observation that the thermocouples at the interface between the molten aluminum and the steel tank rose at least $200^{\circ} \mathrm{C}(200-\mathrm{K})$ above the melt release temperature when the metal/water explosive interaction occurred.

\section{Higgins and Schultz (1957)}

The threshold ignition temperature of $1399^{\circ} \mathrm{C}(1672 \mathrm{~K})$. was taken from Table IV of Higgins and Schultz (1957). In this table, the authors present the results of tests with molten aluminum sprayed into liquid water using the Aerojet explosion dynamometer. We have chosen the onset of ignition to occur at run 56-77 where they report the percentage of reaction to change from $n i l$ to 60 percent, the total impulse to increase about six-fold, the work to increase nearly forty-fold, and the efficiency of the reaction to increase twenty-four-fold. This is an abrupt change as melt-release temperature increases, similar to those observed when ignition occurs. Although they did not report a flash of light (probably because the apparatus blocked $i t$ ), in our opinion the sudden increase in the output parameters justifies assigning $1399^{\circ} \mathrm{C}(1672 \mathrm{~K})$ as the temperature where a significant chemical component was added to the aluminum-water thermal interaction. 
Lemmon (1980)

This author cites numerous experiments in which ignition-type aluminumwater explosions occured. From his Table II, we have chosen:

- Experiment $C-50$ in which $101 \mathrm{bs}(4.5 \mathrm{~kg})$ of melt produced a "very violent" explosion. The melt temperature was $1038^{\circ} \mathrm{C}(1311 \mathrm{~K})$.

- Experiment $C-10$ in which $401 \mathrm{bs}(18.2 \mathrm{~kg})$ of melt produced a "very violent" explosion. The melt temperature was $971^{\circ} \mathrm{C}(1244 \mathrm{~K})$.

These explosions occurred in a water-containing, cubical, steel tank with a rusted interior.

Rengstorff et al. (1969)

We cite here an example of a very forceful explosion in a casting operation, in which 350 to 380 lbs ( 159 to $173 \mathrm{~kg}$ ) of aluminum participated. We believe this to be a chemical ignition-type explosion because of the statement by Rengstroff et al. that "a cloud of dust (powder), principally alumina, filled the enclosure" when the plant was entered about one minute after the explosive event. The melt release temperature was not specified, but it was reported that a large partially:: solidified ingot "broke out" early in the casting process. This suggests .. that the metal was freezing at the interface between the outer solid shell of the ingot and the molten metal within. We assume, then, that the temperature of release was close to the melting temperature of aluminum as we have indicated in Figure 26.

\section{Rightley et al. (1993)}

The threshold of $10 \mathrm{~kg}$ and $1150 \mathrm{~K}$ is taken directly from Tables 1 and 9 of Rightley et al. (1993).

Tao et al. (1989)

The behavior of approximately $50-\mu \mathrm{m}$ diameter molten aluminum drops generated underwater by passing a capacitor discharge through 25 - to 76- $\mu \mathrm{m}$ diameter, 23-mn long aluminum wires, was studied by high-speed streak photography. Tao et.al. (1989) observed the generation of a vapor film around the drops that collapsed, followed by a second generation of vapor. Above a threshold temperature of $2600 \mathrm{~K}$ (calculated from their electrical discharge parameters) this second event became very vigorous and emitted intense 1ight. (There is a striking similarity to our first bubble collapse followed by rapid second bubble growth and light emission for approximately $10 \mathrm{~g}$ drops shown in our Figures $4,13,14,15,23$, and 24.) Tao et al. (1989) saw no analogous behavior when gold drops were generated at similar temperatures under comparable conditions. We conclude, therefore, that their observed very energetic behavior and light emission were caused by ignition of the molten aluminum drops.

\section{This work}

We cite the single experiment $(30-80-1)$ in which approximately $10 \mathrm{~g}$ of molten, high-purity aluminum was released into liquid water at nominally 
$298 \mathrm{~K}$. The ignition was seen on high-speed film as a brilliant flash of light that lasted approximately $1 \mathrm{~ms}$, followed by a rapid bubble volume increase. There was some uncertainty in the measured temperature because there was some vaporization of aerosols in the vicinity of the alumina crucible and the graphite susceptor into the windowless sight path viewed by the optical pyrometer. There is also uncertainty in the actual temperature of the melt at that time of the interaction. Thus the pyrometric temperature at $1500^{\circ} \mathrm{C}(1773 \mathrm{~K})$ measured at the time of release was probably lower than the actual release temperature. On the other hand, the temperature of the globule of aluminum at the time of triggering was probably lower than the actual release temperature because of cooling of the drop during the fall through the ambient atmosphere and the liquid water prior to triggering. Thus, there are two sources of temperature uncertainty that may tend to offset each other when determining the actual threshold temperature at which ignition occurred.

Another source of uncertainty in our data point is the amount of melt actually released during the experiment. A small amount of debris was probably lost due to the uncontrolled flooding caused by the fallure of the chamber. We have conservatively estimated the loss to be about $2 \mathrm{~g}$ of the original $12 \mathrm{~g}$ charge leading to the value of $10 \mathrm{~g}$ of molten aluminum that was used for the abscissa in Figure 26 . 
REFERENCES FOR APPENDIX A

Baker, L. W., Jr., 1965, "Metal-Water Reactions," Nuclear Safety, 7, $25-34$.

Hess, P. D., and Brondyke, K. J., 1969, "Causes of Molten Aluminum-Water Explosions and Their Prevention," Metal Progress, 95, 93-100.

Higgins, H. M., and Schultz, R. D., 1957, The Reaction of Metals With Water and Oxidizing Gases at High Temperatures, IDO-28000, Aerojet-General Corporation, Azusa, CA.

Lemmon, A. W., Jr., 1980. "Explosions of Molten Aluminum and Water," Light Metals 1980, C. J. McMinn, ed., The Metallurgical Society of AIME, Warrendale, PA, 817-836.

Rengstorff, G. W., Lemmon, A. W., Jr., and Hoffman, A. 0., 1969, Review of Knowledge on Explosions Between Molten Aluminum and Water, Battelle Memorial Institute, Columbus, OH. Report to the Aluminum Association, April 11.

Rightley, M. J., Beck, D. F., and Berman, M., 1993, NPR/FCI EXO-FITS

Experiment Series Report, SAND91-1544, Sandia National Laboratories, Albuquerque, NM, January 1993.

Tao, W. C., Frank, A. M., Shepherd, J. E., and Clements, R. E., 1989, "The Fundamentals of Metal Combustion in Composite Explosives Revealed by High Speed Microphotography," Proceedings of the Ninth (International) symposium on Detonation, Portland, OR, August 28-September 1. 


\title{
APPENDIX B
}

\author{
Authors Note
}

This report is part of a study of the steam explosion behavior of drops of aluminum-based melts at Sandia National Laboratories and was supported by the Reactor Safety Group, Savannah River Laboratory, Westinghouse Savannah River Company, Aiken, SC, and its predecessor, E. I. DuPont de Nemours, Co., Aiken, SC. The experimental work began in 1988 and was concluded in 1991. Documentation of this work includes the following:

- "Stean Explosions of Single Drops of Molten Aluminum and 6061 Alloy," by L. S. Nelson, T. Fuketa, M. J. Eatough, and F. J. Vigil. Paper presented at the 27 th National Heat Transfer Symposium of Japan, May 30-June 1, 1990, Nagoya, Japan.

- "The Triggering of Steam Explosions of Single Drops of Pure and Alloyed Molten Aluminum," by L. S. Nelson, T. Fuketa, M. J. Eatough, and F. J. Vigil: Paper presented at the American Nuclear Society Meeting, Nashville, TN, June 10-14, 1990, Transactions of the American Nuclear society, 61, 458.9 (1990).

- The Trigaering of Steam Explosions of Single Drops of Pure and Alloyed Molten Aluminum, SAND90-0131, by L. S. Nelson, T. Fuketa, M. J. Eatough, F. J. Vigil, and P. M. Duda, Sandia National Laboratories, Albuquerque, NM. In preparation.

- "Steam Explosions of Single Drops of Core-Melt Simulants: Triggering, Work Output and Hydrogen Generation," by L. S. Nelson, D. A. Hyndman, and P. M. Duda. Paper presented at the International Topical Meeting on Safety of Thermal Reactors, Portland, OR, July 21-25, 1991. Proceedings published by the American Nuclear Society, LaGrange Park, IL, 324-330.

(Partial support by the sponsors.)

- "Oxidation of Molten Fuel Simulant Drops Under Film Boiling Conditions," by M. F. Young and L. S. Nelson. Paper presented at the International Toplcal Meeting on Safety of Thermal Reactors, Portland, OR, July 21-25, 1991. Proceedings published by the Amorican Nuclear Society, LaGrange Park, IL, 319-323.

(Partial support by the sponsors.)

- "Thermal- and Ignition-Type Steam Explosions of Single Drops of Molten Aluminum," by L. S. Nelson, P. M. Duda, and D. A. Hyndman. Paper presented at the American Nuclear Society Meeting, San Francisco, CA, November 10-14, 1991, Transactions of the American Nuclear Society, 64, 378-9 (1991).

- "Interactions Between Drops of Molten Al-Li Alloys and Liquid Water, " by L. S. Nelson, P. M. Duda, and D. A. Hyndman. Paper presented at the American Nuclear Soclety/European Nuclear Society 1992 International Conference, Chicago, IL, November 15-20, 1992, Transactions of the American Nuclear Society, 66, 331-2 (1992). 
- Interactions Between Drops of Molten Al-Li Alloys and Liquid Water, SAND91-2191, by L. S. Nelson, P. M. Duda, and D. A. Hyndman, Sandia National Laboratories, Albuquerque, NM, January 1993.

- Interactions Between Drops of Molten Al-LI Alloys and Liquid Water, WSRC-TR-93-0178, by M. L. Hyder, L. S. Nelson, P. M. Duda, and D. A. Hyndman, Westinghouse Savannah River Company; Aiken, SC, August 1993.

- Interactions Between Drops of a Molten Aluminum-Lithium Alloy and Liquid Water," by L. S. Nelson, P. M. Duda, and D. A. Hyndman, paper accepted for publication in Metallurgical and Materials Transactions, in press, 1994.

- "Steam Explosions of Single Drops of Pure and Alloyed Molten Aluminum," by L. S. Nelson, paper presented at the Specialist Meeting on Fuel-Coolant Interactions, Committee on the Safety of Nuclear Installations, Santa Barbara, CA, January 5 to 8, 1993; to be published in a special issue of Nuclear Engineering and Design, in press, 1994.

- Ten informal letter reports to the sponsor for the months of September 1990 through May 1991, and for June and July 1991. 


\author{
APPENDIX C \\ Mass of Aluminum That Participated in Laboratory-Scale \\ Steam Explosion of Molten Aluminum
}

After this report was completed, new bubble analyses seem to confirm that only a few percent of the molten aluminum globule actually burned during the ignition-type stean explosion in experiment 30-80-1. These analyses were reported in a memorandum from L. S. Nelson to distribution, dated October 14, 1992. Because these analyses support several conclusions reached in this work, the memorandum is reproduced here as Appendix $C$. 


\section{Sandia National Laboratories}

Albuquerque. New Mexico 87185

date: September 2, 1992
to: Distribution

from: L. S. Nelson, SMTS, 6423

subject: Mass of Aluminum that Participated in a Laboratory-Scale Steam Explosion of Molten Aluminum

The purpose of this memorandum is to offer some new thoughts on experiment $30-80-1$ performed in FY91 for the Westinghouse Savannah River Company. To our knowledge, this is the only laboratory experiment in which a clear photographic image of an ignition-type stean explosion of molten aluminum has been recorded. This experiment is described in References 1 and 2 .

In this experiment, approximately $10 \mathrm{~g}$ of molten, high-purity aluminum was released into deionized water at room temperature; melt temperature was nominally $1500^{\circ} \mathrm{C}(1773 \mathrm{~K})$. The explosion was initiated by a capacitor discharge through an underwater exploding bridgewire located $57 \mathrm{~mm}$ to one side of the drop at triggering time. This transient produced a peak pressure of about $3 \mathrm{MPa}$ at the drop. The experiment was recorded with $16-\mathrm{mm}$, high-speed photography at 4000 fps.

The experiment was accompanied by a flash of light, excessive throwing of water and fallure of a $9.5 \mathrm{~mm}$-thick Lexan chamber. About $8 \mathrm{~g}$ of fragmented metallic material was recovered after the interaction. Some of the debris was assumed to have been lost during the resulting flooding, probably the finer particles.

The high-speed film indicated a bubble that began to form at trigger time and reached $a$ maximum volume of about 0.3 liters in the first $4 \mathrm{ms.}$ This bubble collapsed over the next $4 \mathrm{~ms}$, after which there was a $1 \mathrm{~ms}$. long flash of light followed by the very rapid growth of a second bubble to about 14 liters in another $4 \mathrm{~ms}$. At this point, the bubble exceeded the dimensions of the chamber, broke the water surface and destroyed the apparatus. A plot of the bubble volume as a function of time taken from the fila is shown in Figure 1.

Subsequently, we compared this film with similarly photographed bubbles produced by the underwater explosion of two different commercial detonators (Reynolds Industries Systems, Inc., San Ramon, CA), Type RP-I and Type RP-2 containing 606 and $60 \mathrm{mg}$ of high explosive, respectively. We found that the bubble produced in the aluminum interaction grew at essentially the same rate as the RP-I detonator bubble until our chamber failed. A plot of the growth of the three bubbles is presented in Figure 2 . 
.

$$
\begin{aligned}
& \text { Distribution } \\
& \text { Page } 2 \\
& \text { September 2, } 1992
\end{aligned}
$$

VOLUME (1)

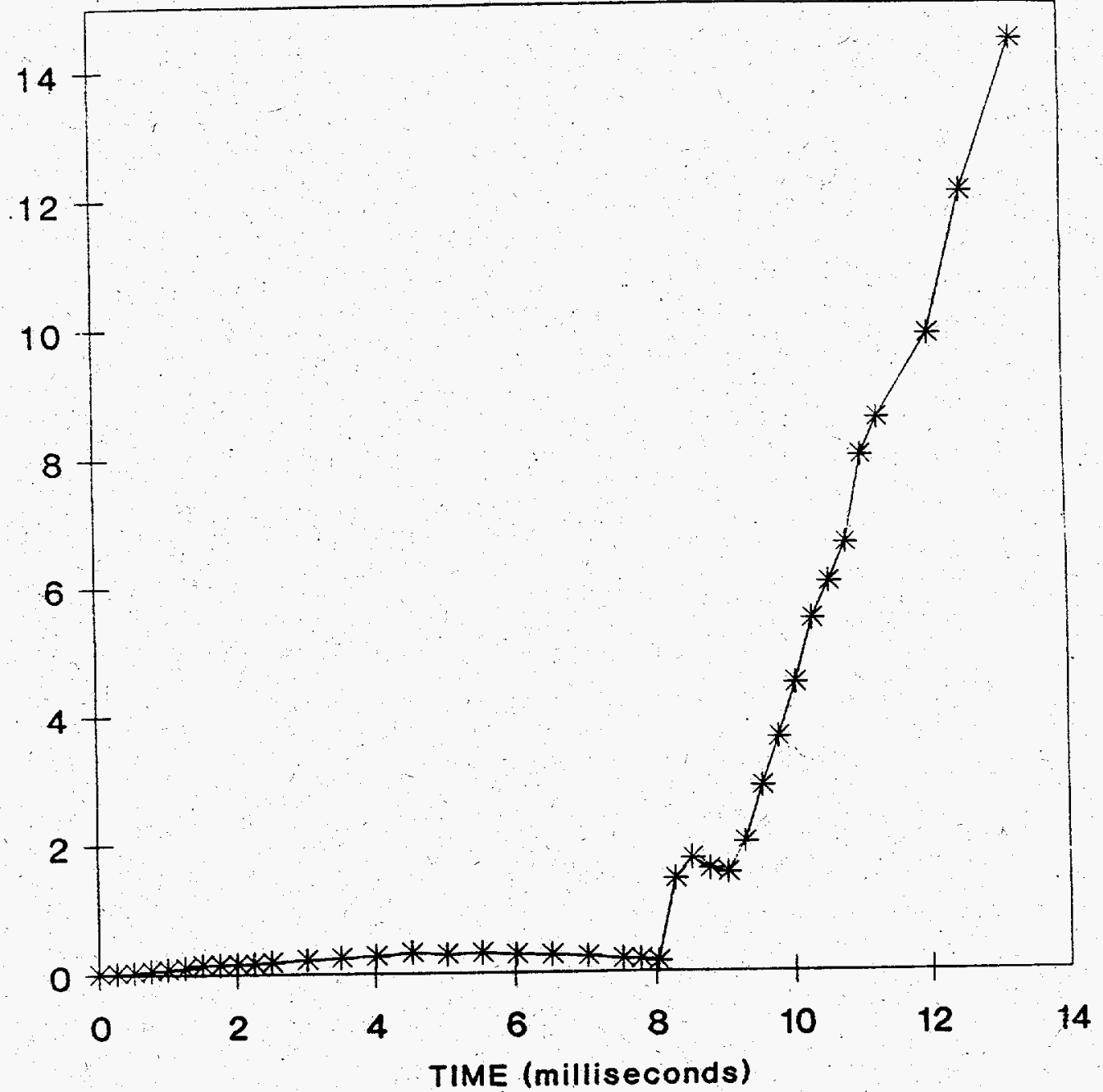

Figure 1. Plot of bubble volume vs. time for the ignition-type steam explosion of a drop of molten aluminum. Release temperature was nominally $1500^{\circ} \mathrm{C}(1773 \mathrm{~K})$. $(30-80-1)$. 
Distribution

Page 3

September 2, 1992

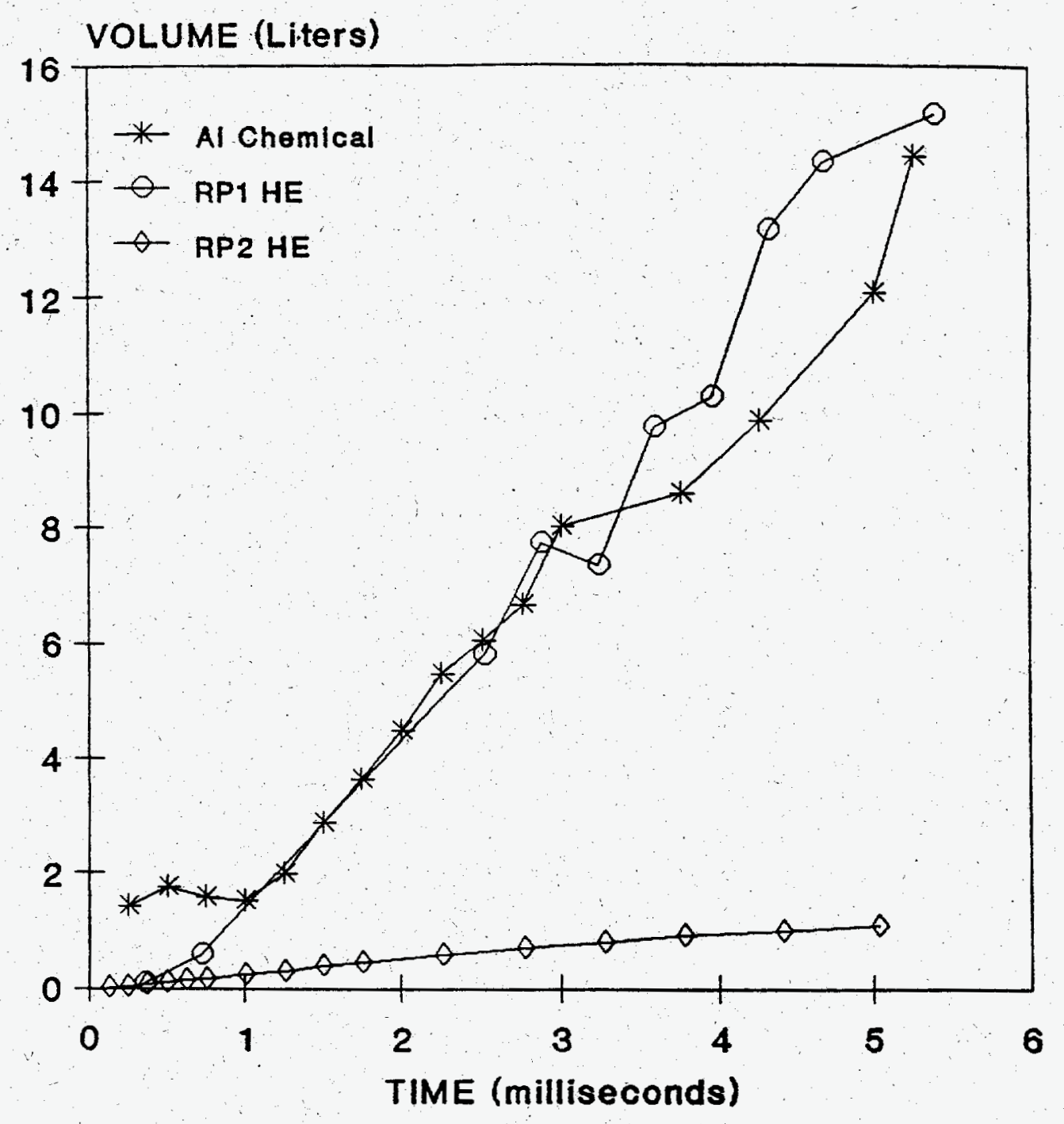

Figure 2. Comparison of bubble volumes versus time produced by an ignition-type steam explosion of a drop of molten pure aluminum $(30-80-1)$ and exploding bridgewire detonators Types RP-1 and RP-2. The release temperature of the molten aluminum was nominally $1500^{\circ} \mathrm{C}(1773 \mathrm{~K})$. 
Distribution

Page 4

September 2,1992

As a result of our preliminary analyses of the NPR FY92 single drop steam explosion studies at Sandia, we have been able to extend our understanding of what occurred during experiment 30-80-1. Our new understanding is based on the following two observations:

- Bubbles that grow with the same initial rates (i.e., same dV/dt slopes) ultimately appear to achieve the same maximum volumes. This has been demonstrated for various capacitor discharge-produced bubbles that have grown almost as large as 1 . liter. The correlation of $V_{\max }$ with dV/dt for these bubbles is shown in Figure 3 .

- The light-emitting combustion of aluminum in water seems to liberate bubble (pressure-volume) energies of 6 to $12 \mathrm{~J} / \mathrm{mg}$. This range of values has been determined from several underwater capacitor discharges through strips of aluminum foil of known weight (up to $14 \mathrm{mg}$ ). Our work follows the lead of Lee, who obtained about $15 \mathrm{~J} / \mathrm{mg}$ with carefully tuned electrical discharge circuits. (Conventional high explosives generate about $4 \mathrm{~J} / \mathrm{mg}$.)

To utilize these preliminary relationships, we present the complete bubble volume-time plot for the RP-I detonator in Figure 4 . The line at the left, about halfway in the growth curve, indicates the time at which the aluminum-generated. bubble destroyed the chamber (see Figure 2). Note that the complete bubble from the detonator achieves a maximum volume of about 31 liters. If we can assume, from the first observation, that the maximum bubble volume for experiment 30-80-1 also would have been 31 liters, the maximum pressure-volume energy release would have been $2670 \mathrm{~J}$.

Using the second observation, that the energy release for aluminum in an ignition-type event underwater lies in the range 6 to $12 \mathrm{~J} / \mathrm{g}$, we estimate that the total amount of aluminum that participated in the ignition type steam explosion was 0.22 to $0.44 \mathrm{~g}$. This is only 3 to 68 of the $8 \mathrm{~g}$ of debris recovered after the experiment and after the fallure of the apparatus. If the yalue of $15 \mathrm{~J} / \mathrm{g}$ reported by $\mathrm{Lee}^{3}$ is a more accurate value, then the total amount of aluminum that reacted according to this analysis would have been only $0.18 \mathrm{~g}$, or about 28 of the $8 \mathrm{~g}$.

The estimate that only a few percent of the metal participated in the ignitiontype steam explosion is consistent with the virtual absence of oxidized aluminum in the debris recovered from experiment 30-80-1. Aluminum oxide could not be observed visually. and was detected only in trace amounts by $X$-ray diffraction. There was no appreciable difference from the debris recovered from comparable thermel-type steam explosions.

The thoughts presented here, while presently based on preliminary data and analyses, provide important insights into the upcoming experimental and theoretical studies of explosive molten aluminum-water interactions for the NPR Program. 


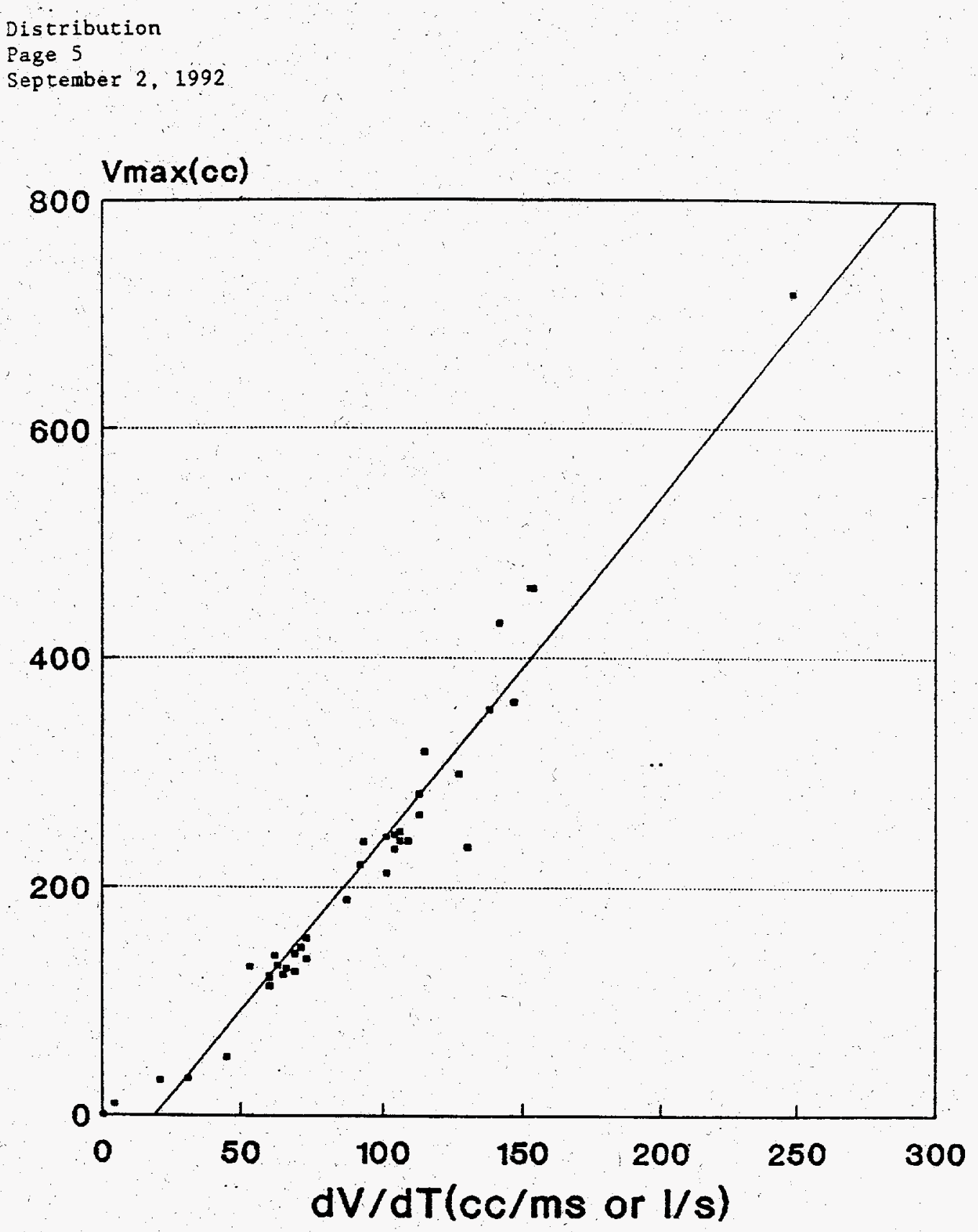

Figure 3.- Plot of maximum volumes achieved, $V_{\max }$, as a function of the initial slopes, $d V / d t$, of various bubbles formed by underwater capacitor discharges. Line was determined by a linear regression analysis. 
Distribution

Page 6

September 2, 1992

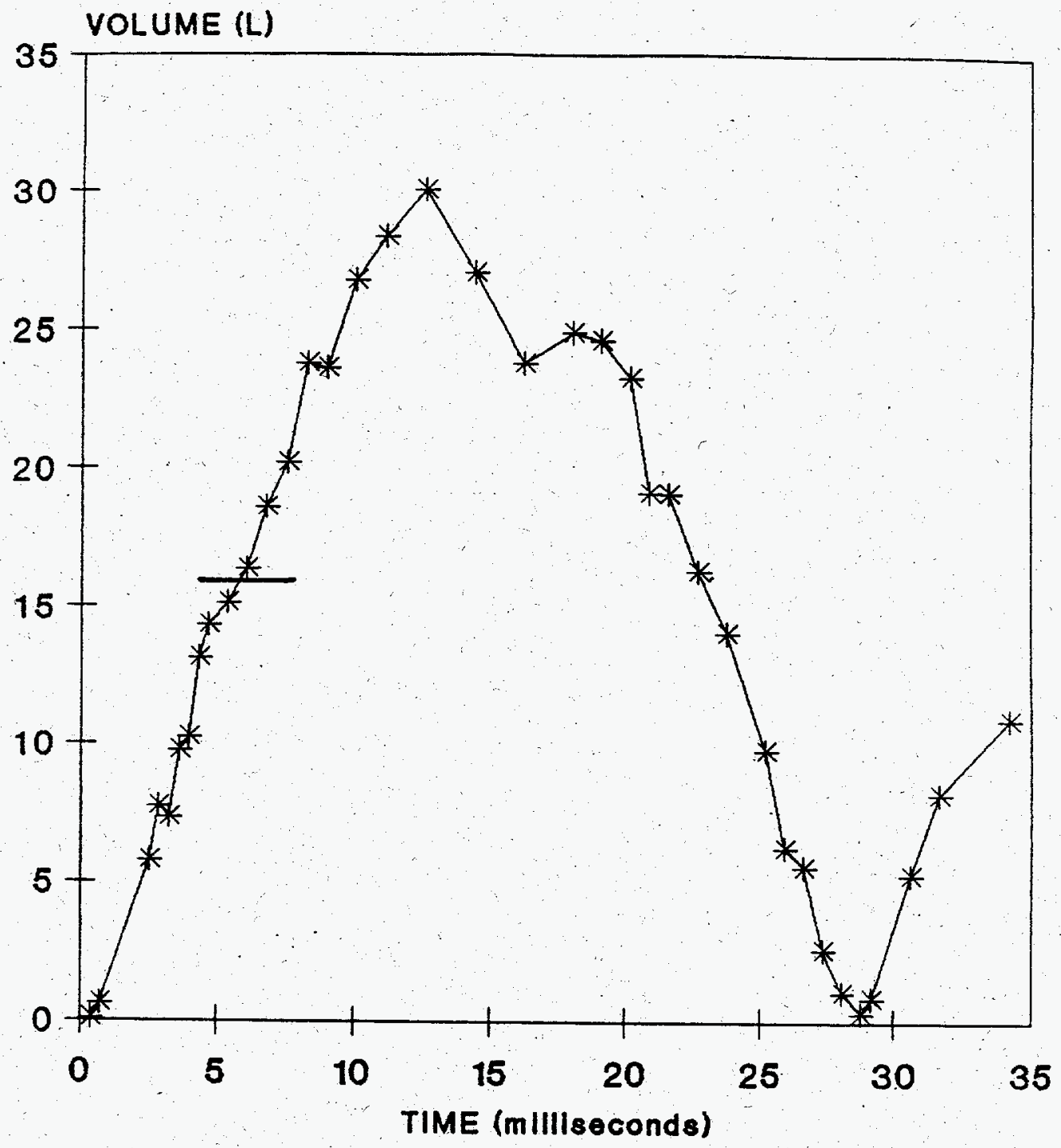

Figure 4. Extended plot of bubble volume as a function of time for the Type RP1 high-explosive detonator fired underwater. The horizontal line indicates the portion of the plot used to prepare Figure 2. 
Distribution

Page 7

September 2, 1992

\section{References}

1. L. S. Nelson, P. M. Duda, and D. A. Hyndman, "Thermal- and Ignition-Type Stean Explosions of Single Drops of Molten Aluminum," Transactions of the American Nuclear Society, 64, 378-379 (1991).

2. L. S. Nelson, P. M. Duda, and D. A. Hyndman, Thermal- and Ignition-Type Steam Explosions of Single Drops of Molten Aluminum, SAND91-1354, Sandia National Laboratories, Albuquerque, NM (1992).

3. W. M. Lee, "Metal/Water Chemical Reaction Coupled to a Pulsed Electrical Discharge", Journal of Applied Physics, 69, 6945-6951 (1991). 